\title{
Operable Unit 7-13/14 In Situ Thermal Desorption Treatability Study Work Plan
}
P. Shaw
D. Nickelson
R. Hyde

L OCKHEED MARTIN 


\section{Operable Unit 7-13/14 In Situ Thermal Desorption Treatability Study Work Plan}

Published May 1999

Idaho National Engineering and Environmental Laboratory

Environmental Restoration Technology Department

Lockheed Martin Idaho Technologies Company

Idaho Falls, Idaho 83415

Prepared for the U.S. Department of Energy

Under DOE Idaho Operations Office

Contract DE-AC07-94ID13223 


\begin{abstract}
This Work Plan provides technical details for conducting a treatability study that will evaluate the application of in situ thermal desorption (ISTD) to landfill waste at the Subsurface Disposal Area (SDA) at the Idaho National Engineering and Environmental Laboratory (INEEL). ISTD is a form of thermally enhanced vapor vacuum extraction that heats contaminated soil and waste underground to raise its temperature and thereby vaporize and destroy most organics. An aboveground vapor vacuum collection and treatment system then destroys or absorbs the remaining organics and vents carbon dioxide and water to the atmosphere. The technology is a byproduct of an advanced oil-well thermal extraction program. The purpose of the ISTD treatability study is to fill performance-based data gaps relative to off-gas system performance, administrative feasibility, effects of the treatment on radioactive contaminants, worker safety during mobilization and demobilization, and effects of landfill type waste on the process (time to remediate, subsidence potential, underground fires, etc.). By performing this treatability study, uncertainties associated with ISTD as a selected remedy will be reduced, providing a better foundation of remedial recommendations and ultimate selection of remedial actions for the SDA.
\end{abstract}




\section{SUMMARY}

This Work Plan provides technical details for conducting a treatability study to determine the effectiveness, implementability, and cost of applying in situ thermal desorption (ISTD) to subsurface waste at the Subsurface Disposal Area (SDA) at the Idaho National Engineering and Environmental Laboratory (INEEL). The SDA falls under the jurisdiction of the Comprehensive Environmental Response, Compensation, and Liability Act (CERCLA, 42 USC $\S 9601$ et seq.). ISTD is one of several treatment options identified in the addendum to the Work Plan for the Operable Unit (OU) 7-13/14 Waste Area Group 7 Comprehensive Remedial Investigation/Feasibility Study (RI/FS). The purpose of this treatability study is to fill performance-based data gaps relative to ISTD. By performing the ISTD treatability study, uncertainties associated with selecting remedies will be reduced. Therefore, a better foundation will be provided for remedial recommendations and the ultimate selection of remedial actions for the SDA.

The overall objective of the ISTD treatability study is to provide sufficient data to evaluate ISTD either as a pretreatment to some other technology or as a long-term in situ disposal option at the SDA. The ISTD Treatability Study Work Plan provides the technical details for conducting the tests, managed through a graded risk approach. The current study will take place in three phases: lab-scale (radioactive), field-scale (nonradioactive), and field-scale (radioactive). The nonradioactive field-scale test will use comparable matrices with surrogates in place of hazardous and radiological contaminants. If the results of this phase are sufficiently encouraging, the technology will then be tested at a radioactive site containing actual contaminants. A formal decision point is structured into the treatability study to ensure that key issues will be addressed satisfactorily before resources are committed to subsequent full-scale testing at the SDA.

Section 1 reviews the history of the SDA at the RWMC, the contaminants placed there, and the waste types and types of containers used to store waste at the SDA. Section 2 describes the ISTD technologies. Section 3 presents the critical and noncritical objectives of the study, focusing on criticality and contamination control of the ISTD process. Section 4 describes the experimental test design that will evaluate ISTD as a possible treatment of buried waste sites within the SDA. Section 5 lists the required equipment and materials for a successful ISTD test.

Section 6 addresses the sampling and analyses that will be conducted to support the ISTD treatability study. A test plan will be prepared by TerraTherm or technology licensee and the INEEL $\mathrm{M} \& \mathrm{O}$ contractor that will describe in detail the testing protocols, sampling, and analytical methods. Specific data quality objectives will also be defined in the test plan based on the test objectives and experimental design described in this work plan.

Sections 7 and 8 discuss how data will be managed, summarized and evaluated. Data will be summarized and evaluated to determine the validity and performance of the treatment process after the testing phases of ISTD are complete. One goal of this evaluation will be to determine the quality of the data collected. All quantitative data will be checked to assess precision (using relative percent difference for duplicate matrix spikes), accuracy (percent recovery of matrix spikes), and completeness (percentage of data that are valid). If the quality assurance objectives are not met, consensus on a path forward will be 
sought with the INEEL Management and Operations contractor, DOE-ID; EPA Region 10; and the Idaho Department of Health and Welfare (IDHW).

The remaining sections discuss management of quality, health and safety, reports, residuals left after the study is completed, staffing, schedule, and budget. The schedule spans three fiscal years (FY-99 to FY-01). Overall budget for the treatability study is $\$ 3.64 \mathrm{M}$. 


\section{CONTENTS}

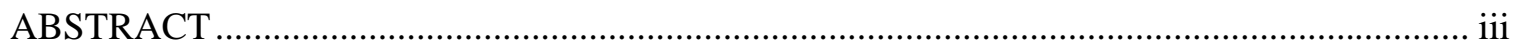

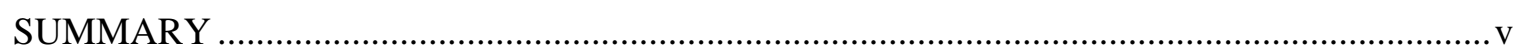

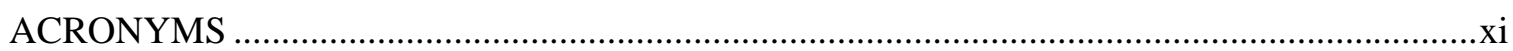

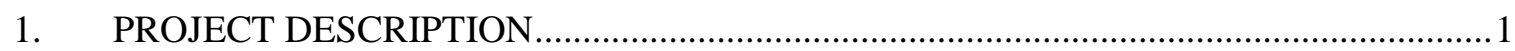

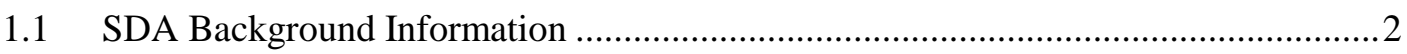

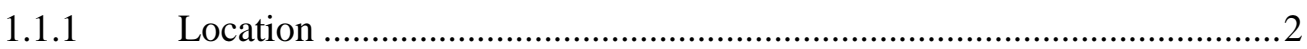

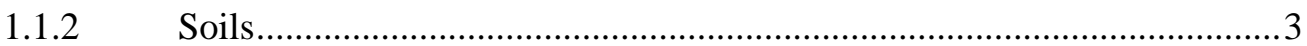

1.1.3 Historical Waste Disposal Operations from 1952 to 1985 .......................4

1.1.4 Contemporary Operations, 1986 to the Present …...................................6

1.1.5 Contaminants of Concern Based on the Interim Risk Assessment ........... 7

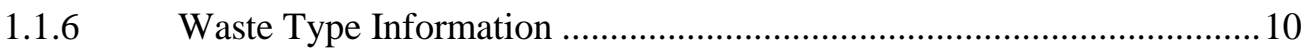

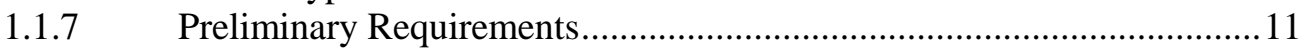

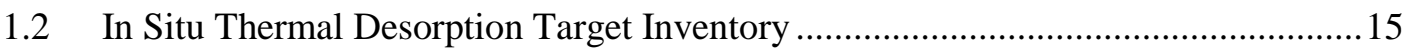

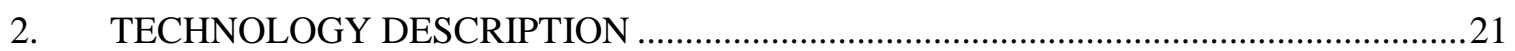

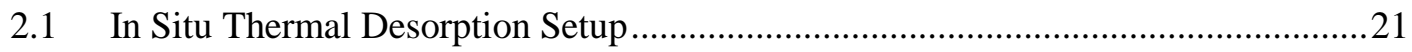

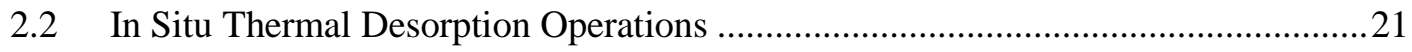

2.3 In Situ Thermal Desorption Applications.................................................................2 23

2.4 In Situ Thermal Desorption Application to Buried Waste ......................................26

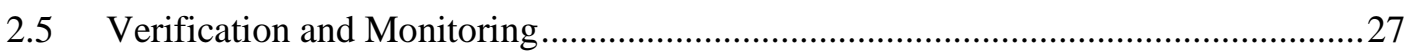

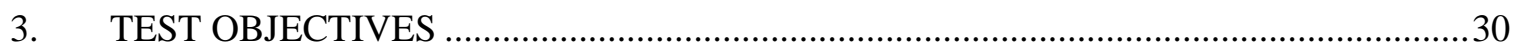

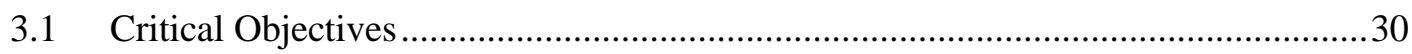

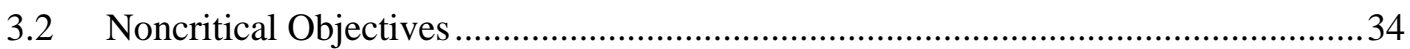

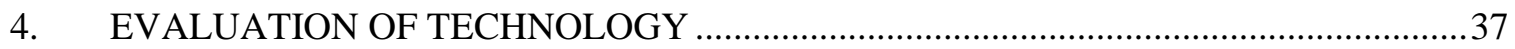

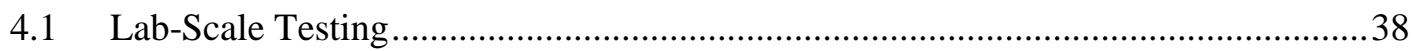

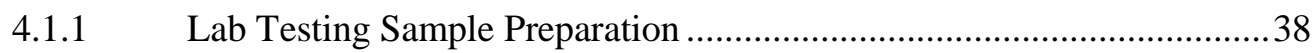

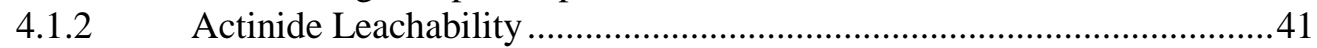

4.1.3 Nitrate Decomposition ...................................................................... 41

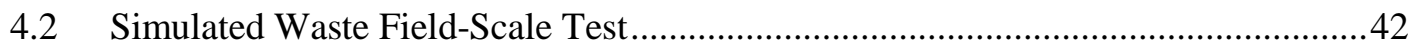

4.2.1 Simulated Waste Pit Preparation ..............................................................42

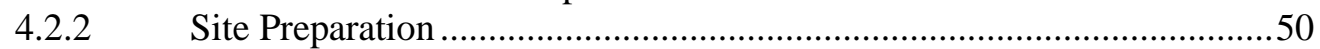

4.2.3 Processing of the Simulated Waste Test Pit..........................................50

4.2.4 Process Monitoring ........................................................................52

4.2.5 Post-Test Sampling and Excavation............................................... 53 


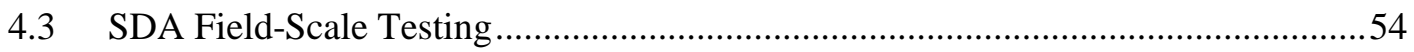

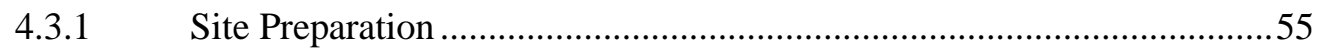

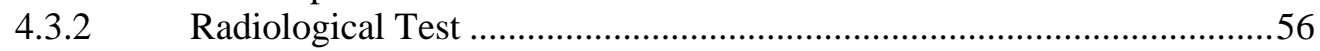

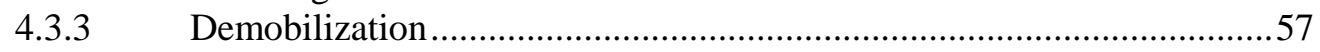

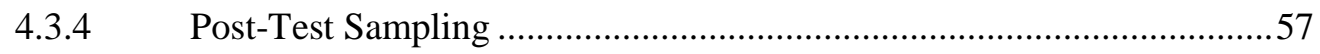

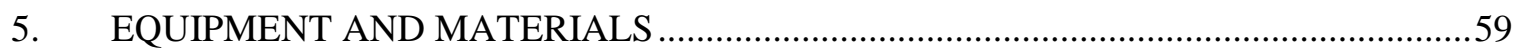

5.1 Required Equipment/Materials for the Lab-Scale Tests........................................59

5.2 Required Equipment/Materials for the Simulated Field-Scale Test ........................59

5.3 Required Equipment for the Radioactive Field-Scale Test .................................61

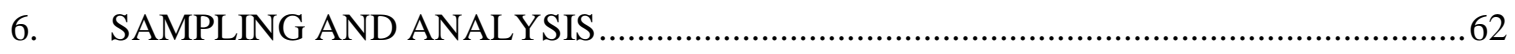

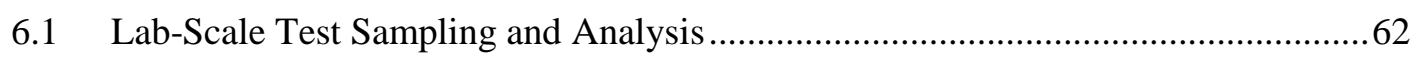

6.1.1 Actinide Leachability .....................................................................63

6.1.2 Nitrate decomposition upon heating ..................................................64

6.2 Simulated Waste Field-Scale Test Sampling and Analysis....................................64

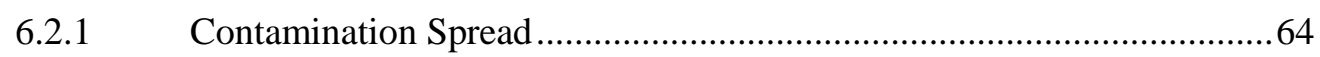

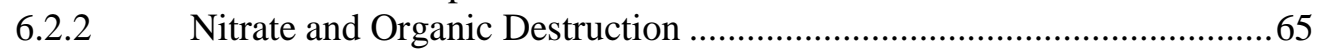

6.2.3 Subsidence/Site Stability and Moisture Return.....................................65

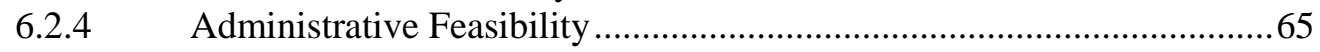

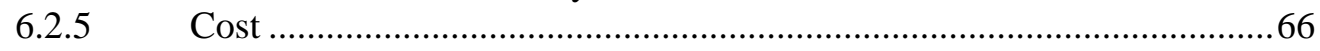

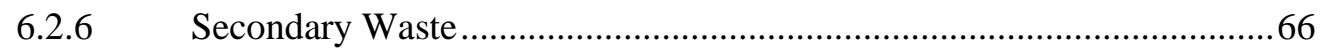

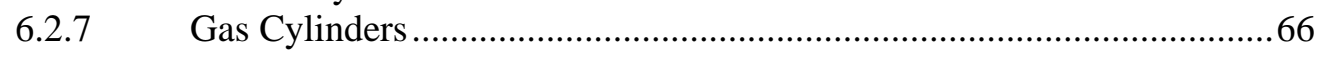

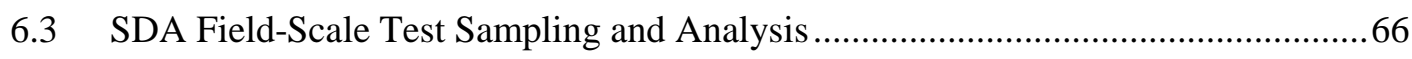

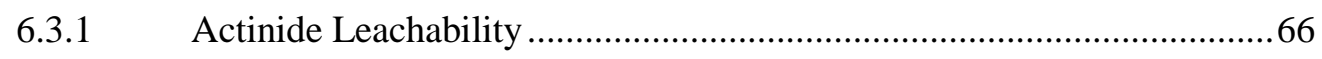

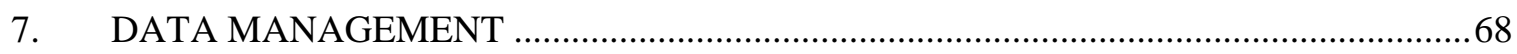

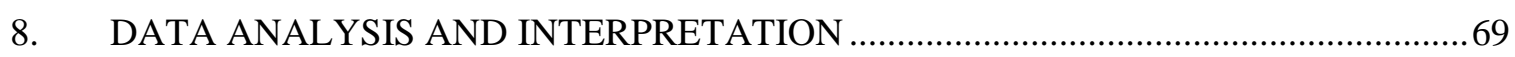

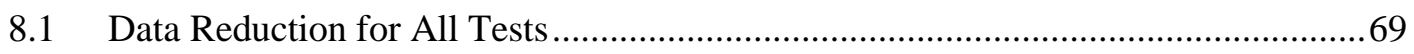

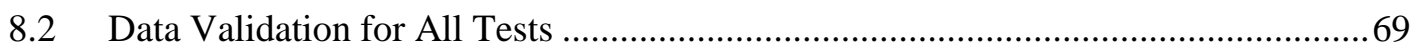

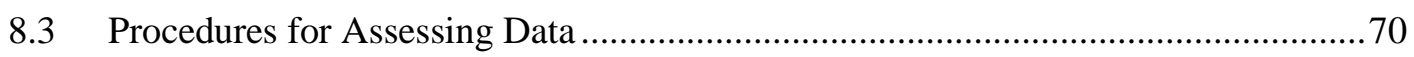

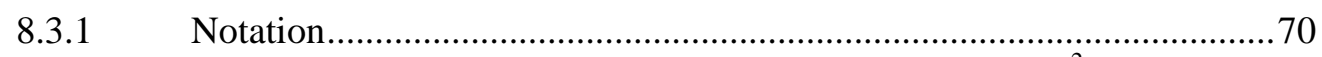

8.3.2 Estimation of the variance of the measurement process $\left(\sigma_{\text {meas }}^{2}\right)$..............70

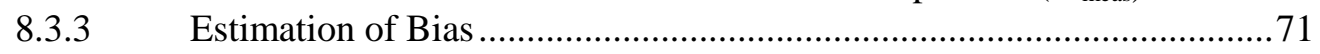

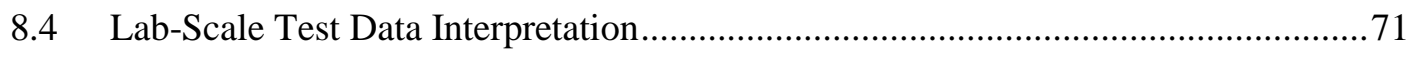

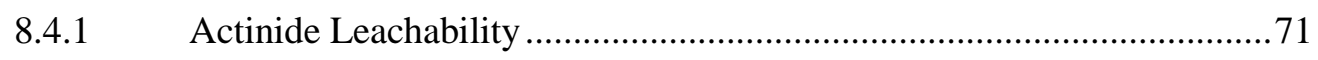

8.4.2 Nitrate Decomposition .................................................................... 71

8.5 Simulated Waste Field-Scale Test Data Interpretation........................................... 72

8.5.1 Contamination Spread During Vacuum and Heater Well Emplacement and

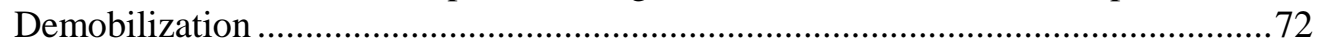

8.5.2 Nitrate and Organic Destruction ....................................................... 72 
8.5.3 Subsidence/Site Stability and Moisture Return.................................. 72

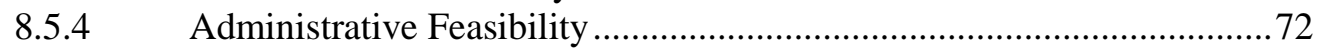

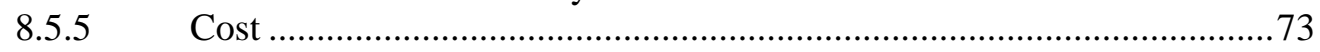

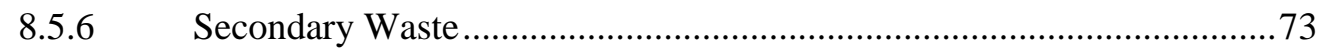

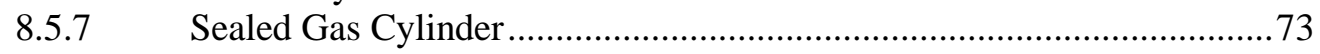

8.6 SDA Field-Scale Test Data Analysis and Interpretation ............................................ 74

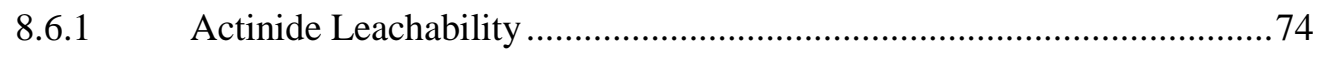

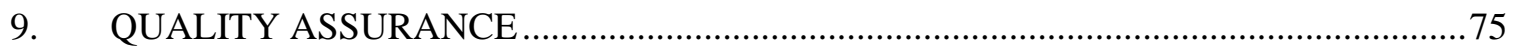

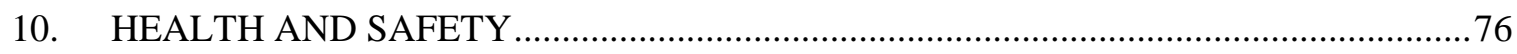

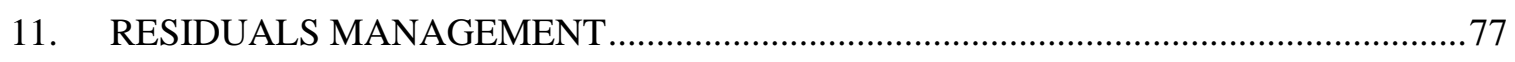

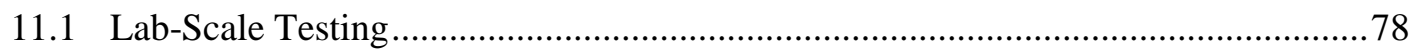

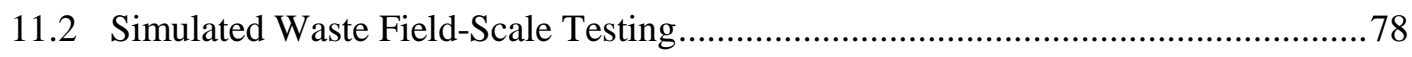

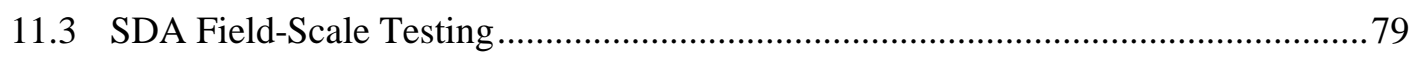

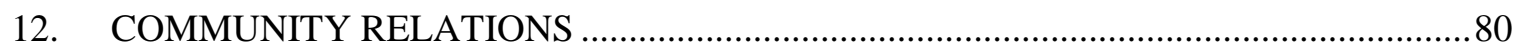

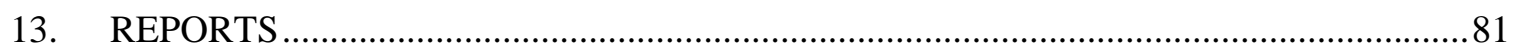

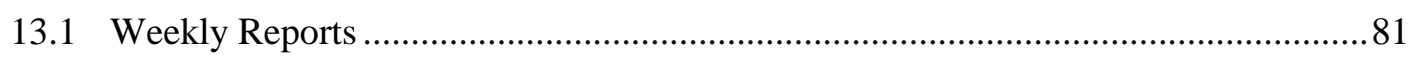

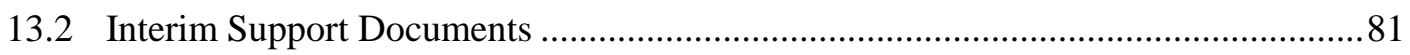

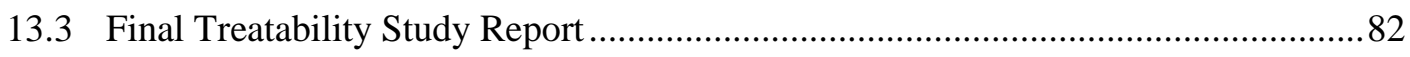

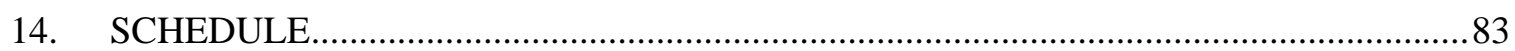

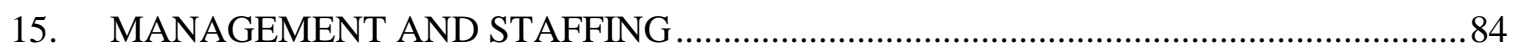

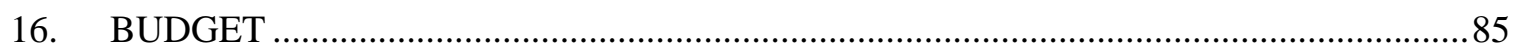

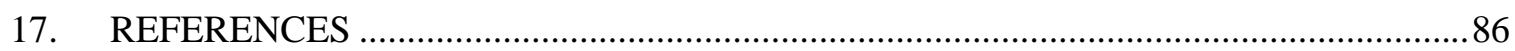

Appendix A-Emplacement Information for In Situ Thermal Desorption Wells

\section{FIGURES}

1. Physical layout of RWMC disposal locations and facilities. ...................................................

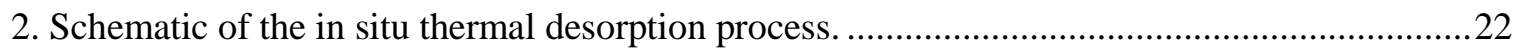

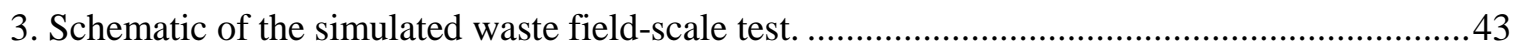

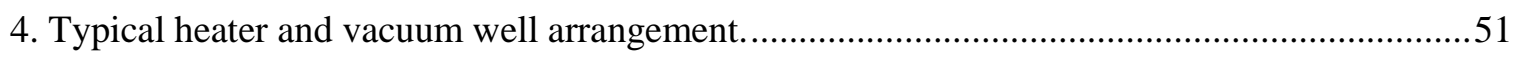

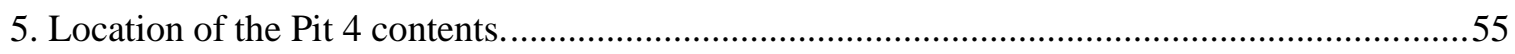

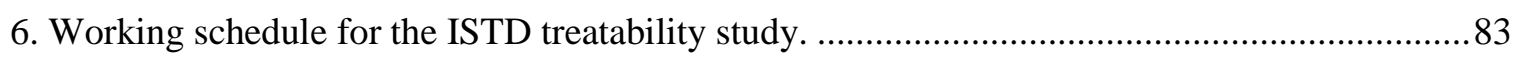




\section{TABLES}

1. Maximum Interim Risk Assessment simulated risks and hazard indices for COPCs during the 1,000-year simulation period (Becker et al. 1996). ........................................... 8

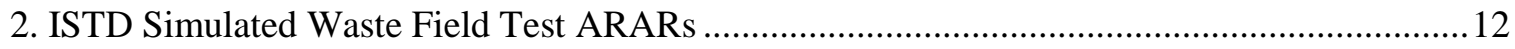

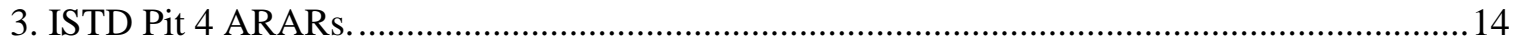

4. Evaluation of SDA contaminant fate following in situ thermal desorption.............................17

5. Comparison of TerraTherm in situ thermal desorption tests and remediations. .......................25

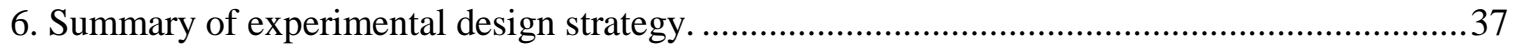

7. Waste packages and contents for the ISTD simulated field-scale test. ...................................44

8. Waste packaging inventory for the simulated field-scale test pit............................................45

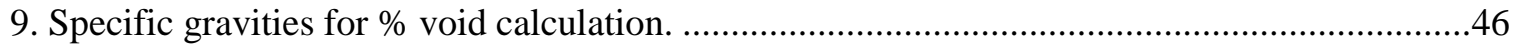

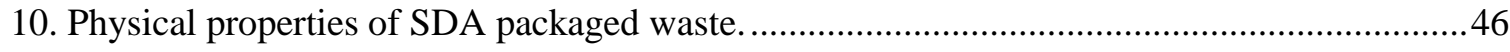

11. Waste packaging inventory comparison for test pit, Pit 4, Pit 9, and the SDA......................47

12. Composition of surrogate and simulated waste matrices. .................................................. 48

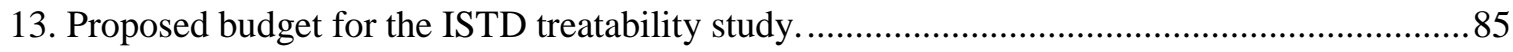




\section{ACRONYMS}

AEC Atomic Energy Commission

ARAR Applicable, Relevant, and Appropriate Requirements

CERCLA Comprehensive Environmental Response, Compensation, and Liability Act

CFR Code of Federal Regulations

CH Contact-Handled

COPC Contaminant of Potential Concern

DOE Department of Energy

DOE-ID Department of Energy-Idaho Operations Office

EPA Environmental Protection Agency

ER Environmental Restoration

ERIS Environmental Restoration Information System

HEPA High Efficiency Particulate Air

HI Hazard Index

HSP Health and Safety Plan

ICP Inductively-Coupled Plasma

ICP-MS Inductively-Coupled Plasma-Mass Spectrometry

IDHW Idaho Department of Health and Welfare

IDW Investigation Derived Waste

INEEL Idaho National Engineering and Environmental Laboratory

INEL Idaho National Engineering Laboratory

IRA Interim Risk Assessment

ISTD In Situ Thermal Desorption

LDR Land Disposal Regulation

LLW Low-Level Waste

LMITCO Lockheed Martin Idaho Technologies Company 


\begin{tabular}{|c|c|}
\hline $\mathrm{M} \& \mathrm{O}$ & Management and Operations \\
\hline $\mathrm{MCP}$ & Management Control Procedure \\
\hline $\mathrm{NO}_{\mathrm{x}}$ & Oxides of Nitrogen \\
\hline NRF & Naval Reactor Facility \\
\hline NRTS & National Reactor Testing Station \\
\hline $\mathrm{OU}$ & Operable Unit \\
\hline PCT & Product Consistency Testing \\
\hline PM & Project Manager \\
\hline QAP & Quality Assurance Program \\
\hline QAPjP & Quality Assurance Project Plan \\
\hline RCRA & Resource Conservation and Recovery Act \\
\hline RFP & Rocky Flats Plant \\
\hline RH & Remote-Handled \\
\hline $\mathrm{RI} / \mathrm{FS}$ & Remedial Investigation/Feasibility Study \\
\hline RWMC & Radioactive Waste Management Complex \\
\hline SDA & Subsurface Disposal Area \\
\hline SRPA & Snake River Plain Aquifer \\
\hline SVR & Soil Vault Row \\
\hline TCA & 1,1,1-Trichloroethane \\
\hline TCE & Trichloroethylene \\
\hline TCLP & Toxicity Characteristic Leaching Procedure \\
\hline TS & Treatability Study \\
\hline TRU & Transuranic \\
\hline TSA & Transuranic Storage Area \\
\hline WAG & Waste Area Group \\
\hline
\end{tabular}




\section{Operable Unit 7-13/14 \\ In Situ Thermal Desorption \\ Treatability Study Work Plan}

\section{PROJECT DESCRIPTION}

This Work Plan provides technical details for conducting a treatability study to determine the effectiveness, implementability, and cost of applying in situ thermal desorption (ISTD) to subsurface waste at the Subsurface Disposal Area (SDA) within the Radioactive Waste Management Complex (RWMC) at the Idaho National Engineering and Environmental Laboratory (INEEL). The SDA falls under the jurisdiction of the Comprehensive Environmental Response, Compensation, and Liability Act (CERCLA, 42 USC $\S 9601$ et seq.); thus, the testing will be a CERCLA treatability study. ISTD is one of several treatment options identified in the addendum to the Work Plan for the Operable Unit (OU) 713/14 Waste Area Group 7 Comprehensive Remedial Investigation/Feasibility Study (RI/FS) (DOE-ID 1998a). The purpose of the OU 7-13/14 ISTD treatability study is to fill performance-based data gaps relative to ISTD. By performing the ISTD treatability study, uncertainties associated with selecting remedies will be reduced. Therefore, a better foundation will be provided for remedial recommendations and the ultimate selection of remedial actions for the SDA.

The overall objective of the ISTD treatability study is to provide sufficient data to evaluate ISTD either as a pretreatment to some other technology or as a long-term in situ disposal option at the SDA. The ISTD Treatability Study Work Plan provides the technical details for conducting the tests, managed through a graded risk approach. The current study will take place in three phases: lab-scale (radioactive), field-scale (radioactive), and field-scale (nonradioactive). The nonradioactive field-scale test will use comparable matrices with surrogates in place of hazardous and radiological contaminants. If the results of this phase are sufficiently encouraging, the technology will then be tested at a radioactive site containing actual contaminants. A formal decision point is structured into the treatability study to ensure that key issues will be addressed satisfactorily before resources are committed to subsequent full-scale testing at the SDA.

As part of the planning for the field-scale testing at the radioactive site, a detailed safety assessment is being conducted per U.S. Department of Energy (DOE) Order 5480.23. The engineering, operational, and administrative controls necessary to mitigate the approved design basis accidents, which are presently under development, will be specified in the treatability study test plan, operational procedures, and health and safety plan. The specific test objectives established for each of these phases must be satisfactorily addressed before initiating the next phase of the treatability study. DOE's Operational Readiness Review process for startup of nuclear facilities is being implemented to ensure that adequate reviews and management oversight of the process is completed before beginning the radioactive field-scale test in Phase 3.

The lab-scale testing phase will include heating a soil sample obtained from the SDA to evaluate the effects of heating on the radionuclides. In addition, a simulated waste will be heated to determine the effects on nitrate salt decomposition.

The field-scale testing phase of simulated SDA wasted will consist of installing heating and vacuum wells, operations, demobilization, and evaluation of the treated zone. The purpose of this test will be to determine the effects of heating a gas cylinder, contamination spread during well emplacement, 
operational effects on landfill-type waste, and the effect of ISTD on pit subsidence, stability, and post-test effects of moisture on the treatment zone.

The field-scale test of actual radioactive SDA waste will be conducted in Pit 4 (see Figure 1 for a map of the RWMC). The test will consist of installing heating and vacuum wells, operations, demobilization, and evaluation of the resultant treated zone.

Section 1.1 gives background information for the SDA where the technology will be applied. Section 1.2 describes the contaminants targeted for ISTD.

\subsection{SDA Background Information}

\subsubsection{Location}

The RWMC covers 70-ha (174-acres) in a natural topographic depression on the southwestern quadrant of the INEEL. The facility is divided into three separate functional areas: the SDA, the Transuranic Storage Area (TSA), and the Administrative Area (Figure 1). The SDA is the primary focus of this treatability study. It is surrounded by a soil dike and perimeter drainage channel and was initially established in 1952 as the National Reactor Testing Station (NRTS) Burial Ground on 5.2 ha (13 acres). The SDA has been used for shallow burial of solid radioactive waste and was expanded to 35.6 ha ( 88 acres) and then to 38.8 ha (95.9 acre) in 1958 and 1988 respectively. The TSA was a 22-ha (56.1-acre)

parcel added onto the east side of the SDA and has been used for the storage of transuranic (TRU) waste. The 8.9-ha (22-acre) Administrative Area includes administrative offices, maintenance buildings, equipment storage, and miscellaneous support facilities.

The region of interest for the WAG 7 Interim Risk Assessment included the RWMC facility, surrounding areas that may have received windblown contaminants, subsurface areas which may have received contaminants migrating laterally or vertically, and contamination of the Snake River Plain Aquifer (SRPA) that originated at the RWMC.

The areas, volumes, and dates of operation for SDA trenches, pits, and soil vault rows (SVRs) are given in References 1 to 3. The annual and total disposal inventories for WAG 7 Contaminants of Potential Concern (COPCs) are listed in Table 1. 


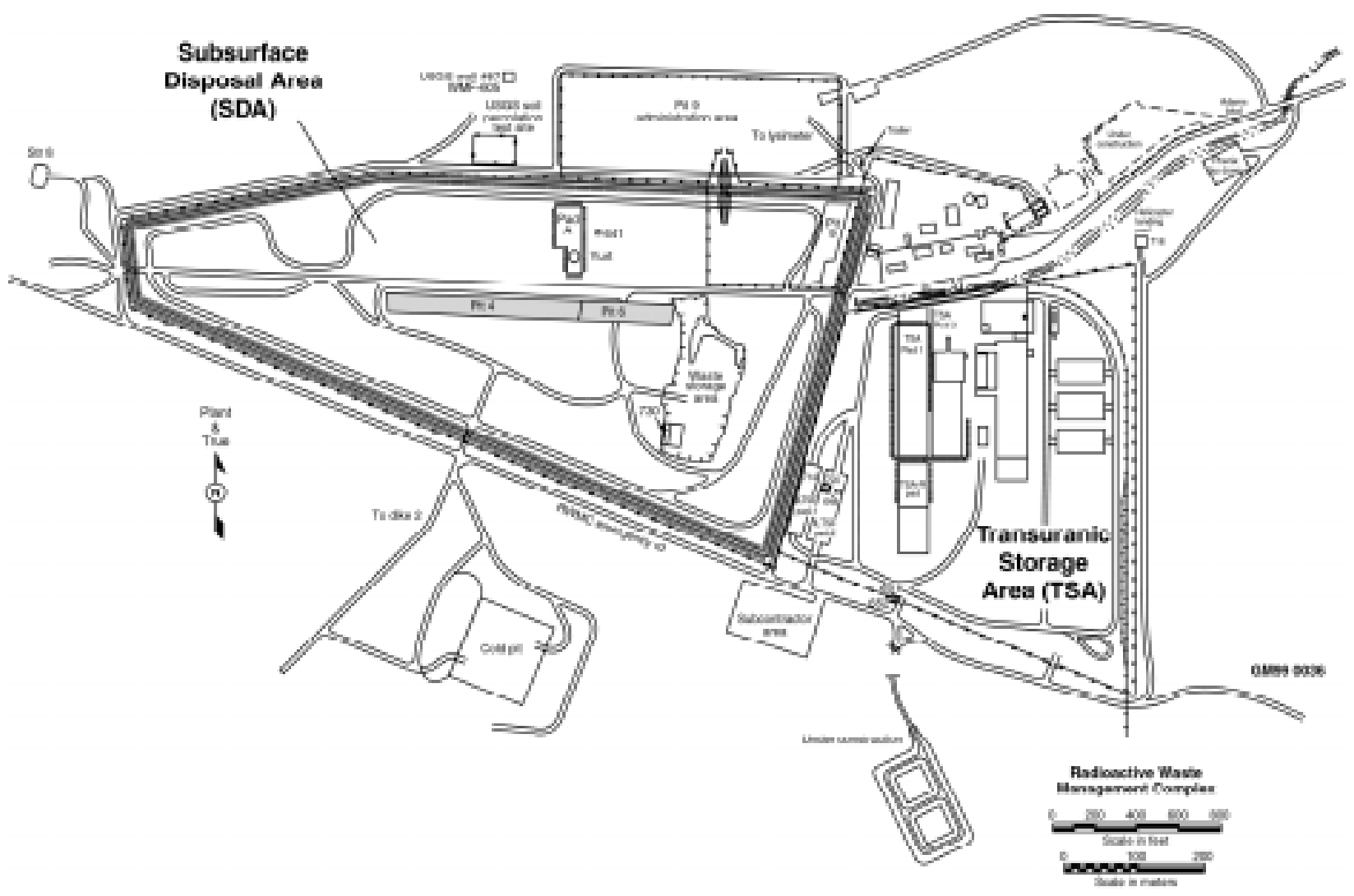

Figure 1. Physical layout of RWMC disposal locations and facilities.

\subsubsection{Soils}

The undisturbed soils at the RWMC were eolian (windblown) deposits (loess) with local concentrations of fluvial gravel and gravelly sand deposited from the historical Big Lost River (EG\&G 1988). The RWMC soils are fine-grained, averaging approximately $36 \%$ clay and $56 \%$ silt, and the soils have moderate to low water-holding capacity (Chatwin et al. 1992; Bowman et al. 1984). The surficial soils are thin and range between 0.6 and $7.0 \mathrm{~m} \mathrm{(2} \mathrm{and} 23 \mathrm{ft}$ ) thick (Anderson et al. 1996). The undisturbed soils pinch and swell on the irregular surface of the underlying basalt and include a variety of structures such as pebble layers, freeze-thaw features, and palette caliche horizons. Surface soil in the waste disposal areas, however, has been thoroughly disturbed and recontoured, and backfill from other areas has been added across the area to control subsidence (settling) and runoff.

The basalt flows which lie beneath surface soils at the RWMC are divided into seven basalt flow groups separated by three sedimentary interbeds (Anderson and Lewis 1989). The flow groups have a maximum thickness of $61 \mathrm{~m}(199 \mathrm{ft})$. The interbeds are primarily unconsolidated sediments, cinders, and breccia, and are referred to by letters designating the overlying and underlying flow groups or by approximate depth. The three uppermost sedimentary layers are the A-B or 30-ft, the B-C or 110-ft, and the C-D or 240-ft interbeds. The C-D interbed is by far the most continuous of these beds, but each interbed has known gaps. 


\subsubsection{Historical Waste Disposal Operations from 1952 to 1985}

Past operations at the SDA are best discussed in four time intervals that share similar disposal practices and waste types: early disposal (1952 to 1959), interim burial ground (1960 to 1963), the midto-late 1960s (1964 to 1969), and 1970 to 1985 (EG\&G 1985). The information that follows was taken from EG\&G (1985).

1.1.3.1 Early Disposal (1952 to 1959). The first trench at the NRTS Burial Ground was opened for solid waste disposal in July 1952, and a total of ten trenches averaging $1.8 \mathrm{~m}$ wide, $274 \mathrm{~m}$ long, and $3.7 \mathrm{~m}$ deep were used between 1952 and 1957 (Trenches 1 through 10). Pit 1 was used to dispose large bulky items in 1957.

Disposal practices depended on classification of the waste as either routine or nonroutine on the basis of radioactivity. Routine waste produced exposures less than daily occupational limits and typically consisted of paper, laboratory ware, filters, metal pipefittings, and other items contaminated by mixed fission products. Routine waste was packaged in cardboard boxes that were taped shut, collected in dumpsters, and emptied into the trenches. Routine waste was not covered with soil until the end of an operating week. Before 1957, there was no upper limit on radiation from waste, and items up to $12,000 \mathrm{R} /$ hour were buried. Items which produced exposures above daily occupational limits were treated as nonroutine waste. This waste was placed in either wooden boxes or garbage cans, transported in special transport containers and vehicles, and immediately covered with soil.

Disposal documentation forms were not required until 1959, and early disposal records are sketchy. From 1954 to 1957, the NRTS Burial Ground accepted waste from the Rocky Flats Plant (RFP), and records did not accompany the shipments. Instead, an annual summary of disposals provided total radionuclide content and waste volume. RFP TRU waste was packaged in drums or wooden crates and stacked horizontally in pits and trenches beside NRTS mixed fission-product waste, and most of the pits and trenches in the original burial ground contain a mixture of the waste types.

Until the late 1950s, trench locations were recorded by reference to metal tags placed at regular intervals along the barbed-wire enclosure surrounding the burial ground. Later, the ends of the centerline and the corners of each pit were marked with concrete survey monuments. Each monument received a brass plate stamped with the trench or pit number, dates the trench or pit was opened and closed, and a direction arrow. Older disposal sites were retrofitted with monuments, but the accuracy of the locations is somewhat uncertain.

1.1.3.2 Interim Burial Ground (1960 to 1963). Trenches 16 through 25 and Pits 2 through 5 were open for waste disposal of waste during this period.

Several changes occurred in Burial Ground operations during this period as a result of the delegation of authority to manage and operate the Burial Ground from the Atomic Energy Commission (AEC) to the NRTS operating contractor. The contractor began to manage radiological surveillance, arranged nonstandard disposal, refined and formalized standard disposal practices, and implemented a record-keeping system.

In the late 1950s, the AEC determined that land disposal was preferable to offshore ocean disposal of solid radioactive waste. Commercially-operated land disposal sites were not available for disposal of waste from AEC-licensed private industry at the time, and the AEC created an interim disposal program, which included the NRTS Burial Ground, to receive solid radioactive waste from licensees while commercial sites were established. Consequently, the NRTS Burial Ground disposed of approved 
shipments from off-site generators together with RFP and NRTS waste during this period. Waste from the three sources was commingled and either stacked or dumped into the pits and trenches.

1.1.3.3 Mid-to-Late 1960s (1964 to 1969). By the mid-1960s, concern about worker safety and environmental impacts of waste disposal, especially potential impacts on the quality of water in the SRPA, began to influence waste management. Disposal practices, monitoring systems, and the adequacy of facilities were scrutinized, and legislation was passed. Drums from the RFP were dumped rather than stacked in pits to reduce labor and control personnel exposures. Environmental monitoring was improved by placing film badges around the perimeter of the burial ground, and these film badges were later replaced with 18 thermoluminescent dosimeters. Water samples from the subsurface were collected and analyzed, and field investigations were conducted to assess leaching. Studies by various agencies recommended improvements in monitoring and steps to mitigate potential impacts from continued waste burial.

Burial procedures were modified to:

- Increase the minimum trench depth from 0.9 to $1.5 \mathrm{~m} \mathrm{(3} \mathrm{to} 5 \mathrm{ft})$

- Line the bottoms of excavations with at least $0.6 \mathrm{~m}(2 \mathrm{ft})$ of soil

- Compact the waste by dropping a heavy steel plate on waste

- Increase soil cover to a minimum of $0.9 \mathrm{~m}(3 \mathrm{ft})$.

TRU disposal, including disposal of plutonium-contaminated waste, ceased in 1969, and all subsequent TRU waste containers were stored above ground at the TSA.

1.1.3.4 Disposals from 1970 to 1985. The greatest departure from previous disposal practices during this period was implementation of the 1970 AEC Policy Statement Regarding Solid Waste Burial (EG\&G 1985; AEC 1970) which required segregated and retrievable storage of TRU waste. Originally, TRU waste was defined as waste contaminated with TRU radionuclides in activities greater than 10 $\mathrm{nCi} / \mathrm{g}$, but in 1982, the TRU waste was redefined to be materials containing any alpha-emitting radionuclide with an atomic number greater than 92, a half-life longer than 20 years, and activity greater than $100 \mathrm{nCi} / \mathrm{g}$ at the end of institutional control. The AEC also committed at this time to remove buried and stored TRU waste from the NRTS (U.S. Department of Energy, Idaho Operations Office [DOE-ID] 1979, Appendix A).

A pad was constructed in the TSA for segregated and retrievable storage of TRU waste. This pad was originally called the "Engineered Waste Storage Area," but the name was changed to the "Transuranic Disposal Area," and then to Pad A. From 1972 to 1978, boxes were stacked around the outside of Pad A while drums were stacked inside in staggered horizontal layers and covered with soil. The pad and waste were covered with a final layer of at least $0.9-\mathrm{m}(3-\mathrm{ft})$ of soil that was contoured to a maximum 3:1 slope and seeded with grass.

Practices were modified to expand the usable disposal volume and extend the operational life of the SDA. Modifications included waste compaction, more stringent waste packaging, and increased pit depths. The Naval Reactor Facility (NRF) began compacting waste in 1971, and by 1974, waste from INEEL facilities other than NRF was sorted and non-TRU compactible waste was shipped to the RWMC in plastic bags for compaction. The volume of disposal pits was expanded by using heavy equipment to remove fractured basalt from the excavations, and beginning with Pit 17 in 1980, explosives were used to deepen pits. Excavations were lined with at least $0.6 \mathrm{~m}(2 \mathrm{ft})$ of soil (and beginning in 1985 with a 
geotextile liner) before waste was interred, and the final compacted soil cover was at least $0.9 \mathrm{~m} \mathrm{(3 \textrm {ft } )}$ thick. Beginning in 1978, waste was stacked in a close-packed array in the pits.

Disposal practices also were modified to minimize personnel radiation exposures. Between 1977 and 1981, soil vaults were used to dispose waste with beta-gamma exposure rates greater than

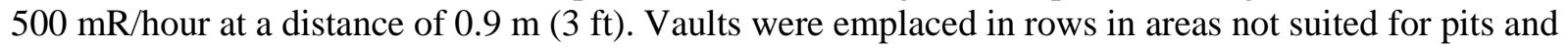
consisted of 0.4 to $2 \mathrm{~m}$ ( 1.3 to $6.5 \mathrm{ft}$ ) diameter vertical cylindrical shafts which averaged approximately

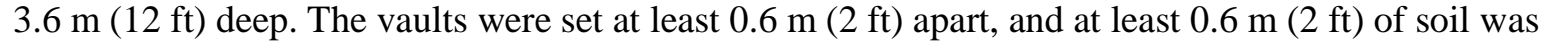
placed in the hole if basalt was penetrated during drilling. Trenches also received high-radiation waste until trench disposal was discontinued in 1981 and the unfilled trench area was redesignated for soil vaults. General disposal practices were the same for pits, trenches, and soil vaults: compacted waste was bailed; larger, bulky items were wrapped in plastic; and smaller noncompactible waste was contained in wooden boxes covered with fire retardant paint. Waste was placed into the excavations by free-air transfer or in shielded casks depending on the exposure rate measured on the outside of the waste container. Full

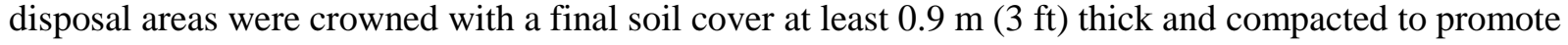
natural drainage.

\subsubsection{Contemporary Operations, 1986 to the Present}

Disposal practices have not changed significantly since 1985 . However, details about the handling of various types of waste have become readily available due to improvements in documentation (LMITCO 1995, DOE-ID 1996). Each waste shipment arriving at the RWMC is visually examined for discrepancies in documentation and damage to packaging. Radiological surveys ensure radiation and contamination readings meet RWMC waste acceptance criteria (DOE-ID 1993; 1997). Any abnormalities are resolved with the generator before acceptance of the waste. Once accepted, the waste is transferred to the TSA or the SDA as appropriate.

1.1.4.1 Contemporary Disposals Within the SDA. Trench burial was discontinued in 1982, and low-level waste (LLW) subsequently has been disposed in pits, soil vaults, and concrete vaults. Pits 17 through 20, including concrete vaults within Pit 20, and SVRs 17, 18, and 20 are presently active. LLW emplaced in the SDA is classified as remote-handled $(\mathrm{RH})$ if radiation levels $1 \mathrm{~m}(3.3 \mathrm{ft})$ from the package surface exceed $500 \mathrm{mR} /$ hour. RH waste is entombed in either a soil or concrete vault. Contacthandled $(\mathrm{CH})$ LLW has lesser exposure rates, and CH-LLW is stacked in the pits. Large bulky items unsuitable for vault disposal are buried occasionally in a pit even though the exposure rate exceeds 500$\mathrm{mR} /$ hour.

1.1.4.2 Pit Disposals. Pits 15 and 16 are closed, but the boundaries between the two pits and Pits 17 and 18 are only administrative (Yokuda 1992). The boxes on the west side of Pits 15 and 16 have been covered with soil for shielding while disposal continues within the large open area of Pits 17 through 20. A contoured earthen berm surrounds Pits 17 through 20.

Waste meeting acceptance criteria is stacked within the pits using forklifts and cranes. The stack height is limited by the strength of the containers and by administrative controls which specify a maximum height of $7.3 \mathrm{~m}(24 \mathrm{ft})$. As areas of the pits become full, waste is covered with at least $1 \mathrm{~m}$ $(3.3 \mathrm{ft})$ of soil which is compacted, sloped for drainage, and seeded with a sod-building grass.

1.1.4.3 Soil Vault Rows. Soil vaults are permanent subsurface receptacles for RH LLW. The soil vaults are unlined holes bored 5.2 to $7.6 \mathrm{~m}$ (17 to $25 \mathrm{ft}$ ) deep that receive containerized waste from

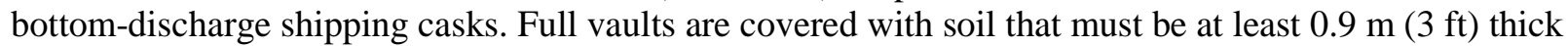
and produce exposure rates at the soil surface above the covered vault less than $1 \mathrm{mR} /$ hour. According to 


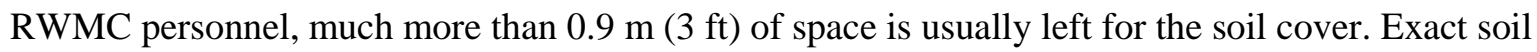

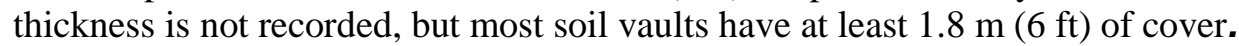

1.1.4.4 Concrete Vaults. Concrete vaults are located in the southwest corner of Pit 20 and were designed to conserve space within the SDA. The concrete vaults, like the soil vaults, are used for RH LLW and receive waste from the same bottom-discharge shipping casks. The vaults were constructed in precast reinforced concrete sections that rest on an integral base plate and are capped with a concrete plug. The vaults are configured in honeycomb arrays with each array being surrounded by soil for additional shielding and seismic stability. Voids between vaults in an array are filled with sand.

\subsubsection{Contaminants of Concern Based on the Interim Risk Assessment}

Contaminants present at unacceptable levels in waste and the subset of these contaminants that can be treated with ISTD are described in this section. COPCs from the WAG-7 Interim Risk Assessment (IRA) are summarized in Table 1. Radionuclides with half-lives less than 2 years were excluded from evaluation, since they are not persistent in waste. C-14, Tc-99, and I-129 may be removed from the COPC list as a result of further refinements in uncertainties in the inventory, contaminant release mechanisms, and fate and transport. These data will assist in risk model calibration and enhance the confidence in predictions of future risk for these specific contaminants (DOE-ID 1998b).

The primary targets of ISTD are chlorinated organic chemicals and nitrate salts. Several contaminants in these classes have risk values or hazard indices (HI) exceeding acceptable values in the 1,000-year simulation of exposures in the IRA (DOE-ID 1998b). The carcinogenic risk from carbon tetrachloride is projected, for example, to have a peak risk greater than $1 \mathrm{E}-04$, and methylene chloride has peak risk in the range of 1E-06 to 1E-04. Carbon tetrachloride, nitrates, and total uranium all have projected HIs greater than 1.

Contaminants with unacceptable risk values or unacceptable hazard indices identified in the IRA (DOE-ID 1998b) include a variety of actinide isotopes and species. A number of contaminants were retained for further evaluation in the Remedial Investigation (RI), including Ac-227, Am-241, C-14, Cl36, Cs-137, I-129, Nb-94, Np-237, Pa-231, Pb-210, Pu-239, Pu-240, Ra-226, Sr-90, Tc-99, U-233, U234, U-235, U-236, U-238, and $\mathrm{U}_{\text {total. }}$ These actinide species are secondary targets of this ISTD treatability study. ISTD treatment of the waste containing these actinide isotopes and species decreases risk values through three mechanisms:

- Destruction of artificial and natural chelating agents such as EDTA, tributyl phosphate, and fulvic acid that can combine with actinides and increase their solubility and mobility;

- Conversion of soluble actinide species, such as actinide nitrates, to relatively insoluble actinide species, such as low-fired actinide oxides

- Fixation of soluble actinide species on to soil and sludge matrix. 
Table 1. Maximum Interim Risk Assessment simulated risks and hazard indices for COPCs during the 1,000-year simulation period (Becker et al. 1996).

\begin{tabular}{|c|c|c|c|c|c|}
\hline $\begin{array}{l}\text { Contaminant of } \\
\text { Potential Concern }\end{array}$ & $\begin{array}{l}\text { Peak } \\
\text { Risk }\end{array}$ & Year & $\begin{array}{c}\text { Peak } \\
\text { Hazard } \\
\text { Index }\end{array}$ & Year & Primary 1,000-Year Exposure Pathway \\
\hline \multicolumn{6}{|c|}{ Radionuclide Contaminants } \\
\hline Ac- $227^{a}$ & 5.E-07 & $2967^{\mathrm{b}}$ & $\mathrm{NA}^{\mathrm{c}}$ & NA & Groundwater ingestion \\
\hline$A m-241$ & 8.E4-05 & $2967^{\mathrm{b}}$ & NA & NA & $\begin{array}{l}\text { Soil ingestion, inhalation, external exposure, } \\
\text { and crop ingestion }\end{array}$ \\
\hline Am-243 & 2.E-08 & $2967^{b}$ & NA & NA & External exposure \\
\hline$C-14$ & 6.E-04 & $2967^{b}$ & NA & NA & Groundwater ingestion \\
\hline $\mathrm{Cl}-36$ & 7.E-06 & 2247 & NA & NA & Groundwater ingestion \\
\hline $\mathrm{Cm}-244$ & 2.E-10 & 2104 & NA & NA & External exposure \\
\hline Co- $60^{d}$ & 4.E-06 ${ }^{\mathrm{d}}$ & 1981 & NA & NA & External exposure \\
\hline Cs-137 & 4.E-04 & 2097 & NA & NA & External exposure \\
\hline Eu-152 & 7.E-08 & 1991 & NA & NA & External exposure \\
\hline Eu-154 & 2.E-07 & 1985 & NA & NA & External exposure \\
\hline $\mathrm{H}-3$ & 7.E-07 & 2097 & NA & NA & Groundwater ingestion \\
\hline I-129 & 2.E-04 & 2116 & NA & NA & Groundwater ingestion \\
\hline $\mathrm{Na}-22$ & 9.E-11 & 1981 & NA & NA & External exposure \\
\hline$N b-94^{a}$ & $\underline{1 . \mathrm{E}-06}$ & $2967^{\mathrm{b}}$ & NA & NA & External exposure (groundwater ingestion) \\
\hline $\mathrm{Ni}-59$ & 7.E-08 & $2967^{\mathrm{b}}$ & 4.E-07 & $2967^{\mathrm{b}}$ & Crop ingestion \\
\hline $\mathrm{Ni}-63$ & 3.E-08 & 2253 & 7.E-11 & 2254 & Crop ingestion \\
\hline$N p-237$ & 2.E-04 & $2967^{\mathrm{b}}$ & NA & NA & Groundwater ingestion \\
\hline$P a-231^{a}$ & 5.E-07 & $2967^{b}$ & NA & NA & Groundwater ingestion \\
\hline$P b-210^{a}$ & 8.E-07 & $2967^{\mathrm{b}}$ & $-\mathrm{e}$ & $\mathrm{-e}^{\mathrm{e}}$ & Soil and crop ingestion \\
\hline $\mathrm{Pu}-238$ & 8.E-09 & 2254 & NA & NA & Soil and crop ingestion \\
\hline$P u-239$ & 2.E-05 & $2967^{\mathrm{b}}$ & NA & NA & Soil and crop ingestion \\
\hline$P u-240$ & $\underline{\text { 5.E-06 }}$ & $2967^{\mathrm{b}}$ & NA & NA & Soil and crop ingestion \\
\hline $\mathrm{Pu}-241$ & 1.E-11 & 1999 & NA & NA & Soil Ingestion \\
\hline $\mathrm{Pu}-242$ & 9.E-10 & 2967 & NA & NA & Soil and crop ingestion \\
\hline$R a-226$ & $\underline{5 . \mathrm{E}-05}$ & $2967^{\mathrm{b}}$ & NA & NA & External exposure \\
\hline $\mathrm{Ra}-228$ & 1.E-07 & $2967^{\mathrm{b}}$ & NA & NA & External exposure \\
\hline Sr-90 & 8.E-04 & 2097 & NA & NA & Crop ingestion \\
\hline Tc-99 & 2.E-04 & 2126 & NA & NA & Groundwater ingestion and crop ingestion \\
\hline Th-228 & 3.E-07 & $2967^{\mathrm{b}}$ & NA & NA & External exposure \\
\hline Th-229 & 2.E-08 & $2967^{b}$ & NA & NA & Groundwater ingestion \\
\hline Th-230 & 2.E-08 & $2967^{b}$ & NA & NA & Groundwater ingestion \\
\hline
\end{tabular}


Table 1. (continued).

\begin{tabular}{|c|c|c|c|c|c|}
\hline $\begin{array}{c}\text { Contaminant of } \\
\text { Potential Concern } \\
\end{array}$ & $\begin{array}{l}\text { Peak } \\
\text { Risk }\end{array}$ & Year & $\begin{array}{c}\text { Peak } \\
\text { Hazard } \\
\text { Index }\end{array}$ & Year & Primary 1,000-Year Exposure Pathway \\
\hline \multicolumn{6}{|c|}{ Radionuclide Contaminants } \\
\hline Th-232 & 4.E-10 & $2967^{\mathrm{b}}$ & NA & NA & Crop ingestion \\
\hline U-232 & 1.E-07 & 2219 & $-\mathrm{f}$ & $-\mathrm{f}$ & Groundwater ingestion \\
\hline$U-233$ & 2.E-06 & $2967^{\mathrm{b}}$ & $-\mathrm{f}$ & $-\mathrm{b}, \mathrm{f}$ & Groundwater ingestion \\
\hline$U-234$ & 2.E-04 & $2967^{\mathrm{b}}$ & $-\mathrm{f}$ & $-\mathrm{b}, \mathrm{f}$ & Groundwater ingestion \\
\hline$U-235$ & $\underline{1 . E-05}$ & $2967^{\mathrm{b}}$ & $-\mathrm{f}$ & $-\mathrm{b}, \mathrm{f}$ & Groundwater ingestion \\
\hline$U-236$ & $\underline{8 . \mathrm{E}-06}$ & $2967^{\mathrm{b}}$ & $-\mathrm{f}$ & $-\mathrm{b}, \mathrm{f}$ & Groundwater ingestion \\
\hline$U-238$ & 6.E-04 & $2967^{\mathrm{b}}$ & $-\mathrm{f}$ & $-\mathrm{b}, \mathrm{f}$ & Groundwater ingestion \\
\hline Acetone & NA & NA & 7.E-03 & 2300 & Groundwater ingestion \\
\hline Antimony & NA & NA & 7.E-05 & 2967 & Groundwater ingestion \\
\hline Beryllium & $5 \mathrm{E}-10$ & 2967 & 6.E-08 & 2967 & Crop ingestion \\
\hline Butanone & NA & NA & 3.E-04 & 2295 & Groundwater ingestion \\
\hline Cadmium & 6.E-12 & 2967 & 1.E-04 & 2967 & Inhalation and crop ingestion \\
\hline Carbon tetrachloride & 6.E-04 & 1968 & 1.E+01 & 2105 & Inhalation and groundwater ingestion \\
\hline Chromium & 3.E-15 & 2159 & 4.E-02 & 2732 & Groundwater ingestion \\
\hline Hydrazine $^{\mathrm{g}}$ & $\underline{2 . \mathrm{E}-05^{\mathrm{g}}}$ & 2280 & NA & NA & Groundwater ingestion \\
\hline Lead & NA & NA & $\mathrm{NA}^{\mathrm{h}}$ & $\mathrm{NA}^{\mathrm{h}}$ & NA \\
\hline Mercury & NA & NA & 5.E-03 & $2967^{\mathrm{b}}$ & Crop ingestion \\
\hline Methylene chloride & 4.E-05 & 2186 & 2.E- $01^{\mathrm{i}}$ & 2185 & Groundwater ingestion \\
\hline Nickel & NA & NA & 4.E-09 & 2967 & Crop ingestion \\
\hline Nitrates & NA & NA & 4. $E+00$ & 2097 & Groundwater ingestion \\
\hline Tetrachloroethylene & NA & 1952 & 5.E- $01^{\mathrm{i}}$ & 2137 & $\begin{array}{l}\text { Groundwater ingestion and dermal exposure } \\
\text { to contaminated water }\end{array}$ \\
\hline Total uranium & $\mathrm{NA}^{\mathrm{j}}$ & $\mathrm{NA}^{\mathrm{j}}$ & 1.E+01 & 2967 & $\begin{array}{l}\text { Groundwater ingestion (primarily because of } \\
\text { U-238) }\end{array}$ \\
\hline
\end{tabular}


Table 1. (continued).

\begin{tabular}{|c|c|c|c|c|c|}
\hline $\begin{array}{c}\text { Contaminant of } \\
\text { Potential Concern }\end{array}$ & $\begin{array}{l}\text { Peak } \\
\text { Risk }\end{array}$ & Year & $\begin{array}{c}\text { Peak } \\
\text { Hazard } \\
\text { Index }\end{array}$ & Year & Primary 1,000-Year Exposure Pathway \\
\hline
\end{tabular}

Note: For toxicological risk, the peak hazard index (HI) is given, and for carcinogenic probability, the peak risk is given.

Green/Italic $=$ the contaminant is retained for evaluation in the WAG 7 comprehensive RI/FS

Red/Bold = carcinogenic risk $>1 \mathrm{E}-04$

Blue/Underline $=$ carcinogenic risk between 1E-06 and 1E-04

Pink/Shaded in PHI column = toxicological (noncarcinogenic) $\mathrm{HI}>1.0$.

a. The contaminant is retained. Though unacceptable groundwater ingestion risks are not predicted in the 1,000year simulation period, risk is greater than $1 \mathrm{E}-06$ in the 10,000-year groundwater ingestion scenario.

b. The peak risk and hazard index for the contaminant do not occur before the end of the 1,000-year simulation period. Therefore, groundwater ingestion risks and hazard indices were simulated for the peak concentration occurring within 10,000 years. These results are not presented in this table.

c. NA = not applicable

d. Cobalt-60 was eliminated from further evaluation. The peak risk is predicted to have occurred in 1981. Based on the short half-life of Co-60 (5.3 years), radioactive decay rapidly reduced external exposure risks.

e. The total toxicological hazard index from all lead isotopes is reported under nonradionuclide contaminants.

f. The total toxicological hazard index from all uranium isotopes is reported under nonradionuclide contaminants.

g. Hydrazine is eliminated from further evaluation. Degradation mechanisms, except for radioactive decay, were not considered in the IRA. However, hydrazine has an environmental half-life of only 2 to 20 days (Environmental Protection Agency [EPA] 1997), and the simulated risk is grossly overestimated.

h. Lead noncarcinogenic effects were predicted using the EPA Integrated Exposure Uptake Biokinetic model. No unacceptable levels were predicted.

i. The inventories for methylene chloride and tetrachloroethylene may be underestimated by a factor of 4 (see Section 4.2). Therefore, noncarcinogenic hazard indices for these two volatile organic compounds will be reevaluated in the BRA.

j. Uranium carcinogenic risks are reported by uranium isotope under radioactive contaminants.

\subsubsection{Waste Type Information}

The wastes to be addressed in this treatability study may be homogenous on the scale of a single truckload, and there may be some gross segregation of wastes between pits and trenches on the basis of size and initial dose of the waste. In general, however, the waste is a heterogeneous mixture, which varies in physical and chemical composition, type and amount of radiological contamination, and moisture content. Boxes, drums, and large items are intermixed. Sludge, debris, salts, metal, and trash are commingled and while most of the waste was initially drummed and boxed, large objects including trucks and pieces of reactor vessels are intermixed. TRU waste, LLW, mixed LLW, and mixed TRU waste were placed side-by-side, and the daily or weekly emplacement of soil cover over the waste resulted in soil throughout. Moisture in the waste, also, can vary dramatically. Mobile COPCs in the soil have been dispersed by leakage and through water movement. 
Potential remedial technologies will have to deal with:

- Contaminated soil—containerized, underburden, overburden, interstitial

- $\quad$ Debris - this includes boxes, drums, concrete blocks, and asphalt, D\&D waste

- $\quad$ Metal—pipes, tanks, machinery

- $\quad$ Large items which were buried intact

- $\quad$ Sludge - this includes inorganic (water-based) sludges, organic (oil-based) sludges

- $\quad$ Salts—nitrate salts

- $\quad$ Trash—rags, plastic, clothes, gloves, blotter paper, bags

- $\quad$ Sealed containers - drums, pressurized gas cylinders.

In some cases, local homogeneities in the waste may allow remedial solutions to be tailored to a limited set of matrices, COPCs, and water contents. Soil vaults, for example, typically contain remotehandled waste with high radiation fields at contact, and remediation of this waste can be designed specifically to deal with the high radioactivity without addressing organic chemical contamination.

\subsubsection{Preliminary Requirements}

Following is a list of preliminary Applicable, Relevant, and Appropriate Requirements (ARARs) for the ISTD treatability study. A detailed applicability analysis of the regulations and requirements will be documented in the treatability study test plan and safety planning documentation.

ISTD will first be demonstrated in a "cold pit" outside the SDA and will not involve the placement or treatment of hazardous waste. Then ISTD will be tested at Pit 4 inside the SDA where hazardous and radioactive waste will be treated in-situ. Hazardous waste ARARs will not be applicable to the cold pit tests because hazardous waste will not be placed into the pit. However, any waste materials from the project must be subjected to a hazardous waste determination prior to disposal.

Hazardous waste ARARs will be applicable to the field-scale test at Pit 4 since the pit contains Resource Conservation and Recovery Act (RCRA) listed waste and possibly RCRA characteristic waste. However, Land Disposal Restriction (LDRs) will not be applicable to the treated waste because all treatment will be conducted in situ. A separate hazardous waste determination and LDR evaluation will be completed on all secondary wastes such as off-gas filters, personnel protective equipment, and decontamination solutions. All wastes from the treatability study will be managed as CERCLA Investigation Derived Waste (IDW). Ultimate IDW disposition will be determined in the final CERCLA ROD for the SDA (see Section 11).

RCRA landfill and groundwater monitoring requirements will not be ARARs for this project since the rest of the pit and SDA will be addressed in a final CERCLA ROD where these ARARs will be included, as appropriate.

Polychlorinated biphenyl (PCB) regulations do not apply to the cold pit tests since PCBs will not be introduced as waste materials or surrogates. PCBs are not expected at Pit 4 , but if found will trigger some PCB-related ARAR considerations. The process will leave no PCBs after treatment and does not generate any as remediation wastes. In past remediations where PCBs were targeted, there were no secondary wastes containing PCBs. The summary table below assumes that no secondary wastes streams will contain PCBs. 
TSCA landfill and groundwater monitoring requirements will not be ARARs for this project since the rest of the pit and SDA will be addressed in a final ROD where these ARARs will be included, as appropriate.

No new drinking water or waste water systems will be installed and no existing systems modified for this project.

Air emissions issues from the project will include fugitive dust, toxic air emissions, and radionuclide emissions. Some portable equipment will be used at the project. It is unknown if the inventory of Pit 4 would trigger ARARs under New Source Performance Standards (NSPS) found in 40 CFR 60. Any limits on this project due to NSPS would likely be Relevant and Appropriate rather than Applicable, due to the narrow applicability of each NSPS category. Additionally, applicable emission limits imposed by Idaho air toxic regulations are likely to impose limitations at least as stringent as those found in NSPS.

A back-up electrical generator will be fueled from a small storage tank located on the same truck/trailer as the generator. A separate fuel tank will not be required.

There are no known archeological or historical sites or endangered species impacted by either set of tests.

The ARARs for this project are presented in two tables: one set for all aspects of the simulated waste field test (see Table 2) and another for all aspects of the Pit 4 test (see Table 3).

Table 2. ISTD Simulated Waste Field Test ARARs

\begin{tabular}{l|l}
\hline Statue, Regulation or Order & Requirement \\
\hline $\begin{array}{l}\text { Toxic Substances IDAPA } \\
\text { 16.01.01.161 }\end{array}$ & $\begin{array}{l}\text { Idaho air regulations limit releases of toxic substances } \\
\text { from stationary and portable sources of air emissions. } \\
\text { Sources must estimate toxic emissions prior to } \\
\text { construction and impose air pollution control equipment } \\
\text { if necessary. Toxic emissions may require routine } \\
\text { monitoring during operation. }\end{array}$ \\
$\begin{array}{l}\text { Toxic Air Emissions IDAPA } \\
\text { 16.01.01.585 - .586 }\end{array}$ & $\begin{array}{l}\text { Idaho air regulations require portable equipment to } \\
\text { operate within state and federal air emissions rules. }\end{array}$ \\
\hline $\begin{array}{l}\text { Requirements for Portable Equipment } \\
\text { IDAPA 16.01.01.500.02 }\end{array}$ & $\begin{array}{l}\text { Idaho air regulations require sources producing fugitive } \\
\text { dust to take action to limit dust suspension. }\end{array}$ \\
\hline $\begin{array}{l}\text { Fugitive Dust IDAPA 16.01.01.650 } \\
\text { and .651 }\end{array}$ & $\begin{array}{l}\text { These federal air regulations apply to emissions of } \\
\text { radionuclides from DOE facilities and limit the radiation } \\
\text { dose to offsite personnel. Radionuclide emissions must } \\
\text { be reported to the INEEL Air Program for aggregation } \\
\text { weSHAPS - Radionuclide Emissions other INEEL sources. }\end{array}$ \\
$\begin{array}{l}\text { from DOE Facilities } \quad 40 \text { CFR } \\
\text { Emission Monitoring } 40 \text { CFR 61.93 }\end{array}$ & \\
$\begin{array}{l}\text { Emission Compliance 40 CFR } \\
61.94(a)\end{array}$ & \\
\hline
\end{tabular}


Table 2. (continued).

\begin{tabular}{l|l}
\hline Statue, Regulation or Order & Requirement \\
\hline $\begin{array}{l}\text { Hazardous Waste - Hazardous waste } \\
\text { determination. IDAPA 16.01.05.006, }\end{array}$ & $\begin{array}{l}\text { Secondary wastes generated during the tests must be } \\
\text { subjected to a hazardous waste determination prior to } \\
\text { disposal. The determination must be formal and } \\
\text { maintained as part of the project records. }\end{array}$ \\
\hline $\begin{array}{l}\text { Idaho Ground Water Quality Rule } \\
\text { IDAPA 16.01.11.200 }\end{array}$ & $\begin{array}{l}\text { These rules establish specific numeric standards for } \\
\text { groundwater contaminants which must not be exceeded } \\
\text { in waters of the state. }\end{array}$ \\
\hline $\begin{array}{l}\text { NPDES, Stormwater } 40 \text { CFR } \\
\text { 122.26 }\end{array}$ & $\begin{array}{l}\text { These regulations address stormwater run off from } \\
\text { various operations including ground disturbance or } \\
\text { excavation and hazardous waste storage and treatment } \\
\text { operations. Stormwater run off shall meet specific } \\
\text { limitations on contaminant concentrations. }\end{array}$ \\
\hline $\begin{array}{l}\text { Spill Prevention, Control, and } \\
\text { Countermeasures (SPCC). 40 CFR } \\
112.3 \text { (b) and 112.7 }\end{array}$ & $\begin{array}{l}\text { While a formal SPCC Plan is an administrative } \\
\text { requirement, operational procedures should meet the } \\
\text { intent of these requirements if a discharge of oil, in } \\
\text { harmful quantities, to waters of the U.S. is possible. }\end{array}$ \\
\hline
\end{tabular}


Table 3. ISTD Pit 4 ARARs.

\begin{tabular}{|c|c|}
\hline Statue, Regulation or Order & Requirement \\
\hline $\begin{array}{l}\text { Toxic Substances IDAPA } \\
\text { 16.01.01.161 } \\
\text { Preconstruction Compliance w/Toxic } \\
\text { Stds IDAPA 16.01.01.210 } \\
\text { Toxic Air Emissions IDAPA } \\
\text { 16.01.01.585 - .586 }\end{array}$ & $\begin{array}{l}\text { Idaho air regulations limit releases of toxic substances } \\
\text { from stationary and portable sources of air emissions. } \\
\text { Sources must estimate toxic emissions prior to } \\
\text { construction and impose air pollution control equipment if } \\
\text { necessary. Toxic emissions may require routine } \\
\text { monitoring during operation. }\end{array}$ \\
\hline $\begin{array}{l}\text { Requirements for Portable } \\
\text { Equipment IDAPA 16.01.01.500.02 }\end{array}$ & $\begin{array}{l}\text { Idaho air regulations require portable equipment to } \\
\text { operate within state and federal air emissions rules. }\end{array}$ \\
\hline $\begin{array}{l}\text { Fugitive Dust IDAPA } \\
16.01 .01 .650 \text { and } .651\end{array}$ & $\begin{array}{l}\text { Idaho air regulations require sources producing fugitive } \\
\text { dust to take action to limit dust suspension. }\end{array}$ \\
\hline $\begin{array}{l}\text { NESHAPS - Radionuclide Emissions } \\
\text { from DOE Facilities } 40 \text { CFR } 61.92\end{array}$ & $\begin{array}{l}\text { These federal air regulations apply to emissions of } \\
\text { radionuclides from DOE facilities and limit the radiation }\end{array}$ \\
\hline $\begin{array}{l}\text { Emission Monitoring } \quad 40 \mathrm{CFR} \\
61.93 \\
\text { Emission Compliance } 40 \mathrm{CFR} \\
61.94(\mathrm{a})\end{array}$ & dose to offsite personnel. \\
\hline $\begin{array}{l}\text { Treatment of PCBs - IDAPA } \\
16.01 .01 .164(\mathrm{c})\end{array}$ & $\begin{array}{l}\text { Systems incinerating PCBs must implement the Best } \\
\text { Available Control Technology for air emissions. ISTD is } \\
\text { not incineration and is permitted for PCB treatment. }\end{array}$ \\
\hline $\begin{array}{l}\text { Idaho Ground Water Quality Rule } \\
\text { IDAPA 16.01.11.200 }\end{array}$ & $\begin{array}{l}\text { These rules establish specific numeric standards for } \\
\text { groundwater contaminants which must not be exceeded in } \\
\text { waters of the state. }\end{array}$ \\
\hline $\begin{array}{l}\text { NPDES, Stormwater } \quad 40 \text { CFR } \\
122.26\end{array}$ & $\begin{array}{l}\text { These regulations address stormwater run off from } \\
\text { various operations including ground disturbance or } \\
\text { excavation and hazardous waste storage and treatment } \\
\text { operations. Stormwater run off shall meet specific } \\
\text { limitations on contaminant concentrations. }\end{array}$ \\
\hline $\begin{array}{l}\text { Spill Prevention, Control, and } \\
\text { Countermeasures. } 40 \text { CFR 112.3(b) } \\
\text { and } 112.7\end{array}$ & $\begin{array}{l}\text { While a formal SPCC Plan is an administrative } \\
\text { requirement, operational procedures should meet the } \\
\text { intent of these requirements if a discharge of oil, in } \\
\text { harmful quantities, to waters of the U.S. is possible or if } \\
\text { liquids with }>50 \text { ppm PCBs are stored. }\end{array}$ \\
\hline $\begin{array}{l}\text { Hazardous Waste - Hazardous waste } \\
\text { determination. IDAPA 16.01.05.006, } \\
\text { 40 CFR 262.11 }\end{array}$ & $\begin{array}{l}\text { Secondary wastes generated during the tests must be } \\
\text { subjected to a hazardous waste determination prior to } \\
\text { disposal. The determination must be formal and } \\
\text { maintained as part of the project records. }\end{array}$ \\
\hline $\begin{array}{l}\text { Remediation Waste Management - } \\
40 \text { CFR 264.1(j) }\end{array}$ & $\begin{array}{l}\text { These federal regulations have not yet been adopted by } \\
\text { Idaho. They will replace } 40 \text { CFR } 264 \text { Subparts B, C, and } \\
\text { D for management of remediation wastes. These } \\
\text { regulations require a waste analysis plan, controlled } \\
\text { access, inspections of waste and equipment, personnel } \\
\text { training, safety procedures, and an on-call emergency } \\
\text { coordinator. }\end{array}$ \\
\hline
\end{tabular}


Table 3. (continued).

\begin{tabular}{|c|c|}
\hline Statue, Regulation or Order & Requirement \\
\hline $\begin{array}{l}\text { Management of Hazardous Waste } \\
\text { Containers - IDAPA 16.01.05.008 - } \\
\text { 40 CFR 264 Subpart I }\end{array}$ & $\begin{array}{l}\text { Standards applicable to management of hazardous waste } \\
\text { in containers. This would be applicable to any secondary } \\
\text { wastes which are either mixed with or derived-from } \\
\text { hazardous wastes in Pit } 4 \text {. Some wastes may also exhibit a } \\
\text { characteristic of hazardous waste independent of Pit } 4 \\
\text { wastes. }\end{array}$ \\
\hline $\begin{array}{l}\text { Miscellaneous Units } 40 \text { CFR Subpart } \\
\mathrm{X}\end{array}$ & $\begin{array}{l}\text { These regulations allow application of hazardous waste } \\
\text { requirements to those units or processes not otherwise } \\
\text { specifically identified in the regulations, but where } \\
\text { application of the requirements seems prudent to protect } \\
\text { human health and the environment. }\end{array}$ \\
\hline $\begin{array}{l}\text { Hazardous Waste Decontamination - } \\
\text { IDAPA 16.01.05.008 - } 40 \text { CFR } \\
264.111 \text { and 264.114. }\end{array}$ & $\begin{array}{l}\text { Equipment which has come into contact with waste from } \\
\text { Pit } 4 \text { must be decontaminated to remove all RCRA listed } \\
\text { waste. Decontamination solutions will remain a RCRA } \\
\text { listed waste. }\end{array}$ \\
\hline $\begin{array}{l}\text { Hazardous Waste Landfill Closure - } \\
\text { IDAPA 16.01.05.008 - } 40 \text { CFR } \\
\text { 264.310(a) }\end{array}$ & $\begin{array}{l}\text { Pit } 4 \text { should be left, after the testing, in such a manner that } \\
\text { risk to groundwater and from other exposure routes is no } \\
\text { greater than before the test. }\end{array}$ \\
\hline $\begin{array}{l}\text { Storage of PCB-Contaminated } \\
\text { Material - } 40 \text { CFR } 761.35\end{array}$ & $\begin{array}{l}\text { Storage requirements for material, such as drill strings, } \\
\text { which have been contaminated with PCBs and which } \\
\text { WILL be used again rather than disposed. }\end{array}$ \\
\hline $\begin{array}{l}\text { PCB Remediation Waste - } 40 \text { CFR } \\
761.50(\mathrm{~b})(3)\end{array}$ & $\begin{array}{l}\text { PCB wastes placed into a landfill prior to } 4 / 18 / 78 \text { may be } \\
\text { left in place subject to a site-specific risk assessment. }\end{array}$ \\
\hline $\begin{array}{l}\text { PCB Decontamination - } 40 \text { CFR } \\
761.61(\mathrm{a})(5)(\mathrm{v})\end{array}$ & $\begin{array}{l}\text { Decontamination requirements for waste with non- } \\
\text { impervious surfaces, such as secondary wastes which } \\
\text { have come into contact with PCB waste. }\end{array}$ \\
\hline PCB Storage - 40 CFR 761.65(c)(9) & $\begin{array}{l}\text { Storage requirements for equipment and secondary wastes } \\
\text { contaminated with PCBs and awaiting decontamination } \\
\text { prior to disposal or awaiting direct disposal as PCB waste. } \\
\text { Storage requirements for secondary wastes sampled for } \\
\text { PCB contamination and awaiting results. }\end{array}$ \\
\hline $\begin{array}{l}\text { PCB Decontamination - } 40 \text { CFR } \\
761.79\end{array}$ & $\begin{array}{l}\text { Decontamination requirements for waste with impervious } \\
\text { surfaces, such as drill strings and internal parts of air } \\
\text { emissions control equipment, which have come into } \\
\text { contact with PCB waste. }\end{array}$ \\
\hline 40 CFR 264 & Pyrolysis zone propagation bounding for landfill seams \\
\hline
\end{tabular}

\subsection{In Situ Thermal Desorption Target Inventory}

The target inventory for the proposed ISTD treatability study was evaluated fully as part of the treatability study planning. The evaluation focused on the ability of ISTD to remediate contaminants and waste types that were buried routinely at the SDA. The evaluation was intended to help predict ISTD performance for the COPCs in Table 1 and to determine whether ISTD would have problems with certain types of waste packages or contaminants that may be commingled with other COPCs. The detailed ISTD target inventory evaluation is summarized in Table 4, which lists the expected fate of the primary COPCs, 
identifies nontarget contaminants and waste types that may potentially present technical challenges for ISTD, the expected fate of the contaminant or waste type, and a determination of whether the contaminant or waste type may affect implementation.

The evaluation identified effectiveness issues such as complete destruction of large amounts of organic debris and nitrate salts, and immobilizing actinides. Other potential implementation issues are associated with applying ISTD to buried waste sites similar to those which exist at the SDA:

- $\quad$ High organic loadings for off-gas system

- $\quad$ Particulate generation during well emplacement, operation, and demobilization.

- $\quad$ Nitrate salt decomposition

- $\quad$ Potential underground fires

- $\quad$ Processing pressurized gas cylinders.

These additional implementation issues were also used to develop the test objectives of the ISTD treatability study (see Section 3). 
Table 4. Evaluation of SDA contaminant fate following in situ thermal desorption.

\begin{tabular}{|c|c|c|}
\hline Contaminant & Contaminant Fate & Concern \\
\hline Ac- 227 & $\begin{array}{l}\text { Immobilized by: destruction of organic ligands, } \\
\text { conversion to oxide, and fixation to soil or } \\
\text { sludge. }\end{array}$ & $\begin{array}{l}\text { None; not a significant } \\
\text { SDA nuclide. }\end{array}$ \\
\hline $\mathrm{Ag}-108 \mathrm{M}$ & $\begin{array}{l}\text { Immobilized by: destruction of organic ligands, } \\
\text { conversion to oxide, and fixation to soil or } \\
\text { sludge }\end{array}$ & $\begin{array}{l}\text { None; not a significant } \\
\text { SDA nuclide. }\end{array}$ \\
\hline Am-241 & $\begin{array}{l}\text { Immobilized by: destruction of organic ligands, } \\
\text { conversion to oxide, and fixation to soil or } \\
\text { sludge }\end{array}$ & None. \\
\hline C-14 & $\begin{array}{l}{ }^{14} \mathrm{C} \text { in carbonates may potentially form }{ }^{14} \mathrm{CO}_{2} \\
\text { and be released in off-gas. Most }{ }^{14} \mathrm{C} \text { is attached } \\
\text { to steel and would not be released }\end{array}$ & $\begin{array}{l}\text { Possible emission } \\
\text { maintained within permitted } \\
\text { limits. However, the Pit } 4 \\
\text { targeted area is assumed to } \\
\text { be free of fission products. }\end{array}$ \\
\hline $\mathrm{Cl}-36$ & $\begin{array}{l}\text { May form } \mathrm{H}^{36} \mathrm{Cl} \text {. Pure beta emitter means very } \\
\text { little dose concern. }\end{array}$ & $\begin{array}{l}\text { None; not a significant } \\
\text { SDA nuclide. }\end{array}$ \\
\hline Co-60 & Stays in irradiated metal. & None. \\
\hline Cr-51 & Stays in irradiated metal. & $\begin{array}{l}\text { None; not a significant } \\
\text { SDA nuclide. }\end{array}$ \\
\hline Cs-137 & Stays in soil or waste & None. \\
\hline Eu-154 & $\begin{array}{l}\text { Immobilized by: destruction of organic ligands, } \\
\text { conversion to oxide, and fixation to soil or } \\
\text { sludge }\end{array}$ & $\begin{array}{l}\text { None; not a significant } \\
\text { SDA nuclide. }\end{array}$ \\
\hline $\mathrm{H}-3$ & $\begin{array}{l}\text { Volatilized and released during ISTD. Pure } \\
\text { beta emitter, means that there is very little dose } \\
\text { concern. }\end{array}$ & $\begin{array}{l}\text { Possible emission problem. } \\
\text { However, the Pit } 4 \text { targeted } \\
\text { area is assumed to be free of } \\
\text { fission products. }\end{array}$ \\
\hline $\mathrm{I}-129$ & $\begin{array}{l}\text { May dissociate and volatilize during ISTD } \\
\text { processing. Small gamma release ( } 38 \mathrm{kEV}) \text {, } \\
\text { means there is little dose concern. }\end{array}$ & $\begin{array}{l}\text { Possible emission contained } \\
\text { by nuclear grade charcoal } \\
\text { filter. However, the Pit } 4 \\
\text { targeted area is assumed to } \\
\text { be free of fission products. }\end{array}$ \\
\hline $\mathrm{Kr}-85$ & Released as gas during ISTD processing. & $\begin{array}{l}\text { None; not a significant } \\
\text { SDA nuclide. }\end{array}$ \\
\hline Mn-53 & Stays in irradiated metal. & $\begin{array}{l}\text { None; not a significant } \\
\text { SDA nuclide. }\end{array}$ \\
\hline $\mathrm{Nb}-94$ & Stays in irradiated metal. & $\begin{array}{l}\text { None; not a significant } \\
\text { SDA nuclide. }\end{array}$ \\
\hline Ni-59 and Ni-63 & Stays in irradiated metal. & $\begin{array}{l}\text { None; not a significant } \\
\text { SDA nuclide. }\end{array}$ \\
\hline
\end{tabular}


Table 4. (continued).

Contaminant

$\mathrm{Np}-237$

$\mathrm{Pa}-231$

$\mathrm{Pb}-210$

$\mathrm{Pu}-239$ and $\mathrm{Pu}-240$

Ra-226

Sb-124 and Sb-125

Sr-90

Tc-99

Th-228

Tl-204

U-232, -233, -234, $-235,-236$, and $¥ 238$

Acetone

Alcohols

Aluminum nitrate nonahydrate-

Antimony

Arsenic

Benzene
Contaminant Fate

Concern

Immobilized by: destruction of organic ligands, May not be absolutely conversion to oxide, and fixation to soil or immobile.

sludge.

Immobilized by: destruction of organic ligands, None; not a significant conversion to oxide, and fixation to soil or sludge.

Potential to stay in metal form. Slight potential for volatilization to off-gas if in metal. Small gamma emission (46 kEV) means there is little dose concern.

Immobilized by: destruction of organic ligands, conversion to oxide, and fixation to soil or sludge.

SDA nuclide.

None; not a significant SDA nuclide.

None.

Immobilized by: destruction of organic ligands, None. conversion to oxide, and fixation to soil or sludge

Stays in irradiated metal.

None; not a significant SDA nuclide.

Stays in soil or waste

None.

Stays in irradiated metal.

None.

Immobilized by: destruction of organic ligands, None. conversion to oxide, and fixation to soil or sludge

Stays in soil or waste. Pure beta emitter, so there is no dose concern.

None; not a significant SDA nuclide.

Immobilized by: destruction of organic ligands, None. conversion to oxide, and fixation to soil or sludge.

Destroyed in situ or volatilized and destroyed. None; not a significant SDA contaminant.

Destroyed in situ or volatilized and destroyed. None; not a significant SDA organic.

Nitrates and nonahydrates dissociate and off- $\quad \mathrm{NO}_{\mathrm{x}}$ in off-gas. gas during ISTD processing.

Immobilized by: destruction of organic ligands, None; not a significant conversion to oxide, and fixation to soil or sludge.

SDA contaminant.

Stays in soil or waste.

None; not a significant SDA contaminant.

Destroyed in situ or volatilized and destroyed. None; not a significant SDA organic. 
Table 4. (continued).

\begin{tabular}{|c|c|c|}
\hline Contaminant & Contaminant Fate & Concern \\
\hline Benzine & Destroyed in situ or volatilized and destroyed. & $\begin{array}{l}\text { None; not a significant } \\
\text { SDA organic. }\end{array}$ \\
\hline Beryllium & Stays in soil or waste. & None. \\
\hline Beryllium oxide & Stays in soil or waste. & None. \\
\hline $\begin{array}{l}\text { 1,4-Bis }(5 \text {-phenyloxazol- } \\
\text { 2-YL)benzene }\end{array}$ & Destroyed in situ or volatilized and destroyed. & $\begin{array}{l}\text { None; not a significant } \\
\text { SDA organic. }\end{array}$ \\
\hline 2-Butanone & Destroyed in situ or volatilized and destroyed. & $\begin{array}{l}\text { None; not a significant } \\
\text { SDA organic. }\end{array}$ \\
\hline Butyl alcohol & Destroyed in situ or volatilized and destroyed. & $\begin{array}{l}\text { None; not a significant } \\
\text { SDA organic. }\end{array}$ \\
\hline Cadmium & Stays in soil or waste. & None. \\
\hline Carbon tetrachloride-Y & Destroyed in situ or volatilized and destroyed. & None. \\
\hline Chloroform & Destroyed in situ or volatilized and destroyed. & None. \\
\hline Chromium & Stays in metal, soil or waste. & None. \\
\hline Copper & Stays in metal, soil or waste. & $\begin{array}{l}\text { None; not a significant } \\
\text { SDA contaminant. }\end{array}$ \\
\hline Copper nitrate & $\begin{array}{l}\text { Nitrates dissociate and off-gas during ISTD } \\
\text { processing, metals remains. }\end{array}$ & $\mathrm{NO}_{\mathrm{x}}$ in off-gas. \\
\hline Dibutylethylcarbutol & Destroyed in situ or volatilized and destroyed. & $\begin{array}{l}\text { None; not a significant } \\
\text { SDA organic. }\end{array}$ \\
\hline $\begin{array}{l}\text { Diisopropylfluoro- } \\
\text { Phosphate }\end{array}$ & Destroyed in situ or volatilized and destroyed. & $\begin{array}{l}\text { None; not a significant } \\
\text { SDA organic. }\end{array}$ \\
\hline Ether & Destroyed in situ or volatilized and destroyed. & $\begin{array}{l}\text { None; not a significant } \\
\text { SDA organic. }\end{array}$ \\
\hline Ethyl alcohol & Destroyed in situ or volatilized and destroyed. & None. \\
\hline Hydrazine & $\begin{array}{l}\text { Destroyed in situ or volatilized, extracted, and } \\
\text { destroyed. }\end{array}$ & None. \\
\hline Lead & $\begin{array}{l}\text { Stays in metal, soil, or waste. No volatilization } \\
\text { at ISTD temperatures. }\end{array}$ & None. \\
\hline $\begin{array}{l}\text { Mercury nitrate } \\
\text { Monohydrate }\end{array}$ & $\begin{array}{l}\text { Nitrates and monohydrates dissociate and off- } \\
\text { gas during ISTD processing. Mercury } \\
\text { volatilizes. }\end{array}$ & $\mathrm{Hg}$ and $\mathrm{NO}_{\mathrm{x}}$ in off-gas. \\
\hline Methyl alcohol & Destroyed in situ or volatilized and destroyed. & $\begin{array}{l}\text { None; not a significant } \\
\text { SDA organic. }\end{array}$ \\
\hline 3-Methylcholanthrene & Destroyed in situ or volatilized and destroyed. & $\begin{array}{l}\text { None; not a significant } \\
\text { SDA organic. }\end{array}$ \\
\hline Methyl isobutyl ketone & Destroyed in situ or volatilized and destroyed. & None. \\
\hline Methylene chloride & Destroyed in situ or volatilized and destroyed & None. \\
\hline
\end{tabular}


Table 4. (continued).

\begin{tabular}{|c|c|c|}
\hline Contaminant & Contaminant Fate & Concern \\
\hline Nickel & Stays in metal. & None. \\
\hline Nitric acid & Dissociates and off-gasses during processing. & $\mathrm{NO}_{\mathrm{x}}$ emissions. \\
\hline Potassium nitrate & $\begin{array}{l}\text { Nitrates dissociate and off-gas during ISTD } \\
\text { processing. }\end{array}$ & $\mathrm{NO}_{\mathrm{x}}$ emissions. \\
\hline Silver & Stays in soil or waste. & None. \\
\hline Terphenyl & Destroyed in situ or volatilized and destroyed. & None. \\
\hline Tetrachloroethylene & Destroyed in situ or volatilized and destroyed. & None. \\
\hline Toluene & Destroyed in situ or volatilized and destroyed. & None. \\
\hline Tributyl phosphate & Destroyed in situ or volatilized and destroyed. & None. \\
\hline 1,1,1-Trichloroethane & Destroyed in situ or volatilized and destroyed. & None. \\
\hline Trichloroethylene & Destroyed in situ or volatilized and destroyed. & None. \\
\hline $\begin{array}{l}\text { 1,1,2-Trichloro-1,2,2- } \\
\text { trifluoroethane }\end{array}$ & Destroyed in situ or volatilized and destroyed. & $\begin{array}{l}\text { None; not a significan } \\
\text { SDA organic. }\end{array}$ \\
\hline $\begin{array}{l}\text { Trimethylolpropane- } \\
\text { Triester }\end{array}$ & Destroyed in situ or volatilized and destroyed. & $\begin{array}{l}\text { None; not a significant } \\
\text { SDA organic. }\end{array}$ \\
\hline Uranyl nitrate & $\begin{array}{l}\text { Nitrates dissociate and off-gas during ISTD } \\
\text { processing. Uranyl ions converted to low-fired } \\
\text { oxides, fixed to soil or waste. }\end{array}$ & $\mathrm{NO}_{\mathrm{x}}$ in off-gas. \\
\hline
\end{tabular}

The target inventory evaluation lays a foundation for developing the objectives and test designs for the ISTD treatability study. The evaluation shows that ISTD may be able to treat many of the radiological, hazardous, organic contaminants, and waste types buried in the SDA and that ISTD may potentially be applied in much of the SDA.

Table 4 in general shows that ISTD eliminates most if not all organic contaminants of concern either in the ground or the thermal oxidizer. During initial startup, small amounts of volatile organics are removed intact as the system acts in a vapor vacuum extraction mode. During cool down, there are little if any significant changes in the state of the inorganic contaminants in terms of physical or chemical form. Some that are not affected by heating remain as they were before the process. Many of the inorganic contaminants that we are addressing should affix to matrix material from the heating and remain that way during cooling. 


\section{TECHNOLOGY DESCRIPTION}

\subsection{In Situ Thermal Desorption Setup}

The ISTD process uses electrical resistance heating elements to heat soil in place, as shown in Figure 2 (Vinegar et al. 1996). The ISTD treatment system consists of an electrical power transformer, resistive heaters, heater wells, vacuum wells, a thermal oxidizer off-gas treatment system, and a process control system. The vacuum maintained in the vacuum wells collects off-gases, which are then piped to the trailer-mounted off-gas treatment system. The off-gas treatment system oxidizes organic emissions and consists of high-temperature particulate filters to remove particulate, thermal oxidation units to remove trace organics, and, if necessary, activated carbon absorbers to remove any remaining trace contaminants.

Heat is applied through resistive wire placed in stainless steel tubes (wells) for subsurface applications deeper than $3 \mathrm{ft}$ (Stegemeier 1995). The resistance heaters are placed in the subsurface wells throughout the entire area to be treated. The heater wells are arranged in a hexagonal pattern around vacuum/heater wells. The vacuum/heater wells are in triangular pattern. Heater and vacuum wells can be 5-15 ft apart. Typically there is one well for every 30 square $\mathrm{ft}$ of remediation area. The wells can extend to any depth, but most remediations have occurred in depths of less than $20 \mathrm{ft}$. Vermiculite can be used on the surface for thermal insulation, but the soil overburden is usually sufficient for this purpose.

\subsection{In Situ Thermal Desorption Operations}

A vacuum of about 1-2 inches of water is applied to those wells with slotted screens that surround some of the heaters. After the initial water and easily vaporized substances in the immediate vicinity of the wells come off, the heating elements are energized. Soil temperatures rise to the boiling point of water, where it remains until all water is gone. The temperature is uniform $\left( \pm 20^{\circ} \mathrm{C}\right)$ through most of the heated zone during this time. Depending on the heat injection rate and the amount of water that must be boiled from the soil, it will remain at $100 \pm 20^{\circ} \mathrm{C}$ for a number of days. Some organic liquids volatilize during this steam distillation period. Organics with higher boiling points pyrolize after the steam distillation period as they are drawn through the hot, dry soil surrounding the heater wells.

After the water is driven from the soil, temperatures rise more rapidly. This temperature is controlled by the voltage applied to the heating elements, how many are turned on, and by the length of time the soil and waste is heated. The heat zone grows steadily outward through the contaminated media until the soil between heater elements reach or exceeds the target temperature. Temperatures of $450 \pm 50^{\circ} \mathrm{C}$ will be sufficient to decompose the organic compounds and the nitrate salts found in the SDA. Temperatures above $500^{\circ} \mathrm{C}$ between wells can be achieved, but these temperatures will only be necessary if organic compounds which resist pyrolysis are targeted for treatment, or if a higher temperature is necessary to fix plutonium and other actinides. The temperatures of vapor released from soil and waste theoretically can approach the temperature of the resistive elements $\left(950^{\circ} \mathrm{C}\right.$ or $\left.1,750^{\circ} \mathrm{F}\right)$. Typically the soil in this region is "red hot" at temperatures of about $540^{\circ} \mathrm{C}$ or $1,000^{\circ} \mathrm{F}$. The total process time depends on the water content of the soil and number of heating elements or wells in a given area, i.e., well spacing. Typically, in moist soil it takes $2-3$ months to reach $500^{\circ} \mathrm{C}$ with 6 -ft spaced wells. 


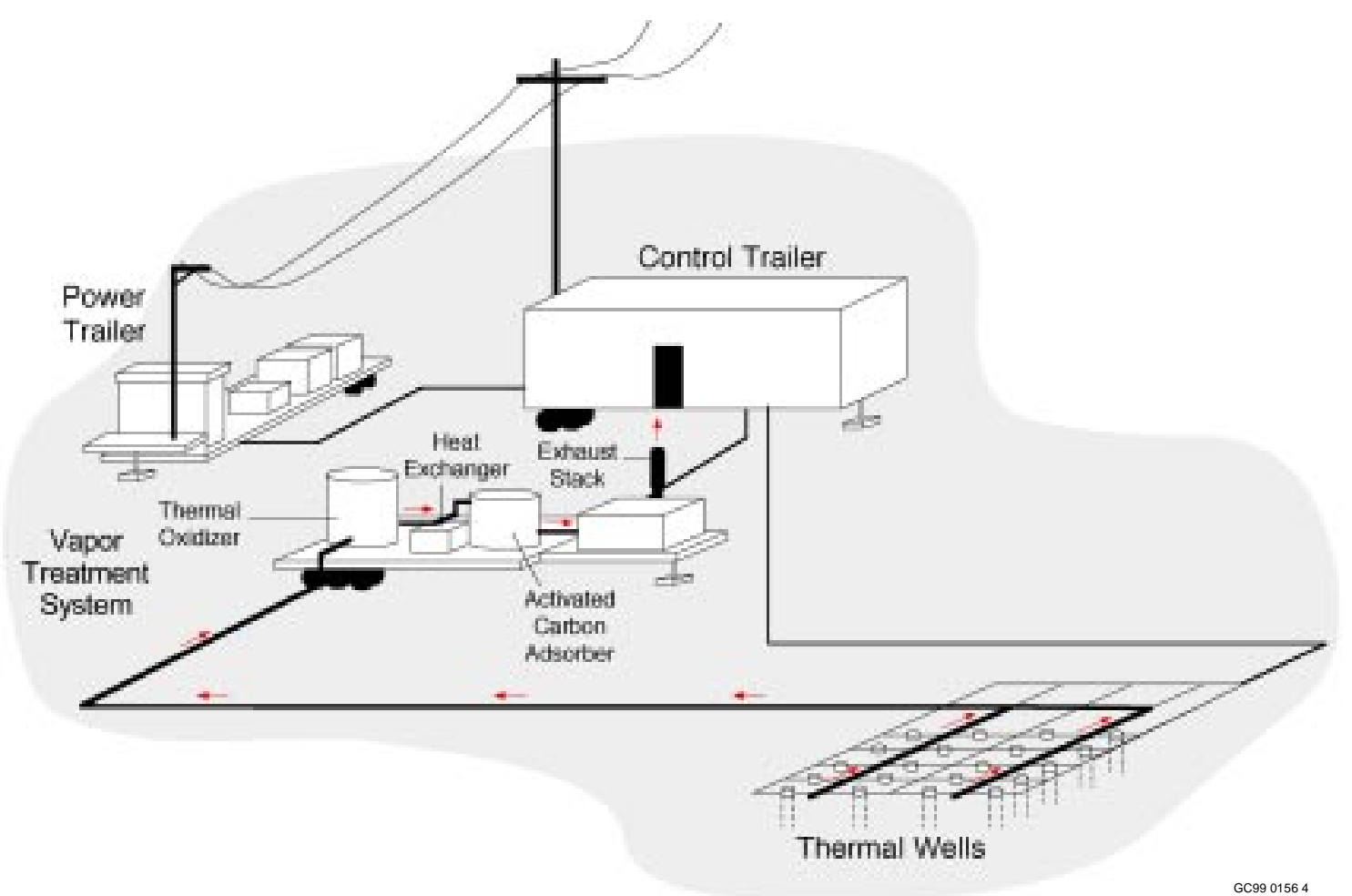

Figure 2. Schematic of the in situ thermal desorption process.

As the resistance heaters raise the soil temperature, gases are removed by the vacuum wells and transported to the off-gas treatment system. Most of the destruction of chlorinated organics, such as PCBs, has taken place underground through pyrolysis in the soils or as the vapor ascends through the heated wells (Vinegar et al. 1997). Pyrolysis products and organics that are not destroyed in the soil or vacuum wells travel to the off-gas treatment system where they are oxidized in a thermal oxidizer.

The thermal oxidation unit is the key component of the off-gas treatment system. TerraTherm's mobile processing unit consists of a particulate cyclone separator and flameless thermal oxidizer operating at $1,000^{\circ} \mathrm{C}$. Water vapor and any trace amounts of organic compounds that are not destroyed in the thermal oxidizer are passed through the Activated Carbon Adsorber before being vented to the atmosphere (Vinegar et al. 1997).

Contaminants released by the heat cannot migrate outside the heated zone during ISTD treatment because the vacuum system collects all heated vapor and even vapors from the region outside the heated zone, either above ( most likely from natural convection) or below. The permeability of the soil exceeds its thermal conductivity, particularly for clayey soils that shrink when heated. Thus the vacuum always pulls ahead of the heat front and the natural gas flow is from colder areas to hotter ones. Thermal desorption performed on PCB-contaminated soils has demonstrated that there is no migration to areas outside the treatment area since the zone of vacuum influence expands more quickly and extends farther than the zone of heat influence. Demonstration tests and full-scale remediation results on PCB contaminated soils are given by Vinegar et al. 1997.

Contaminants are also contained by the sealed off-gas system. A high-temperature blanket is placed over the entire site as a further protection against surface vapor release. The $6 \mathrm{ft}$ of overburden and 
the sealed wells also prevent contamination release. The entire vacuum system is under closely monitored negative pressure so leaks merely introduce air into the system. In fact, some applications in the past required controlled air leakage to maintain some flow through the system. The plausibility of contaminant release through induced criticality or underground fire is addressed in Appendix A.

Volatile metals (such as mercury) may be vaporized and removed in the off-gas during ISTD processing. Nonvolatile metals and radionuclides may remain unchanged or partition into new or altered phases of soil and waste during treatment. The changes in soil and waste may decrease the mobility of some nonvolatile COPCs. Uranium and plutonium, for example, may be less mobile following treatment because ISTD processing leaves soil and waste free of natural and artificial complexing agents that can mobilize actinides and because the actinide oxides formed by heating should resist leaching (Navatril et al. 1980; Cleveland 1979).

\subsection{In Situ Thermal Desorption Applications}

The patent holder for ISTD is Shell Technology International Ventures, Inc. The technology has been solely licensed to TerraTherm. The technology has been applied at:

Glenn Falls, New York

Cape Girardeau, Missouri

Lower Base, Saipan MP

Eugene, Oregon

Portland, Indiana

Mare Island, California

Houston, Texas

Centerville Beach, California.

The first commercial demonstration of TerraTherm's ISTD process at a contaminated site used a surface thermal blanket system. Surface soil containing PCBs at South Glens Falls Drag Strip Superfund Site in eastern New York was treated. A 4,800- $\mathrm{ft}^{2}$ area, $1.5 \mathrm{ft}$ deep, with PCB concentrations ranging up to 5,212 ppm, was remediated to less than 2 ppm with $99.99999 \%$ of the PCBs destroyed (Sheldon et al. 1996). Table 5 compares TerraTherm's remediation results for the eight sites listed above.

The first field demonstration of the TerraTherm thermal well system was the remediation of PCBs at the Cape Girardeau Missouri Electric Works Superfund Site in southeast Missouri (Vinegar, et. al. 1997). A 200- $\mathrm{ft}^{2}$ area, $12 \mathrm{ft}$ deep, with PCB concentrations ranging up to 20,000 ppm, was remediated to less than 33 ppb with $99.9999998 \%$ of the PCBs destroyed (Vinegar et al. 1997).

TerraTherm demonstrated thermal wells for the heating and extraction of hydrocarbon contaminants from beneath a building in Eugene, Oregon (Vinegar et al., 1997). A total of 761 thermal wells were installed at a former railroad bulk fuel loading terminal, including 100 wells installed through a concrete floor under a building to remediate total petroleum hydrocarbons. A total of 11 skid-mounted thermal destruction units are used to handle the off-gas. One-third of the wells are used for the dual 
purpose of both vacuum and thermal contaminant treatment, and two-thirds for thermal contaminant treatment only (Vinegar et al. 1998).

The most recent ISTD remediation has just been completed in Eureka, California at the Centerville Beach Naval facility. A $30 \times 50$-ft area with elevated PCB concentrations $17 \mathrm{ft}$ deep has been heated using 53 thermal placements including 17 combination thermal vacuum wells. A portion of this remediation was performed beneath a building. Trailer-mounted thermal destruction units were used to handle the off-gas. One-third of the wells were used for the dual purpose of both removing gases (vacuum) and to maintain a vaporous state (heating) in the well. Extra thermal wells are used because they improve the uniformity and the rate of heating. 
Table 5. Comparison of TerraTherm in situ thermal desorption tests and remediations.

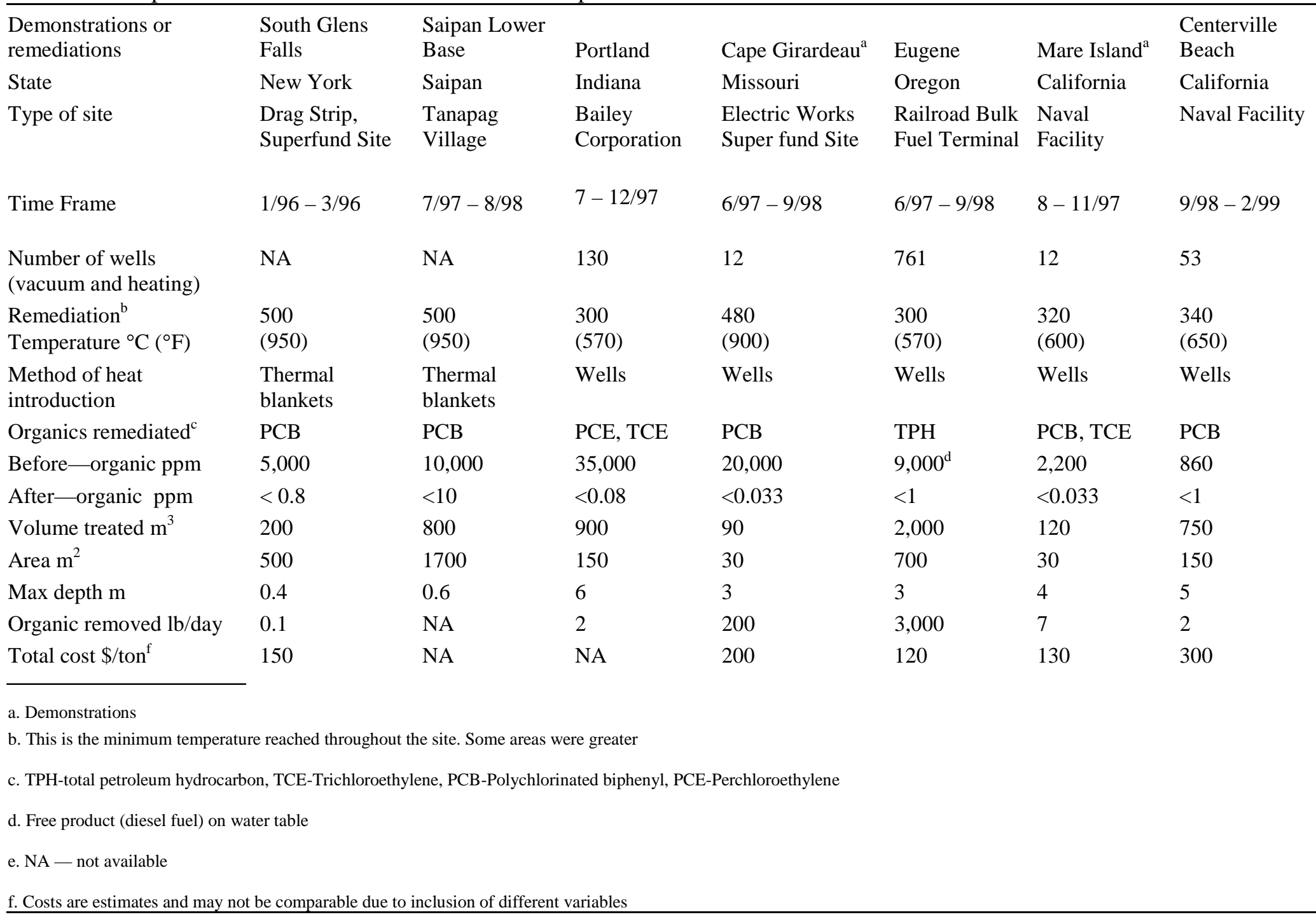




\subsection{In Situ Thermal Desorption Application to Buried Waste}

ISTD has features that make it a viable alternative for remediation of WAG 7 volatile organics, particularly carbon tetrachloride. The technology removes all organics in the waste zone to nondetectable levels and is robust enough for operation in metals, debris, and containerized waste as well as soil. Treatment would destroy targeted organic COPCs, and it would also destroy organic materials such as polyethylene, polyvinyl chloride, latex, paper, ion exchange resins, solvents, machine oil, asphalt, and heavy oils in the waste and soil. ISTD will also decompose inorganic nitrate salts if temperatures are allowed to go beyond $400^{\circ} \mathrm{C}$. At these temperatures, some inorganic COPCs, including mercury, tritium, and C-14, may be volatilized by ISTD. Other COPCs, including plutonium and uranium, may be chemically stabilized and affix more tightly to surrounding soil or waste at this temperature.

Most thermal destruction takes place underground, but thermal destruction also will occur in the off-gas treatment system. The formation of chlorinated organic compounds, such as dioxins, downstream of the thermal oxidizer have not been observed, probably because of the high efficiency and the good mixing in the flameless thermal oxidizer. The nitrate salts will all decompose at ISTD processing temperatures greater than $400^{\circ} \mathrm{C}$ and no further treatment should be necessary for the resulting byproducts.

ISTD has not been widely applied to waste and debris, and no tests have been conducted on the use of ISTD well heating on waste in landfill-type conditions (i.e., with waste stored in multiple containers and the presence of debris, which is characteristic of the SDA). Pilot tests have been performed to assess the applicability of ISTD for both closed containers and organic debris such as those found at the SDA site.

Pilot tests were performed at Shell's Gasmer Road Field Research facility in Houston, Texas to test specialized problems presented by containerized buried waste. The tests dealt with heating containerized organic waste that was represented by burying closed, new 30-gal steel drums filled with ethanol. The underground region in the vicinity of the drums was heated with thermal wells. In tests with normal drums, the rubber seals at the bungs started to leak after reaching only $10 \mathrm{psi}$ of pressure at a temperature well below $100^{\circ} \mathrm{C}$, thereby slowly releasing the organic fluids (Vinegar et al., 1997). However, in a test to see what would happen if there were no rubber seals, the bungs were welded on new, 30-gal steel drums to prevent leakage. The drums reached a pressure of $100 \mathrm{psi}$, at which time the crimped upper lid of a vertical drum failed, blowing out $2 \mathrm{ft}$ of overburden sand and venting the ethanol. Calculations by researchers indicated that $5 \mathrm{ft}$ of overburden would have contained this pressurization.

Another small-scale demonstration was been performed (Hansen et al. 1998) on coal tar for potential application in cleaning up manufactured gas plants (MGP). Actual MGP tar samples were heated at a lab-scale with almost complete destruction of even high boiling benzopyrenes (boiling point $925^{\circ} \mathrm{F}$ or $\left.496^{\circ} \mathrm{C}\right)$ at 3 days while remaining below the boiling point $\left(300^{\circ} \mathrm{C}\right)$. A small field-scale test involved about a ton of sand and tar placed in a shallow $3 \times 5 \mathrm{ft}$ pipe about a foot wider in diameter and 2 $\mathrm{ft}$ higher than a 55-gal drum. One well in the center provided heat and vacuum. The test was run for 9 days until all points exceeded $480^{\circ} \mathrm{C}$. The off-gas was monitored and most of the organics were removed by the 7 days. No pressurization occurred (the top of the pipe was sealed with clay, the bottom was a welded steel plate). Upon examination of the contents after cooling, most of the sand was clean, all tar was pyrolized, with only traces of carbon soot remaining near the edge of the pipe. There was no odor from the drum or coke remaining in the well. Outside lab analysis of the sand detected no petroleum hydrocarbons or polyaromatic hydrocarbons. 
A small-scale field remediation has been performed on waste with organic debris. An abandoned army base in Saipan contained PCB contaminated asphalt and other construction debris. This debris was staged in a shallow $20 \times 8 \times 1 \mathrm{ft}$ box. This remediation used a thermal blanket over the box to heat the debris and asphalt. Vacuum applied through lines under the sealing silicone surface cover and thermal blanket removed the vapors from pyrolyzed PCB and asphalt debris. The asphalt was pyrolyzed with only carbon soot remaining in the soil and sand under the thermal blanket.

\subsection{Verification and Monitoring}

Verifying the success will involve extensive operational monitoring, limited posttest monitoring, and documentation that ISTD treatment meets regulatory, cleanup and contractual requirements. Requirements include verifying the following:

- Stack gas discharges meet applicable or relevant and appropriate regulatory limits

- Waste stream meets treatment requirements for chlorinated organic compounds.

- Entire treatment volume has been heated to the target minimum temperature.

- Monitoring for post-treatment subsidence, changes in soil structure, and hydrogeologic properties.

- Any need for follow up treatments such as ISG or ISV.

Additional radiological monitoring will be required for the Pit 4 test.

The verification sampling program is designed to collect data throughout the ISTD treatment process and for 2 years after treatment. The off-gas will be sampled during ISTD treatment to show compliance with the applicable or relevant and appropriate regulatory requirements (ARARs). The offgas will be monitored continuously (real-time) and by grab samples. Parameters monitored in real-time will include: temperature, pressure, flow, oxygen, nitrogen oxides, hydrogen chloride, carbon monoxide, carbon dioxide sulfur dioxide, water and total organic carbon. Real-time data will be used as an indicator of how the process is performing.

The ISTD heating rate and the off-gas flow rate will be adjusted to keep the real-time parameters within acceptable ranges. Gross radioactivity and targeted specific nuclides also will be monitored on a real-time (or near real-time) basis. Grab samples will be taken periodically to verify real time monitoring results and to analyze parameters (such as dioxins, furans, heavy metals, and radionuclides) which cannot be determined with sufficient accuracy with real time techniques. The frequency of grab sampling will be set to meet regulatory requirements.

There will be limited long-term monitoring of the ISTD treated section of an SDA Pit. The simulated pit may be monitored for 2 years following the test. Verification samples will be collected from the heated section to show contractual obligations have been met once ISTD processing is completed and the soil/waste has cooled (which may take over a year). Since organics have been removed, the evidence for immobility of inorganic contaminants will be obtained primarily from lab-scale testing. If permitted, samples will be taken from the heated waste and soil. Core samples from the heated section will be taken at randomly selected locations to provide conclusive proof that the entire treatment zone has been processed. Selected core samples containing radionuclides will be subjected to leach testing to determine post-treatment leachability of radionuclides. The subsidence will be monitored with ground survey measurements and observations of the physical appearance of the site. 
Based on the results of the verification sampling, the treated area may be released for closure or targeted for additional treatment. Unheated portions of the area targeted for treatment can be reprocessed with minimal difficulty. In commercial operation to date (approximately 20,000 tons processed), no largescale ISTD remediation has failed to remove/destroy the targeted organic contaminants. This success extends to PCBs that have high boiling points for organic compounds and resist thermal treatment. This success can be attributed to:

- The slow and complete heating of soil and waste

- The long residence time of vapors in the soil

- Treatment temperatures that greatly exceed the boiling points of the COPCs

- The greater than $90 \%$ destruction of contaminants (organics and nitrates) in the soil that prevents overloading of the off-gas treatment system.

Potential contaminant release pathways are direct exposure, biotic uptake, inhalation, and leaching to groundwater. Direct exposure pathway is not expected to present a significant risk for the following reasons:

- Radionuclides are immobilized on soil and sludge when heated

- Mobilizing organics have been destroyed

- The heated area will be covered with several feet of soil and may be compacted, vitrified, or grouted

The direct exposure pathway can be monitored by radiation survey or visually inspecting the treated site and looking for signs of physical disturbances such as subsidence. The additional layer of soil added before the test will fill in any subsidence during testing and if necessary additional soil can be added above the heated section.

Exposure by the inhalation pathway is also expected to present minimal risk because:

- The heated waste is agglomerated and mobilizing factors have been reduced or eliminated

- The heated section is covered with several feet of soil which would prevent fine-grained material from being entrained in the air

- Organic chemical COPCs and organic rubbish have been eliminated to eliminate release of landfill gases.

Exposure through biotic pathways such as plants and animals also will be reduced because:

- There is no organic substrate for plants or animals to live and extract heavy metal or radionuclide contaminants

- Nutrients have been eliminated, so there is no reason for animal intrusion

- There is about $6 \mathrm{ft}$ of soil cover over the waste 
- The site is essentially sterile and may remain so for some time.

The nature of the soil and waste treated with ISTD contributes to diminished groundwater contamination. Treatment will leave soil and clay in a sintered sandy state. Both physical and chemical degradation of the soil and waste should diminish. Chemical degradation, like biological action, is expected to be extremely slow given the inherent inertness of sintered inorganic soils and sludges. The 6 $\mathrm{ft}$ of soil cover over the waste provides some protection from weathering, keeping the waste dry and preventing most chemical reactions from occurring.

Most of the void space created by organic destruction will be filled in by the extra overlying soil. Containers that are not physically changed by heating like steel drums will remain for some time if moisture is excluded. Some moisture monitoring of the treated waste may be performed after the cold test as part of the post test monitoring. This will also measure the infiltration and evapotranspiration within the $6 \mathrm{ft}$ of soil cover and the waste seam. Post-ISTD activities such as capping, in situ grouting, or in situ vitrification might not be required based on monitoring data. 


\section{TEST OBJECTIVES}

Remedial alternatives such as ISTD developed during the OU 7-13/14 feasibility study must be evaluated against EPA established criteria under CERCLA (EPA 1988). Sufficient information regarding ISTD for application at the SDA is currently not complete. Therefore, this treatability study was initiated to address data gaps so this technology could be evaluated during the feasibility study. The data gaps associated with ISTD, as well as safety issues, form the basis of the test objectives.

A number of performance issues and objectives were identified previously in the Addendum to the Work Plan for the Operable Unit 7-13/14 Waste Area Group 7 Comprehensive Remedial Investigation/ Feasibility Study (DOE-ID 1998). Two important safety issues identified at that time, criticality and contamination control, have been studied to help focus the objectives that are presented in this Work Plan. A preliminary evaluation of the criticality potential induced by ISTD has been documented (Farnsworth 1999, draft revision 1). Contamination control during well emplacement is being investigated. Appendix A presents results from well emplacement studies to minimize release of particulate contamination while drilling

Based on the evaluations of performance data gaps and safety (criticality and contamination control) issues, critical and noncritical objectives have been identified for this treatability study. Critical objectives refer to the objectives that are considered essential to the successful demonstration and evaluation of the technology. Noncritical objectives are important, but are not essential to the evaluation of ISTD as an alternative for OU 7-13/14 feasibility study, either because the information is not as important or because enough previously collected data is available that would provide some level of confidence in a performance estimate for the feasibility study. All issues will be addressed in some fashion in this treatability study, but with limited time or budget, tests to support the noncritical objectives could be scaled back or eliminated. These objectives may change as the safety assessment is completed and approved. Any changes to test objectives will be clearly documented in the treatability study test plan.

Two tables follow the discussion of objectives for summary purposes. The overall objective of the ISTD treatability study is to provide sufficient data to evaluate the technology for buried waste treatment at the SDA. The treatability study will be judged successful if sufficient data are collected to allow evaluation of ISTD on the basis of implementability, effectiveness, and cost criteria as required by EPA under CERCLA (42 USC $\S 9601$ et seq.) as described below as critical or noncritical objectives. Each objective also describes the intended use of the data and describes how the objective relates to preliminary remediation goals, if applicable. The testing strategy is to collect necessary data for addressing these test objectives as defined in Section 4.

\subsection{Critical Objectives}

The critical objectives of the ISTD treatability are listed below. Each objective is broken down into subsections of test requirements, objective purpose, proposed data usage, and the relevant CERCLA criteria to be answered by the objective. The critical objectives are identified by number.

\section{Test Objective 1: Evaluate INEEL administrative feasibility for well emplacement and ISTD process implementation.}

Test Requirements: During the simulated field-scale test and radioactive field-scale test, a qualitative assessment will be made of the administrative feasibility of applying ISTD to buried waste sites containing mixed transuranic waste at the INEEL. Specific evaluation shall be made of the approval process, requirements needed for implementation, support and coordination during 
well emplacement, waste processing, and demobilization. Feasibility and contamination control will be ascertained in the radiological phase of the testing.

Purpose: The data is needed to properly determine feasibility, estimate costs, and evaluate implementability for ISTD remediation at the INEEL.

Data Usage: The resulting data and observations will help provide a more accurate estimate of the cost of implementing ISTD at the SDA and the feasibility of it's application.

Relevant CERCLA Criteria: Implementability and cost.

Test Objective 2: Determine the degree and safety of hazardous organic contaminant and nitrate destruction in the soil, waste, containers, and off-gas treatment system.

Test Requirements: The primary goal of ISTD is the complete destruction of two of the contaminants of potential concern, hazardous organics and nitrates in a safe and controlled manner. Both are to be completely removed from the soil, waste, containers and off-gas system. Most destruction occurs in the ground with remaining trace organics destroyed in the off-gas system. This destruction must not result in any uncontrolled reactions that might breach the offgas system. Operational monitoring will verify no underground fires are occurring, that conditions remain such that they cannot occur (oxygen limiting environment) and that the temperature progression is as predicted.

Verification for the feasibility study of complete removal/destruction will be determined by temperature monitoring of the surrounding soil during both simulated and radioactive field-scale tests and off-gas monitoring and post-sample testing in both simulated and radioactive field-scale tests. Gases are continuously monitored during ISTD processing by continuous stack sampling for chloride and nitrogen oxide gases. The extensive off-gas monitoring will be used to confirm the completion of organic and nitrate salt destruction during ISTD processing and the absence of any post-off-gas dioxin formation.

In addition to verifying that ISTD destroys the organic and nitrate salt, a portion of the simulated field-scale test will be excavated to visually verify that ISTD destroys combustible organic matrix such as plastic pipe, clothing, and waste paper. Samples will be taken of the final heated mass from the nonradioactive field-scale test after allowing sufficient time for the waste to cool. Solid samples will be analyzed for a range of metals, particularly sodium and potassium, to define the alkaline characteristics of the remaining waste following the nitrate salt destruction. Core samples from the radioactive field-scale test will be obtained and analyzed to confirm the absence of organics and nitrates in the treated zone. Complete destruction of nitrate salts will also be verified in lab-scale testing.

Purpose: The absence of organics and nitrate salts in the waste and surrounding soil, following ISTD processing, is verified by temperature, monitoring and sampling data. The data will be useful in estimating the effectiveness of the ISTD process in eliminating risks associated with the nitrate salt and organic matrix of waste. ISTD processing of large volumes of nitrate salts and trash results in some emission of oxides of nitrogen $\left(\mathrm{NO}_{\mathrm{x}}\right)$ and hydrochloric acid $(\mathrm{HCl})$ which are regulated through air permits and which must pass through the thermal oxidizer and entire off-gas system.

Data Usage: The intended use of this data is for evaluating the effectiveness of the thermal destruction of hazardous organic and nitrate COPCs, while obtaining design data, for the OU 713/14 feasibility study. The information will be used to define the ultimate design of the off-gas 
system needed for ISTD remediation of SDA pits and trenches and possible applicability of ISTD to Pad A.

Relevant CERCLA Criteria: Short-term effectiveness, compliance with ARARs implementability, and cost.

Test Objective 3: Evaluate the extent of actinide particulate contaminant release during heater and vacuum well emplacement thermal desorption, and demobilization.

Test Requirements: Containment of contamination during well emplacement methods will be tested in the field simulated test and verified in the radiological environment of the SDA test. A pre test of alternate placement methods, such as lancing may be performed. Multiple wells will be both drilled and lanced to determine the ease of operation in soil and debris. Air sample filters will be taken during these two different types of well emplacements to compare particulate release. The relative particulate contamination control will be weighed against the ease of operation and reliability in buried waste.

The acceptable release of contamination is determined by the Radiological Control Manual as 20 dpm alpha. Health Physics requirements also give limits such as derived air concentration for the radionuclides in question. It is hard if not impossible to directly relate tracer data to specific numeric radiological criteria for a number of reasons. One indication of acceptable control is simply comparing the total dust generated by a process to the ambient particulate concentration in air. For this test any statistical concentrating of the tracer over background in the air filters will indicate unacceptable release of contamination from the well. Appendix A presents results from well emplacement paper studies that investigated how to minimize particulate contamination release.

Air sample filters will be taken during insertion of the well drilling heater and vacuum screen. Air samples will also be taken following the simulated test during header removal and heater and vacuum screen removal (if performed) and well closure. In both the simulated and radioactive field-scale tests, particulate contaminant migration will be verified. Mitigation features developed for Pit 9 well drilling will be used in sonic drilling operations for ISTD well emplacement. To simulate the radioactive component in the SDA pits, a large amount of finely divided lanthanum oxide (or other appropriate rare earth tracer) will be placed in the simulated test pit. Analysis of filter samples from all operations during the simulated field test will include both total particulate collected on the filters, as well as the amount of lanthanum and other rare earth oxides in those samples. During operations, sampling of filters in the ISTD off-gas system will be performed to verify any migration of particulate contamination during processing. Analysis of the filter samples from the SDA radioactive test will be submitted for radionuclide composition during and after the field test. The results will define the level of equipment decontamination required for the ISTD offgas system, the best method for removal of above-ground piping and headers, and whether wells and heaters should be removed or left in place and capped.

Purpose: A primary concern identified with ISTD is the potential for spreading radioactive contamination during heater and vacuum well emplacement, operations, and demobilization. This needs to be quantified to determine whether the mitigation features developed for Pit 9 drilling are successful or whether the difficulties of nondrilling options such as lancing prepacked columns and pre set heater cylinders are offset by the reduction of particulate contamination spread. The results of the heater well emplacement drilling and lancing tests will be used to determine which technology is the preferred well emplacement technology for buried TRU pits and trenches at the SDA. Evaluating contaminant emission to the off-gas treatment system during ISTD processing 
will be useful in defining the degree of equipment decontamination needed. Monitoring during demobilization will demonstrate contamination control methods needed and determine whether well equipment can be removed or should be left in place. Results from the cold field-scale test will determine the well emplacement technology and demobilization strategy to be used for the radioactive field-scale test.

Data Usage: The intended use of this data is for assessing well emplacement contamination control performance; obtaining design data for mitigation methods; and obtaining cost data for the feasibility study.

Relevant CERCLA Criteria: Short-term effectiveness, conformance to ARARs, and implementability.

\section{Test Objective 4: Determine the leachability and degree of actinide fixation on treated soil and other waste media.}

Test Requirements: Core samples from a radioactive pit (Pit 4, 6, 9, or 10) will be taken under planned sampling for some of these pits. Radioactively contaminated soil and waste (organic and inorganic sludges) will be separated into general sample matrices and radiologically characterized. Samples of each type of waste material and soil will be heated during a lab-scale test and then submitted for bulk compositional analysis and leach testing. Core samples of the treated waste will be taken from the radioactive field-scale test zone after it has cooled sufficiently (approximately one month). Portions of the treated material will be submitted for actinide compositional analysis and leach tested. The results from the hot field-scale core samples will be compared with results from the lab-scale test to verify leach reduction of the resultant soil and waste.

Purpose: The purpose of this test objective is to estimate the release rate of the actinide COPCs from the treated soil and other waste media. This objective is considered critical since the use of the technology on areas with inorganic COPCs will depend in part on verifying that metals are not more susceptible to mobilization. This will be required regardless of efficacy of organic removal. This is also mandatory for consideration of ISTD as a stand-alone technology. Leachability analysis is important to the secondary benefit of ISTD, reducing mobility of inorganic contaminants and radionuclides. The results should establish the estimated release rates for those contaminants (nonorganic) that remain after treatment. The evaluation of actinide leachability is needed to confirm past data indicating fixation of actinides to a soil matrix upon heating (Wick 1980).

Data Usage: The test results will support the risk assessment, risk model, and performance evaluation portion of the OU 7-13/14 feasibility study.

Relevant CERCLA Criteria: Overall protection of human health and the environment; compliance with ARARs; long-term effectiveness; and reduction of toxicity, mobility, and volume.

\section{Test Objective 5: Evaluate subsidence and site stability during thermal desorption and following operations.}

Test Requirements: During the simulated field-scale test and radioactive field-scale test, all the water, most of the organic mass, and many nonmetallic containers will be vaporized. This vaporization is expected to increase the physical instability of the pit. The site will subside as soil falls to fill voids during or after processing. Subsidence may make maintenance of heaters and vacuum wells during operations difficult and require special procedures for equipment removal and 
demobilization. Monitoring measurements will be made of the carbon dioxide and carbon monoxide released during treatment to estimate amount of organic destruction. The water released is also monitored and gives an estimate of the extent of combustion. Long-term subsidence monitoring will include visual observations of the pit and ground surveying of the pit site for at least 2 years after the test to quantify subsidence.

Stability of the simulated test site after treatment will be evaluated with a trac-hoe. The bucket will be lowered to the surface in an area between headers and wells, then a force gradually applied lifting the front end of the trac-hoe. The force will be estimated from the weight of the trac-hoe. It has been estimated that the $5 \mathrm{ft}$ of overburden will fill in, or bridge, the void space created from organic removal and box destruction. Drums, though partially empty, should remain intact and support the overburden. Following ISTD processing and this test, a portion of the simulated waste pit will be excavated, to visually evaluate the physical effects of volatilizing the water, organics, and combustibles in sealed 55-gal drums and cardboard and wooden boxes in the simulated landfill.

Purpose: A primary safety concern identified with implementing ISTD is the increase in subsidence potential above the buried waste site from removal of water and organics including all cardboard and wooden boxes. Some subsidence is expected during operations and further instability impeding site access may continue until all voids have collapsed. Site stability needs to be quantified for safe maintenance operations and site demobilization and to determine the longterm physical state of an ISTD treated buried waste site.

Data Usage: The data is needed to estimate physical effects of ISTD remediation in buried debris type waste in a silty clay soil typical at the SDA. The intended use of this data is for assessing subsidence for maintenance and demobilization operations. The long-term state of the site and any post treatment stabilization that may be needed can be assessed particularly in terms of capping the treated site. The data will be used for assessing technology implementability in a buried waste environment; and obtaining cost data (post-treatment needs) for the feasibility study.

Relevant CERCLA Criteria: Short-term effectiveness, long-term effectiveness, implementability, and cost.

\subsection{Noncritical Objectives}

Noncritical objectives of the ISTD treatability study are listed below. Each objective is broken down into subsections of test requirements, objective purpose, proposed data usage, and the relevant CERCLA criteria to be answered by the objective. The noncritical objectives are identified by letter to differentiate them from critical objectives that were identified by number.

\section{Test Objective A: Evaluate the moisture return to the treated waste site.}

Test Requirements: The treated site will be monitored for 2 years after ISTD is performed to determine the extent and affect of rehydration of the treated site. Tensiometers or other hydrogeologic tools will be placed after the waste has cooled and be used to monitor the nonradioactive field-scale test. This monitoring will occur along with the subsidence measurements previously discussed. Besides organic removal, ISTD significantly changes the structure of the INEEL clay soil. The high temperatures used to remove nitrate salts will sinter the soil to some extent and may change its porosity permanently. The release rate for inorganic COPCs is part of Test Objective 4. The infiltration rate is useful in conjunction with Objective 4 data to demonstrate 
the need or lack thereof of secondary treatment. The change over time in heated INEEL soil with environmental exposure has never been studied.

Purpose: The data will be used with data from previous ISTD operations to determine the extent and speed of rehydration following ISTD. This will help determine what follow up treatment (ISV, ISG, cap, etc.) may be needed.

Data Usage: Results from the post treatment water monitoring will indicate the need for subsequent treatments or a cap. Subsequent treatments influence overall cost associated with ISTD processing of buried waste at the SDA for the OU 7-13/14 feasibility study.

Relevant CERCLA Criterion: Long-term effectiveness and reduction of toxicity, mobility, and volume through treatment

Test Objective B: Determine the time, equipment, labor and general feasibility for mobilization, full-scale processing operations, maintenance and demobilization.

Test Requirements: Extensive monitoring and recording will be performed during both the radioactive and nonradioactive field-scale tests to define the time, equipment, and labor requirements associated with mobilization, demobilization, and operation of ISTD. In addition, the total amount of electrical power used during operations will be calculated and used to determine a total power efficiency (in kilowatt-hours/kilogram of waste treated). Fuel requirements for well emplacement will also be determined.

Purpose: The data will be used with data from previous ISTD operations to produce an applicability assessment section of the final ISTD treatability study report. The applicability assessment will estimate the cost associated with remediating an acre-size buried waste site at the SDA.

Data Usage: Results from the applicability assessment will improve estimates of cost and schedule associated with ISTD processing of buried waste at the SDA for the OU 7-13/14 feasibility study.

Relevant CERCLA Criterion: Cost.

Test Objective C: Evaluate the volume, type, and expected disposition of secondary waste.

Test Requirements: Following the radioactive field-scale test, a determination will be made of the total volume and type of secondary waste that was generated. The disposition of the secondary waste will be determined and potential reuse and recycling options identified for future ISTD remediations. Due to the extensive off-gas treatment system and operations above the dew point of water, only prefilter contaminated piping, particulate, and charcoal filters are expected to be secondary waste items.

Purpose: The secondary waste determination will be used to estimate the total volume of secondary waste expected to be generated during actual remediation of an ISTD waste site. This estimate (applied to a 1-acre site) will be included in the applicability analysis section of the final treatability study report.

Data Usage: Results from the applicability assessment will improve the estimates of cost and implementability associated with ISTD processing of buried waste at the SDA for the OU 7-13/14 feasibility study. 
Relevant CERCLA Criteria: Implementability and cost.

\section{Test Objective D: Evaluate ability to process gas cylinders.}

Test Requirements: There are few if any sealed gas cylinders expected in the SDA. Historical evidence shows only three gas cylinders from INEEL operations have been disposed at the SDA. Furthermore, these cylinders were disposed of with the low-level waste, rather than as Rocky Flats Plant waste (the target waste for ISTD as discussed in Section 1.2). A remote possibility does exist of a fire-damaged contaminated cylinder deposited as part of debris from a Rocky Flats Plant fire. If a gas cylinder is encountered during processing and it is full, it would be expected to release the overpressure/over temperature valve found on every gas cylinder made since 1910. Gas cylinder valves are solder plugs that release at about 3,300 psi or $220^{\circ} \mathrm{C}\left(430^{\circ} \mathrm{F}\right)$. ISTD temperatures of $450^{\circ} \mathrm{C}\left(840^{\circ} \mathrm{F}\right)$ should bring a gas cylinder with 2,000 psi of gas to about $5,000 \mathrm{psi}$; thus it will release either by temperature or pressure through the relief valve. A partially full gas cylinder with pressure under 1,300 psi (a more typical case) would not overpressure the cylinder and release through the valve.

Due to the overburden, presence of voids, and the slowness of heating, the chance for vaporized material to surge through the soil exceeding the applied vacuum of the off-gas system is virtually nonexistent. The material surge from drums has been tested and is different from a release from a high pressure gas cylinder. While welded drums are susceptible to greater pressure buildup, there are no welded drums in the areas of concern or evidence that routine waste was weld sealed. All drums that we know of from RFP have gasketed enclosures. Most drums have at least pinhole leaks as evidenced by the Pad A retrieval of one drum. Though in good shape and in better condition than most of the subsurface drums, the drum was not perfectly gas-tight. The loss of vacuum potential upon heating sealed 55-gal drums, filled with vaporizable materials (e.g., water, oil, volatile organics, and nitrate salts) in buried pits and trenches at the SDA is not considered to be significant based on previous vendor tests. In a previous field test performed by TerraTherm, ISTD heating of a buried sealed 30-gal drum of ethanol was slow enough, that the rupture of the drum occurred at less than $10 \mathrm{psi}$ without a catastrophic pressure buildup. Loss of vacuum during ISTD due to the presence of sealed cylinders will be evaluated as part of the simulated field-scale test.

Purpose: Though not commonly buried in transuranic pits and trenches at the SDA, there is a small chance that a partially full gas cylinder may be encountered during in situ processing at the SDA. Previously conducted field tests on sealed containers (Vinegar 1998) and engineering calculations (Stegemeier 1995) indicate that the potential of there being an environmental concern, personnel safety, or equipment safety concern is minimal.

Data Usage: The results of heating a gas cylinder beyond pressurization will be used to verify ISTD can be safely performed for any future remediations in buried waste sites where there might be a sealed, partially full gas cylinder. The result of this evaluation will assist the OU 7-13/14 feasibility study in defining the potential applicability of ISTD to all buried waste sites within the SDA.

Relevant CERCLA Criteria: Implementability and short-term effectiveness. 


\section{EVALUATION OF TECHNOLOGY}

The purpose of this section is to describe the experimental test design that will evaluate ISTD as a possible treatment of buried waste sites within the SDA. The treatability study tests are designed to resolve the technical issues (i.e., data gaps) that have been identified for ISTD processing of buried TRU waste sites. There are three phases associated with this experimental design:

1. Lab-scale ISTD testing

2. Field-scale ISTD testing on simulated wastes

3. Field-scale ISTD testing in SDA Pit 4.

The strategy for performing the ISTD treatability study will take advantage of performance data from previous vendor testing and applications and surveillance of ongoing ISTD activities. The treatability study will be structured to focus on critical data gaps specific to the SDA application. Table 6 relates the test objectives to the experimental design strategy. Each of these phases is subsequently discussed.

Table 6. Summary of experimental design strategy.

\begin{tabular}{|c|c|c|c|}
\hline Test Objective & Lab-Scale & $\begin{array}{l}\text { Cold field- } \\
\text { scale }\end{array}$ & $\begin{array}{l}\text { Hot field- } \\
\text { scale }\end{array}$ \\
\hline \multicolumn{4}{|l|}{ Critical Test Objectives } \\
\hline $\begin{array}{l}\text { Evaluate INEEL administrative feasibility for well } \\
\text { emplacement and ISTD process implementation }\end{array}$ & & $\mathrm{x}$ & $\mathrm{x}$ \\
\hline $\begin{array}{l}\text { Determine the degree of hazardous organic contaminants } \\
\text { and nitrate destruction in the soil, waste, containers, and } \\
\text { off-gas treatment system }\end{array}$ & $\mathrm{x}$ & $\mathrm{x}$ & $\mathrm{x}$ \\
\hline $\begin{array}{l}\text { Evaluate the extent of actinide particulate contaminant } \\
\text { release during heater and vacuum well emplacement, } \\
\text { thermal desorption, and demobilization }\end{array}$ & & $\mathrm{x}$ & $\mathrm{x}$ \\
\hline $\begin{array}{l}\text { Determine the leachability and degree of actinide fixation } \\
\text { on treated soil }\end{array}$ & $\mathrm{x}$ & & $\mathrm{x}$ \\
\hline $\begin{array}{l}\text { Evaluate subsidence and site stability during thermal } \\
\text { desorption and following operations }\end{array}$ & & $\mathrm{x}$ & $\mathrm{x}$ \\
\hline \multicolumn{4}{|l|}{ Noncritical Test Objectives } \\
\hline Evaluate the moisture return to the treated waste site & & $\mathrm{x}$ & \\
\hline $\begin{array}{l}\text { Determine time, equipment, labor and general feasibility } \\
\text { for mobilization, full-scale processing operations, } \\
\text { maintenance, and demobilization }\end{array}$ & & $\mathrm{x}$ & $\mathrm{x}$ \\
\hline $\begin{array}{l}\text { Evaluate the volume, type, and disposition of secondary } \\
\text { waste }\end{array}$ & & $\mathrm{x}$ & $\mathrm{x}$ \\
\hline Evaluate ability to process gas cylinders & & $\mathrm{x}$ & \\
\hline
\end{tabular}




\subsection{Lab-Scale Testing}

The purpose of lab-scale testing on radioactive samples or simulated SDA waste and soil is to obtain data crucial to the ISTD treatability study that cannot be obtained as part of either the simulated or the radioactive field-scale test. Field tests have environmental, source-term, or implementation limitations that limit the data that can be obtained. Lab-scale testing will focus primarily on effects of heating nitrate salts and actinide contaminated soils, salts, and sludges. To prepare for radiological testing, surrogate samples will be used to investigate physical effects of waste heating and nitrate salt decomposition. Spiked samples or actual radiological samples are needed for studying physical and chemical affects on heated hazardous and radiological COPCs.

The primary focus of the test is to evaluate the fixation of actinides on soils or sludges following heating and secondarily on the kinetics of Rocky Flats Plant nitrate salt decomposition. Quantifying the change in actinide contaminant leachability from SDA waste media is critical for input to the residual risk modeling of ISTD-processed buried waste. This testing will evaluate actinide contaminant fate and transport in SDA waste media before and after heating.

Actinide fixation on the soil and waste can be studied at lab-scale because data:

- Is not scale-dependent, thus can be obtained without field-scale testing

- Cannot be obtained from a nonradioactive simulated field-scale test

- Is needed to fully understand the effects of treatment before performing a field-scale test in a radioactive environment

- Is more easily quantifiable (because the media can be better characterized before treatment) from lab-scale tests than from the radioactive field-scale test.

Spiked waste and actual contaminated samples will be used to determine the effect of heat on leachability of actinides and to quantify the reduction of aqueous transport of inorganic COPCs remaining in the waste. The radiological lab-scale test will be conducted before the radioactive field-scale test to fully understand the effects of treatment before implementation in the SDA. Actinide fixation testing will require either minute quantities of actinide standards or actual contaminated waste (soil, sludge).

A substantial amount of information exists on how ISTD will affect the organic hazardous contaminants in WAG 7 buried waste (Vinegar, Stegemeier, and Sheldon 1997). However, there is little information on the effects of slowly heating large amounts of nitrate salts. This will also be evaluated in sufficient detail to demonstrate the safety of the process in the ISTD field test. Tracers on matrix simulants and the use of actual nitrate salts will also help in understanding the probable fate of radionuclides after decomposition of the matrix, and quantify potential particulate releases to the off-gas stream.

\subsubsection{Lab Testing Sample Preparation}

\subsubsection{Spiked Waste Sample Preparation}

Radioactive, hazardous, and rare-earth-metal spiked waste samples will be prepared as surrogates for SDA wastes. These samples will be used to test procedures and provide data to show the similarity of surrogates with SDA waste samples. Rocky Flats Plant Series 741-745 sludges will be simulated for lab testing and used in the field-scale surrogate studies. Four matrices representing these sludges will be 
spiked: salts, organic sludges, inorganic sludges, and soil. Each matrix is prepared separately as each drum contains one matrix. The segregated core material samples are expected to be predominantly a single matrix with perhaps contaminating soil present

Solutions of $\mathrm{Am}, \mathrm{Pu}, \mathrm{Np}$, and $\mathrm{U}$ nitrate will be added to each waste matrix. The slurry is mixed wet and air dried with sufficient quantity for triplicate samples of each portion of the leach test. The amount of nuclide placed with each waste matrix will be determined by the:

- Spike solutions available

- Leach amounts expected (detection limits)

- Detection method chosen (surface barrier alpha spectrometry preferred)

- Radiological limits for this type or work in a hood.

\subsubsection{Simulated Waste Preparation}

Both the lab and field test will require simulated waste matrices. Four waste matrices will be prepared as a base material for the spiked samples and used in the laboratory tests: salts, organic sludges, inorganic sludges and soil. Each matrix for the lab-scale tests will be prepared as one waste type since each drum contains but one matrix. The ISTD process does not mix matrices.

For the simulated field test, inorganic sludges will be treated as soil. The field test will have the debris, trash, and metal wastes that are not conducive to lab-scale testing. Rocky Flats Plant sludges for three types of "sludge" matrices are numbered as a Series 741-745 and are listed in Tables 10 and 12. Simulations of salts, organic sludges, debris, metal and trash matrices will use the actual base material when possible or be closely surrogated with available materials. Tables 9 and 11 list some waste matrices that might be used.

A brief summary of the preparation, composition, and relationship to actual waste types and volumes for Rocky Flats Plant organic sludges, inorganic sludges, and salts is given below. Preparation of matrices for the field-scale test that were not used in the lab-scale test is described in Section 4.2.

Contaminated debris or trash simulant matrices are not used in lab studies due to the handling and scaling difficulties, but will comprise nearly half of the waste in the field test. INEEL soil will be used for the soil matrix.

Inorganic $(741,742)$ and organic $(743,744)$ sludge simulants have been prepared for several past simulated waste test pits and incinerator studies. The formulas for the organic and inorganic sludges follow Schuman (1981) and Arrenholz and Knight (1991). The inorganic sludges are inorganic precipitates following neutralization of acidic and clean up residues. Various aluminum, iron, calcium, and silicon solutions can be precipitated to prepare this matrix for detailed studies like filtration testing (Schuman 1981).

Simulants in the past were prepared in more detail for lab- and bench-scale tests. RWMC lake bed soil and water, with a lanthanide oxide added has been used as a physical sludge simulant for testing retrieval of TRU material leached on to soil (Loomis, 1992). The amount of simulant waste matrix and surrogate radioactive spike is determined from SDA inventories and historical practices as the waste were formed. The amount of water in the inorganic sludge simulants will be 40-60 wt $\%$. Dry Portland cement was added to the top and bottom of the inorganic and nitrate salt drums, to minimize free liquids. This may be done in the simulants if the additional water is not absorbed. 
Based on the Interim Risk Assessment for WAG 7 (DOE-ID 1998b), the source of nearly all of the volatile organic COPCs in the SDA are the organic sludge drums from Rocky Flats Plant. The primary halogenated hydrocarbon COPC in the organic sludge is carbon tetrachloride. This cannot be used in a field test pit and cannot be simulated by other chlorinated organics with similar vapor pressures. Chlorinated organics, such as PVC plastic, will be used in the trash matrix to provide a source of chlorides as would occur from carbon tetrachloride destruction. Isopropanol, a nonhazardous volatile organic, can simulate volatile organic COPCs to verify lack of migration and complete destruction. Isopropanol has a similar vapor pressure and will also be used in some drums to verify that there is no excessive pressurization in the drums during treatment.

A simulated sludge will be prepared using the average matrix contents of the original Rocky Flats Plant Series 743/744 organic sludge without the contamination or organic chloride solvents. Both laboratory and field simulated organic sludge matrices will be prepared using calcium silicate, Oil-Dri, and Texaco Regal Oil (R\&O 68). For field preparation calcium silicate is added to each simulated organic sludge drum until it is half full. The oil is added, the remaining absorbent Oil-Dri is placed on top, and the drum rotated in a drum mixer. The organic sludge simulant will be the largest single waste type for the field-scale test. Each sludge simulant will be prepared and mixed in the drum.

Simulations of the Rocky Flats Plant Series 745 sludge will be prepared using technical grades of sodium and potassium nitrate, sodium chloride, and sodium sulfate. The composition of the surrogate salt will come from the major components found in actual RFP salts analyses (Shaw, 1993). The nitrate salt mixture will consist of approximately $25 \mathrm{wt} \%$ potassium nitrate, $55 \mathrm{wt} \%$ sodium nitrate, $5 \mathrm{wt} \%$ sodium chloride, $5 \mathrm{wt} \%$ sodium sulfate, and $10 \mathrm{wt} \%$ water. A sodium and potassium nitrate mixture, that is not classified as an oxidizer under DOT regulations, will be used in the field test. Land Disposal Restrictions under IDAPA 16.01.05.005 (40 CFR part 261.4f .6) prevent placing reactive or corrosive materials directly in the ground. The nitrate salt simulant will be placed in drums and the ISTD process will effectively destroy all nitrates. Small amounts of the nitrate salt cake mixture will also be placed with the soil/inorganic sludge simulant.

Most lanthanum oxides can be effective physical surrogates for actinide oxides. Rare earth oxides like dysprosium, lanthanum, cerium, and praseodymium are included in all the simulated waste (organic and inorganic sludge, combustibles, and debris) to simulate actinides in terms of physical transfer (contamination). This simulant will trace particulate release during well emplacement, operations, and demobilization portions of the test. Lanthanum oxides are used for field spiking and to test entrainment in during decomposition testing. Lanthanum nitrates can be used for leach test method development. Actinide oxides will not be used for leach testing as they are not soluble, hard to obtain, and the nitrates are the most leachable form.

Sufficient tracer is placed in each container to increase its concentration in the resultant treated waste to at least 10 times the soil background concentration (Turk and Roswell 1978). Lanthanum series oxides, in terms of background concentration, require less surrogate be placed in each container but are also more expensive. Cerium oxide is often used as an aerosol particulate surrogate for $\mathrm{Pu}$ (Langer 1980) and dysprosium has been used in INEEL incinerator tests (Harding 1988). Usually at least $200 \mathrm{~g}$ of the selected lanthanum oxide is placed into each waste package, duplicating the maximum weight of TRU contaminants permitted in a 55 gal waste drum. All of the drums and cardboard boxes will have at least this amount with up to 1,000 $\mathrm{g}$ of lanthanum oxides in large wooden boxes of debris and combustibles. All other debris wastes will be simulated using the same amount of metal, combustibles, wood, paper, concrete, and asphalt that is expected to be present in the SDA TRU pits and trenches (Arrenholz and Knight 1991). 
The amount of water in the lab-scale waste simulants will be sufficient to allow mixing of the waste with the surrogate. The field simulants do not need to be as well mixed and water is only used for simulating Rocky Flats Plant waste compositions. The amount of tracer placed with each waste matrix will be at least $0.1 \mathrm{wt} \%$ concentration which is at least 10 times background concentrations, based on data from Turk and Roswell, 1978. Since most lanthanide oxides are effective physical surrogates for actinide oxides, several will be used including cerium, dysprosium, and lanthanum oxide. The lanthanide oxide will be mixed dry into each waste type package. Tracer content can be verified for the dry blends used in the laboratory test depending on the scale of preparation. The field blended tracer compositions will not depend on good mixing within each drum. Differences in mixing will not change treatment efficiency or mass balance calculations.

Sufficient surrogates will be prepared for the lab-scale tests to allow three leach tests at three temperatures above ambient. Either a modified accelerated leach test, Toxicity Characteristic Leaching Procedure (TCLP) test, or ANS 16.1 test can be used to leach samples at each temperature range. Liquid samples obtained from the leachates are analyzed by Inductively-Coupled Plasma-Mass Spectrometry (ICP-MS).

\subsubsection{SDA Sample Waste Preparation}

The SAP for the SDA pit coring activities will determine the types of contaminated waste matrices, radionuclides, and radionuclide concentrations that can be obtained from the SDA. Attempts will be made to obtain samples contaminated with as many actinides as possible of the predominant waste matrices: organic sludges, inorganic sludges, salts, and soil. The preparation of samples will depend on the analytical needs of the SAP but eventually all samples will be physically sized (sieved) and total radionuclide concentration determined. The amount of sample needed for each waste matrix will be determined in the surrogate and radioactive spiked portion of the test.

\subsubsection{Actinide Leachability}

As buried waste is heated, chemical and physical changes occur both in the matrix and the contaminants. Actinides might change oxidation state and/or attach to the waste chemically or physically (Wick 1980). This is commonly referred to as fixation. As nitrate salts and organics are destroyed, physical/chemical changes in the surrounding actinides will also take place. These changes will be measured by a series of leach tests commonly used to test contaminant mobility from treated waste forms. Both spiked or actual contaminated samples will be tested before and after treatment.

\subsubsection{Nitrate Decomposition}

The primary purpose of lab-scale testing on waste containing high quantities of nitrate salts is to verify the safety of ISTD when decomposing nitrate salt cake wastes (Rocky Flats Plant Series 745 sludge). Substantial quantities of nitrous oxide gases will be generated and control of gas generation rates and processing efficiency in the off-gas system will be evaluated. Part of the test will determine whether heated salts would mobilize or entrain actinide contaminants in the surrounding waste. The lab-scale test will concentrate on heating high concentrations of nitrate salts $(90 \mathrm{wt} \%)$. The results will also be somewhat applicable to the lower concentrations of nitrate salt cake waste found with the inorganic sludges expected in the buried TRU pits at the SDA and other thermal processing technologies such as ex situ and in situ vitrification of nitrate containing wastes.

In this test, actual Rocky Flats Plant waste salts and/or various mixtures of nitrate salt simulants and soil or sludge will be heated slowly, simulating the ISTD process. Each mixture will be monitored for temperature and be attached to a system capturing gases generated as heating commences. The pressure 
and flow within this system will be monitored. The rate of gas generation as a function of temperature, the gas composition, and any particulate found in the filtration system will be measured. The composition of the alkali residue and the amount and physical state of the actinide surrogate will be determined. The data will help to verify that process control can be maintained when heating nitrate salts and indicate what type of residues remain. The lab-scale test results should also be sufficient to verify the safety of slowly heating high concentrations of nitrate salt waste.

\subsection{Simulated Waste Field-Scale Test}

The field-scale test on nonradioactive, nonhazardous simulated SDA waste will address ISTD processing requirements and contamination control techniques for remediation at the SDA. A subsequent test plan will give more specific procedures for performing the test and will include a detailed sampling and analysis plan for all testing and sampling activities. The purpose of simulated field-scale testing is to obtain effectiveness and implementability data that cannot be collected in the laboratory but is necessary to address safety and operational issues for SDA testing.

The simulated field-scale test will evaluate the effectiveness of ISTD to remove organics from debris, trash and sludges within containers such as 55 gal steel drums. The field-scale test will measure subsidence, off-gas, pressure, and temperature changes. The results of the simulated field-scale test will also be evaluated to determine if ISTD can be used as a preconditioning technology for ISV. The pit will simulate general SDA TRU pits with some variations in waste composition to emphasize processing concerns associated with ISTD and the selected radioactive field-scale test site (i.e., Pit 4). As a result, the simulated test setup will contain additional combustible debris, boxed waste, nitrate salts, and a gas cylinder though these were not typically disposed of in Pit 4 . The preparation of the waste pit and an overview of the test are given below.

\subsubsection{Simulated Waste Pit Preparation}

The initial activity associated with this phase is to prepare a nonradioactive, nonhazardous buried waste test pit that effectively simulates anticipated conditions within the SDA. Simulated buried waste field-scale test pits have been used for technology testing at the RWMC for 14 years (Low 1986, Loomis 1987, Loomis 1988, Loomis 1989). All of these pits use an average composition of buried waste based on SDA shipping records (Arrenholz and Knight 1991). Tables 7, 8, 9, and 10 contain the cold test pit simulated waste inventory and physical properties. The types of waste in this test pit will be similar to the average waste types suspected to be in Pit 4 . The simulated waste pit will deviate from the Pit 4 average to emphasize the primary goal of ISTD processing (organic wastes and nitrate salts). The waste packages that will be placed in the test pit will be of the same types of materials that are buried in the SDA, including 55-gal drums, cardboard boxes, and plastic bags of trash. Waste includes COPC surrogates used in lab-scale testing for the organic and inorganic sludges. The simulated field-scale test will be conducted in an area located north of the SDA.

The simulated field-scale test site is a nominal $22 \times 15 \times 20 \mathrm{ft}\left(6,600 \mathrm{ft}^{3}\right.$ or $\left.192 \mathrm{~m}^{3}\right)$. The average depths to basalt for buried TRU pits and trenches at the SDA (Arrenholz and Knight 1991), is about $20 \mathrm{ft}$ with the irregular basalt surface beneath the SDA resulting in depths of $25 \mathrm{ft}$ in some areas. A schematic of the proposed field-scale test heater/vacuum well configuration is shown in Figure 3. A total ground surface to basalt depth of $20 \mathrm{ft}$ is available at the selected test site thus the waste seam will be nominally $12 \mathrm{ft}$, with $6 \mathrm{ft}$ of overburden and $2 \mathrm{ft}$ of underburden. These thicknesses also simulate the average overburden and underburden thicknesses for Pit 4 . The excavation of the test site will be large enough to place the waste seam (nominally $22 \times 15 \times 12 \mathrm{ft}$., 4,000 $\mathrm{ft}^{3}$ ) with sufficient space for pit side-wall slope stability. The selected location of the pit will be furnished with $0.5 \mathrm{MW}$ electrical power. 


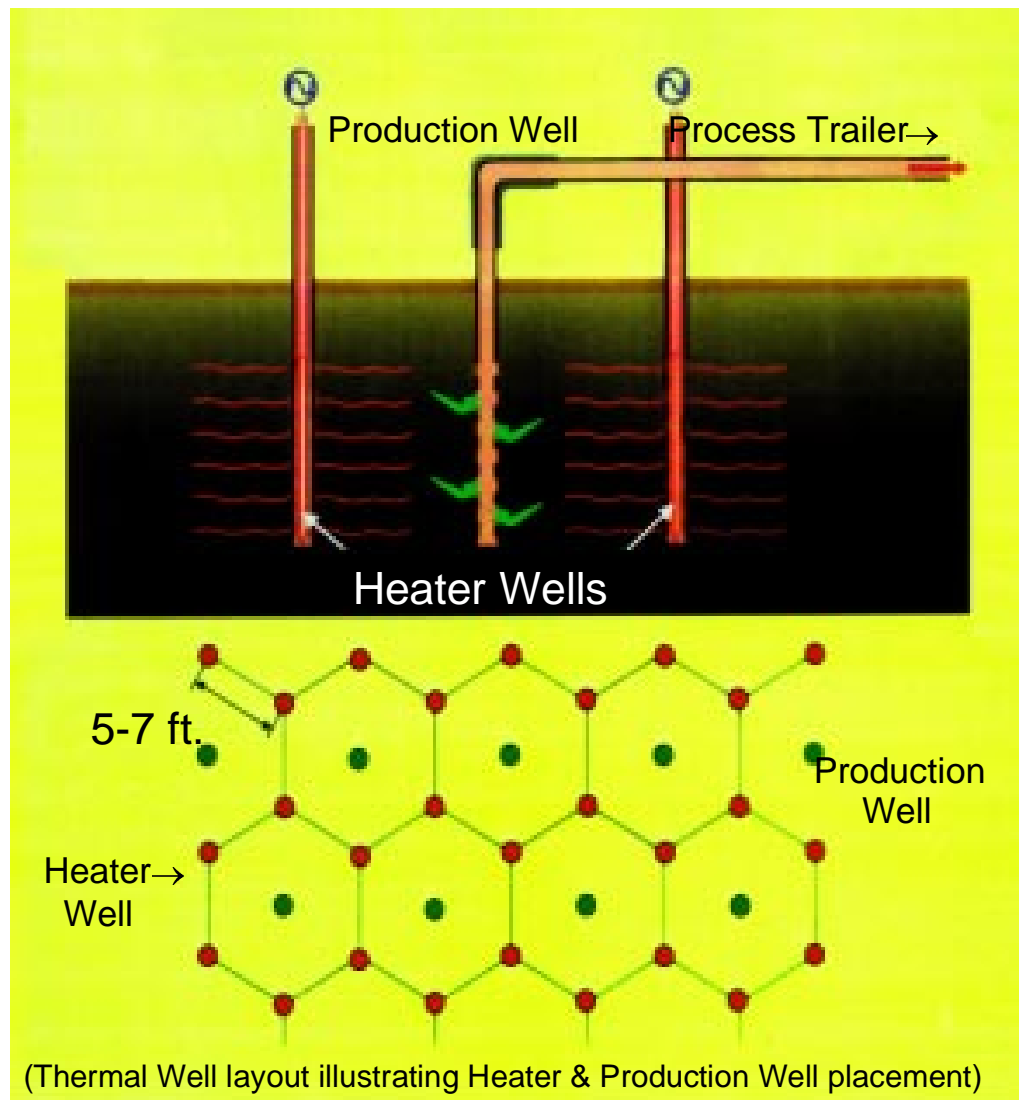

Figure 3. Schematic of the simulated waste field-scale test. 
Table 7. Waste packages and contents for the ISTD simulated field-scale test.

\begin{tabular}{|c|c|c|c|c|c|c|}
\hline No. & $\begin{array}{c}\text { Void } \\
(\text { vol \%) }\end{array}$ & Waste Package Description & $\begin{array}{c}\text { Bulk } \\
\text { Density } \\
(\mathrm{g} / \mathrm{cc})\end{array}$ & $\begin{array}{c}\text { weight } \\
\text { per } \\
\text { package } \\
\text { (lb) }\end{array}$ & Package Contents & $\begin{array}{l}\text { Tracer } \\
\text { (ppm) }\end{array}$ \\
\hline \multirow[t]{2}{*}{50} & 80 & Cardboard boxes $(2 \mathrm{ft} \times 2 \mathrm{ft} \times 2 \mathrm{ft})$ & 0.12 & 60 & Combustibles & \\
\hline & & & & 0.2 & Terbium oxide & 1600 \\
\hline \multirow[t]{6}{*}{2} & 87 & Wooden boxes $(4 \mathrm{ft} \times 4 \mathrm{ft} \times 8 \mathrm{ft})$ & 0.29 & 300 & Paper, & \\
\hline & & & & 50 & wood & \\
\hline & & & & 100 & asphalt & \\
\hline & & & & 100 & concrete & \\
\hline & & & & 1800 & metal & \\
\hline & & & & 0.9 & rare earth oxide & 300 \\
\hline \multirow[t]{2}{*}{8} & 69 & 55-gal metal drums & 0.55 & 250 & Asphalt, & \\
\hline & & & & 0.6 & rare earth oxide & 1,900 \\
\hline \multirow[t]{2}{*}{4} & 93 & 55-gal metal drums & 0.55 & 250 & Metals & \\
\hline & & & & 0.4 & rare earth oxide & 1,800 \\
\hline \multirow[t]{2}{*}{8} & 69 & 55-gal metal drums & 0.76 & 350 & Concrete & \\
\hline & & & & 0.6 & rare earth oxide & 1,400 \\
\hline \multirow[t]{2}{*}{5} & 77 & 55-gal metal drums & 0.33 & 150 & Combustibles & \\
\hline & & & & 0.2 & rare earth oxide & 1500 \\
\hline \multirow[t]{2}{*}{5} & 84 & 55-gal metal drums & 0.33 & 100 & wood and paper & \\
\hline & & & & 0.6 & rare earth oxide & 4800 \\
\hline \multirow[t]{5}{*}{30} & 28 & 55-gal metal drums & 0.82 & 160 & Water & \\
\hline & & & & 140 & soil /sludge & \\
\hline & & & & 40 & Portland cement & \\
\hline & & & & 36 & sodium nitrate & \\
\hline & & & & 0.4 & rare earth oxide & 1,000 \\
\hline \multirow[t]{4}{*}{50} & 32 & 55-gal metal drums & 0.65 & 165 & Texaco Regal Oil & \\
\hline & & & & 100 & calcium silicate & \\
\hline & & & & 35 & Oil-Dri & \\
\hline & & & & 0.1 & rare earth oxide & 500 \\
\hline \multirow[t]{4}{*}{20} & 69 & 55-gal metal drums & 0.69 & 190 & sodium nitrate & \\
\hline & & & & 95 & potassium nitrate & \\
\hline & & & & 16 & sodium chloride & \\
\hline & & & & 16 & sodium sulfate & \\
\hline
\end{tabular}


Table 8. Waste packaging inventory for the simulated field-scale test pit.

\begin{tabular}{|c|c|c|c|c|c|c|c|c|c|}
\hline $\begin{array}{c}\text { Waste } \\
\text { Category }\end{array}$ & $\begin{array}{l}\text { Waste type } \\
\text { Processed }\end{array}$ & Container & Number & $\begin{array}{l}\text { size } \\
(\mathrm{ft})\end{array}$ & $\begin{array}{l}\text { Cont. Vol } \\
\left(\mathrm{ft}^{3}\right)\end{array}$ & $\begin{array}{l}\text { Tot. Vol. } \\
\left(\mathrm{ft}^{3}\right)\end{array}$ & $\begin{array}{c}\text { Cont mass } \\
\text { (lb) }\end{array}$ & $\begin{array}{l}\text { Tot Mass } \\
\text { (lb) }\end{array}$ & $\begin{array}{c}\text { Waste bulk } \\
\text { density } \\
(\mathrm{g} / \mathrm{cc})\end{array}$ \\
\hline & & Boxes & & & & & & & \\
\hline Combustible & $\begin{array}{l}\text { plastics wood } \\
\text { paper gloves } \\
\text { rags }\end{array}$ & cardboard & 50 & $2 \times 2 \times 2$ & 8 & 400 & 60 & 3,000 & 0.2 \\
\hline Combustible & $\begin{array}{l}\text { plastics wood } \\
\text { paper metal } \\
\text { asphalt }\end{array}$ & $\begin{array}{l}\text { large } \\
\text { wooden }\end{array}$ & 2 & $4 \times 4 \times 8$ & 128 & 256 & 2450 & 4,900 & 0.3 \\
\hline Total Boxes & & & 52 & & & 656 & & 7,900 & 0.2 \\
\hline Sludge & Soil & Drums & 30 & $55 \mathrm{gal}$ & 7.3 & 219 & 376 & 11,280 & 0.9 \\
\hline Debris & Asphalt & Drums & 8 & $55 \mathrm{gal}$ & 7.3 & 58 & 350 & 2800 & 0.8 \\
\hline Debris & Metal & Drums & 4 & $55 \mathrm{gal}$ & 7.3 & 29 & 250 & 1000 & 0.5 \\
\hline Debris & Concrete & Drums & 8 & $55 \mathrm{gal}$ & 7.3 & 58 & 350 & 2800 & 0.8 \\
\hline Combustible & wood paper & Drums & 5 & $55 \mathrm{gal}$ & 7.3 & 36 & 100 & 500 & 0.2 \\
\hline Combustible & $\begin{array}{l}\text { plastics gloves } \\
\text { rags }\end{array}$ & Drums & 5 & $55 \mathrm{gal}$ & 7.3 & 36 & 150 & 750 & 0.3 \\
\hline Sludge & oil/ kitty litter & Drums & 50 & $55 \mathrm{gal}$ & 7.3 & 365 & 300 & 15,000 & 0.6 \\
\hline Salt & nitrate & Drums & 20 & $55 \mathrm{gal}$ & 7.3 & 146 & 317 & 6340 & 0.7 \\
\hline $\begin{array}{l}\text { Total Metal } \\
\text { Drums }\end{array}$ & & & 130 & & & 949 & & 40,470 & 0.7 \\
\hline Total & & & 182 & & & 1,605 & & 48,370 & 0.5 \\
\hline
\end{tabular}


Table 9. Specific gravities for \% void calculation.

\begin{tabular}{lllll}
\hline $\begin{array}{l}\text { Waste } \\
\text { Category }\end{array}$ & Waste & Sp Gr g/cc & Waste & Sp Gr g/cc \\
\hline $\begin{array}{l}\text { Organic } \\
\text { Liquids }\end{array}$ & $\begin{array}{l}\text { chlorinated } \\
\text { organics }\end{array}$ & 1.4 & $\begin{array}{l}\text { Texaco Regal } \\
\text { Oil }\end{array}$ & 0.9 \\
\hline Combustibles & wood & 1.3 & plastic & 1.1 \\
& paper & 1.6 & & \\
& steel & 7.9 & $\begin{array}{l}\text { concrete } \\
\text { with aggregate }\end{array}$ & 2.5 \\
\hline Debris & aluminum & 2.7 & soil & 2.9 \\
& & & $\begin{array}{l}\text { asphalt with } \\
\text { aggregate }\end{array}$ & 2.1 \\
& & sludge-oil dry & 2.2 \\
& & calcium silicate & \\
\hline $\begin{array}{l}\text { Salt and } \\
\text { Sludge }\end{array}$ & nitrate salt & 2.2 & & \\
\hline
\end{tabular}

Table 10. Physical properties of SDA packaged waste.

\begin{tabular}{llllll}
\hline Sludge type & RFP Series\# & $\begin{array}{l}\text { Void } \\
\text { volume in } \\
\text { drum (vol\%) }\end{array}$ & $\begin{array}{l}\text { Average } \\
\text { mass in } \\
\text { drum (wt lb) }\end{array}$ & $\begin{array}{l}\text { Water } \\
(\mathrm{wt} \%)\end{array}$ & $\begin{array}{l}\text { Organic } \\
(\mathrm{wt} \%)\end{array}$ \\
\hline $\begin{array}{l}\text { Inorganic } \\
\text { 1st stage }\end{array}$ & 741 & 30 & 400 & 40 & $<1$ \\
$\begin{array}{l}\text { Inorganic } \\
\text { 2nd stage }\end{array}$ & 742 & 30 & 400 & 40 & $<5$ \\
Organic & 743 & 50 & 380 & 5 & 45 \\
$\begin{array}{l}\text { Organic- } \\
\text { Special }\end{array}$ & 744 & 80 & 300 & 5 & 45 \\
& & & & & \\
Nitrate Salt & 745 & 60 & 330 & 10 & $<1$ \\
$\begin{array}{l}\text { Debris } \\
\text { Trash }\end{array}$ & 80 & 350 & $<1$ & \\
& 70 & 200 & $<1$ & 90 \\
\hline
\end{tabular}

The test site will be excavated down to basalt and a layer of underburden will be placed to level the floor. A conduit for the gas cylinder instrumentation wires will be placed such that it rises to grade outside the waste seam to be ISTD processed. Once in place, the conduit can be positioned in a manner that augments other instrumentation. The instrumentation conduit will include wires for type $\mathrm{K}$ 
thermocouples and a pressure transducer. Most of the instrumentation will be lanced in place after the pit is constructed and the wells have been emplaced.

Information from Arrenholz and Knight (1991) and Grandy, Eddy, and Anderson (1993) were used to determine waste volumes and types for the simulated field-scale test. Waste volume in SDA pits varies from about $21-50 \mathrm{vol} \%$ of the total excavated volume. The test pit waste seam volume will be about $50 \%$, which is $40 \%$ below the maximum volume that can be contained in a stacked drum array of 90 vol\% (Tucker, Nelson, and Miller 1983). The waste seam volume represents the highest average volume of waste found amongst the various pits and trenches within the SDA (in Pit 10). Since Pit 10 also has a random drum orientation (as opposed to stacked orientation), a $50 \mathrm{vol} \%$ waste seam is applicable to random drum orientations at the entire SDA. Organic sludge drums in the simulated field-scale test will be about $35 \mathrm{vol} \%$ of the total waste volume. Combustible debris and trash will be in both boxes and drums, about $40 \mathrm{vol} \%$ of the waste volume. About $10 \mathrm{vol} \%$ of the test pit contents will be nitrate salts all in drums. The other $15 \mathrm{vol} \%$ will be metal and construction debris in both boxes and drums. The proposed buried waste configuration has about 20 vol\% contained in wooden boxes and cardboard boxes. Most of the waste at the SDA and in Pit 4 is contained in 55-gal metal drums. A higher volume percentage of boxes will help reveal subsidence potential when waste containers are eliminated. Table 11 summarizes properties in the test pit, Pit 4, Pit 9, and those of the entire SDA.

Table 11. Waste packaging inventory comparison for test pit, Pit 4, Pit 9, and the SDA.

\begin{tabular}{|c|c|c|c|c|c|c|c|c|c|}
\hline $\begin{array}{c}\text { Waste } \\
\text { Category }\end{array}$ & $\begin{array}{c}\text { Waste } \\
\text { type } \\
\text { Processed }\end{array}$ & $\begin{array}{l}\text { Test } \\
\text { Pit }\end{array}$ & Pit 4 & Pit 9 & SDA & $\begin{array}{c}\text { Test } \\
\text { Pit }\end{array}$ & Pit 4 & Pit 9 & SDA \\
\hline & & \multicolumn{4}{|c|}{$\mathrm{wt} \%$} & \multicolumn{4}{|c|}{ vol\% } \\
\hline Combustible & $\begin{array}{l}\text { plastics } \\
\text { wood } \\
\text { paper } \\
\text { gloves } \\
\text { rags }\end{array}$ & 22 & 10 & 2 & 23 & 20 & 24 & 7 & 53 \\
\hline Salt & nitrate & 15 & 11 & 13 & 7 & 12 & 10 & 11 & 5 \\
\hline Metal & $\begin{array}{l}\text { pipes, file } \\
\text { cabinets }\end{array}$ & 8 & 10 & 36 & 26 & 10 & 6 & 41 & 11 \\
\hline Debris & $\begin{array}{l}\text { concrete, } \\
\text { bricks } \\
\text { soil, } \\
\text { asphalt }\end{array}$ & 8 & 7 & 5 & 12 & 10 & 5 & 8 & 12 \\
\hline $\begin{array}{l}\text { Organic } \\
\text { sludge }\end{array}$ & $\begin{array}{l}\text { oil/ kitty } \\
\text { litter }\end{array}$ & 30 & 22 & 41 & 10 & 31 & 20 & 26 & 6 \\
\hline $\begin{array}{l}\text { Inorganic } \\
\text { sludge }\end{array}$ & $\begin{array}{l}\text { Hydrated } \\
\text { Oxide }\end{array}$ & 17 & 40 & 3 & 21 & 17 & 35 & 7 & 13 \\
\hline Total & & 100 & 100 & 100 & 100 & 100 & 100 & 100 & 100 \\
\hline
\end{tabular}

The waste surrogates that need to be prepared for the simulated field-scale test are shown in Table 12. The simulated inorganic sludge drums will be made up of a synthetic sludge or soil. Both half sized (4 $\mathrm{x} 4 \mathrm{x} 4 \mathrm{ft}$ ) and full sized ( 4 x $4 \times 7 \mathrm{ft})$ wooden boxes will be included in the waste seam. These boxes, filled with paper and trash will serve to evaluate the effect of large voids created after ISTD processing. 
Table 12. Composition of surrogate and simulated waste matrices.

\begin{tabular}{|c|c|c|c|c|}
\hline Waste type & Inorganic & Organic & Nitrate Salt & Debris \\
\hline \multirow[t]{3}{*}{ RFP Series \# } & 741 & 743 & 745 & NA \\
\hline & 742 & 744 & & \\
\hline & \multicolumn{4}{|c|}{ Weight Percentage } \\
\hline Soil & $85^{\mathrm{a}}$ & 0 & 0 & 30 \\
\hline Synthetic Sludge & $70^{\mathrm{a}}$ & & 0 & 0 \\
\hline Water & $15^{\mathrm{a}}$ & 0 & 10 & 0 \\
\hline Portland cement & 4 & 3 & 5 & 20 \\
\hline $\mathrm{NaNO}_{3}$ & 6 & 0 & 40 & 0 \\
\hline $\mathrm{KNO}_{3}$ & 3 & 0 & 20 & 0 \\
\hline Rare earth tracer & 2 & 2 & 1 & 1 \\
\hline Texaco Regal Oil & 0 & 30 & 0 & 0 \\
\hline Isopropanol & 0 & 20 & 0 & 0 \\
\hline Vermiculite & 0 & 20 & 0 & 0 \\
\hline $\begin{array}{l}\text { Calcium silicate or Oil- } \\
\text { Dri }\end{array}$ & 0 & 25 & 0 & 0 \\
\hline $\begin{array}{l}\text { a. Soil may be substitute } \\
\text { sludge and water }\end{array}$ & for synthet & & & \\
\hline
\end{tabular}


The entire void volume of all boxes in the test pit will be $1,036 \mathrm{ft}^{3}$. The actual space occupied by their contents after combustion of the boxes and the combustible content could cause over $800 \mathrm{ft}^{3}$ of void space to develop. If this is spread evenly throughout the entire pit about 2.5 feet of subsidence is possible. Approximately 2.5 feet of soil will be placed on the overburden to compensate for this subsidence

The waste packages will be placed into the simulated test pit in a random dump orientation. Waste will be placed in layers, continually filling in with soil as construction proceeds. The total thickness of the waste seam (containerized waste and interstitial soil) should be 10-12 ft thick.

A sealed, full, standard 2,000 psi air gas cylinder will be placed at the bottom of the waste seam (near an edge). The gas cylinder will be processed along with the simulated wastes. The cylinder's pressure transducer and type $\mathrm{K}$ thermocouple will be connected to the conduit instrumentation (keeping the connection outside the waste seam). The cylinder and its instrumentation will be surveyed to verify its location and depth in the waste.

Range finders will be placed in the wooden boxes to monitor void space. The range finders will serve to determine whether the void volumes in the space occupied by wooden boxes is lost when the overlying soil fills the space after they are destroyed or the space remains due to soil bridging. Details on the number and placement of range finders in the wooden boxes will be included in the test plan. In addition to the pressure transducer and type $\mathrm{K}$ thermocouple for the sealed gas cylinder, thermocouples and pressure transducers will be placed with each well after the pit is complete as part of the well emplacement.

Temperature and pressure transducer instruments will be installed in various 55-gal drums that contain organic materials (trash and organic sludge). The instruments will provide the data necessary to determine specific drum pressure and temperatures during ISTD processing. Once in place, the drum and box instrumentation shall be connected to the instrumentation wires coming out of the conduit. After the waste seam is constructed a 3-5 ft thick overburden layer of soil will be placed.

Throughout the discussion of ISTD's potential application to buried waste sites, it has been assumed there are few if any sealed, full or partially-full gas cylinders. If gas cylinders are present in the SDA they are likely not full due to galvanic enhanced corrosion of the brass nozzles during 30 years of burial. However, even if the cylinders are full they should not pose a problem due to safety release valves. These valves are both heat and pressure sensitive.

The ISTD process is run remotely and there are no personnel or critical structures in the waste heating area. Environmental releases possible from heating a gas cylinder should be negligible and operational dangers are small and can easily be minimized. Nevertheless, the inclusion of a pressurized gas cylinder in the simulated waste field test is necessary to verify operational safety.

Recent investigations into the types of wastes typically buried at the SDA have found that disposal of sealed gas cylinders in the SDA might have occurred, in a few isolated cases. The practice was not part of any routine waste from Rocky Flats Plant and could have either been a part of nonroutine Rocky Flats Plant fire debris or LLW from another source. This latter possibility currently is the only record of cylinders being deposited at a TRU pit. All standard gas cylinders made since 1910 gas cylinders have burst seals that release the cylinder contents in a "fast but controlled" manner either at temperatures above $200^{\circ} \mathrm{C}$ or pressures above $3,300 \mathrm{psi}$. In addition, the varying heat points and coefficients of thermal expansion associated with the steel or aluminum gas cylinders and the brass nozzle are such that the release of gas from such a cylinder would be through the nozzle or burst seal, rather than via catastrophic heat of the steel cylinder shell. 
The pressurized gas cylinder will be standard and have the same brass nozzle and burst seal that is typically found on most buried gas cylinders. The pressurized cylinder will be instrumented with a pressure transducer tap (to measure the internal pressure in the gas cylinder) and thermocouples welded near the top and bottom of each cylinder (to define the temperature gradient across the cylinder). The cylinder will either be filled with compressed air, carbon dioxide, or water. The gas cylinder will be placed in the waste seam at least 10 feet below grade.

\subsubsection{Site Preparation}

Following the preparation of the simulated waste pit, the ISTD vacuum and thermal well and piping system will be set up. Options for vacuum well emplacement is discussed in Appendix A.

Resistance heaters will be placed either through drilled holes or by lancing. Either method will stop at the bottom of the waste seam rather than going through the underburden, to the basalt. This is necessary to avoid damage to the heaters and placement tool. The well and heating system will be set up to effect a 510 foot area around the waste seam. There will be a $5 \mathrm{ft}$ heater and vacuum spacing. A schematic of the hexagonal arrangement with a third of wells combination heater and production (vacuum) is shown in Figure 3. A typical heater/vacuum well arrangement is shown in Figure 4. The simulated field-scale test involves resistive heater and vacuum well placement over the entire waste pit in a hexagonal arrangement with no heat in the 3-5 ft of overburden. The same spacing of wells for ISTD use in soil should be adequate for buried debris. A $5 \mathrm{ft}$ spacing for the heater and vacuum wells will be used to minimize the number of wells and accomplish the test in under 3 months. The speed of the remediation increases with the number of heating wells at the cost of drilling wells and the contamination from drilling. The number of vacuum wells and off-gas modules also change. The desired desorption minimum temperature of 425$450^{\circ} \mathrm{C}$ for ISTD was derived from the minimum temperature needed to decompose the nitrate salts.

Heater wells are lanced using 3-inch solid stainless steel pipe. Vacuum wells use slotted pipes and are placed to sample at least $4 \mathrm{ft}$ beyond the area of the pit that is to be ISTD processed. Temperature and pressure are measured at each well and at selected points between heaters (i.e., the last points to reach temperature). The test pit will be monitored real-time by an extensive system the vendor has developed from previous remediations.

\subsubsection{Processing of the Simulated Waste Test Pit}

ISTD processing begins with the off-gas treatment system extracting vapor with the heat shut off. A flow sufficient to remove all vapors generated must maintained throughout the remediation with out removing excessive heat being applied at each well. This usually requires about 2-4 inches of water vacuum and in most soils is about $0.5 \mathrm{cfm} /$ foot depth/well. Vacuum is applied for several days at ambient temperature until some of the water immediately adjacent to the vacuum wells is removed. This levels out the initial surge of water vapor when heat is applied. In addition, the drying of the area around the vacuum well causes an increase in soil porosity (Stegemeier 1996), ensuring all vapors are channeled toward the greater porosity areas to the vacuum well and through the off-gas system.

Following initial vacuum extraction, the heater wells are turned on and the temperature slowly rises as water is actively boiled off. This is the slowest phase of the ISTD remediation and consumes the most electricity. The water removal increases the soil permeability as the clay shrinks. There is substantial steam distillation in this phase removing organics below their boiling points. The off-gas system monitors provide data indicating the amount of organic destruction occurring and the point when water is evaporated. The initial temperature rise during this phase is about $4{ }^{\circ} \mathrm{C}$ per day in soil up to the boiling point of water. It remains at $100 \pm 20^{\circ} \mathrm{C}$ for as long as 2 weeks. 

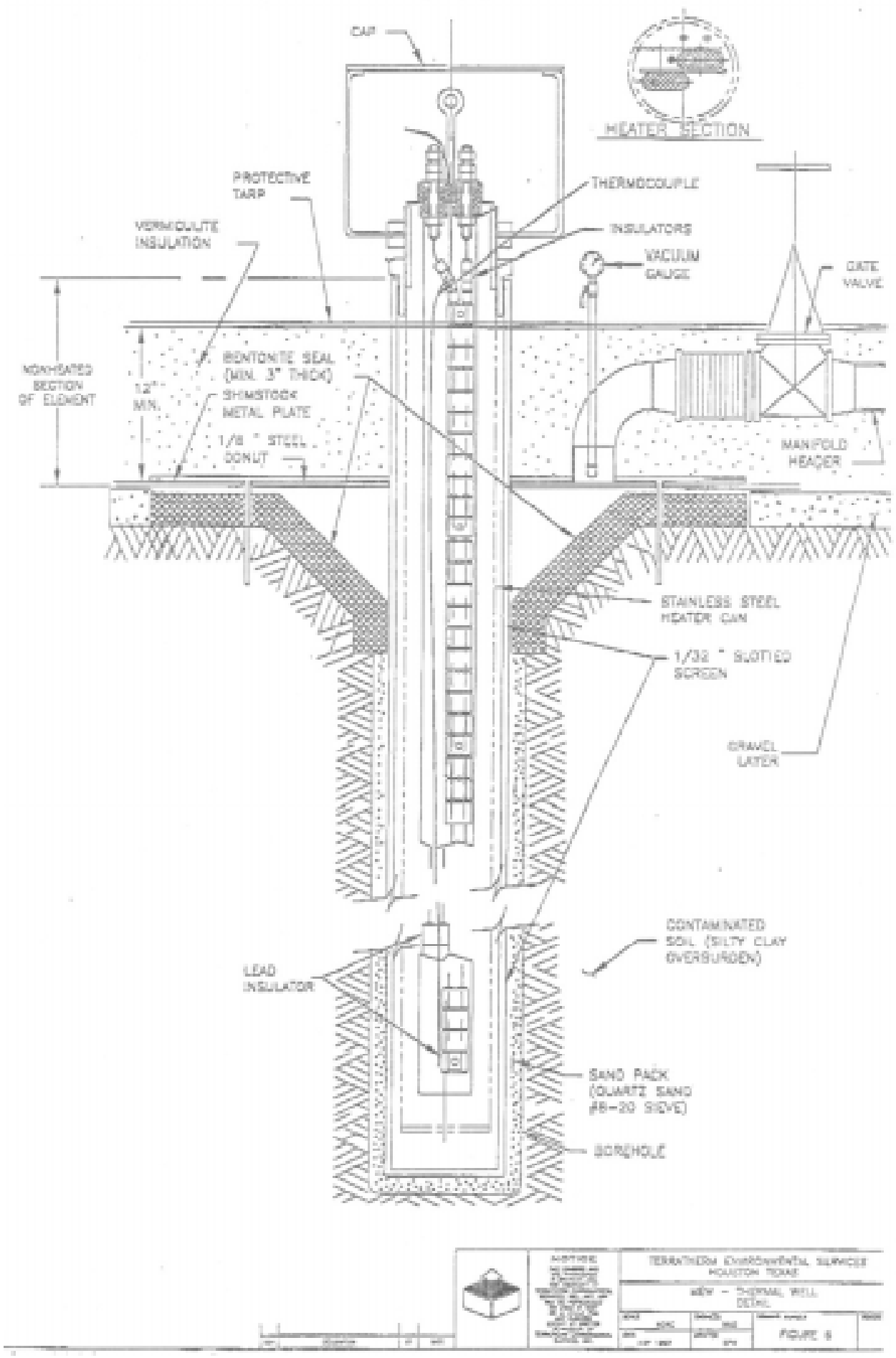

Figure 4. Typical heater and vacuum well arrangement. 
After water is removed, the temperature rises rapidly up to $25^{\circ} \mathrm{C} /$ day. This temperature rise is augmented by additional heat from combustion (oxidative process). Pyrolysis is an endothermic process requiring heat. During this phase, the carbon dioxide and carbon monoxide concentration in the off-gas is high. Controlled air can be introduced to adjust the degree of hydrocarbon oxidation. Most organics decompose in the $150-320{ }^{\circ} \mathrm{C}$ range. The amount of $\mathrm{HCl}$ in the off-gas is indicative of chlorinated organic destruction.

The nature of the heating along with the heat capacity of the soil and the endothermic character of pyrolysis makes the uncontrolled heating beyond the waste seam boundary an improbable event. The waste seam will have zones of heated and unheated waste as the heat propagates from the heater wells. Any combustion will be noted by thermocouples throughout the waste seam. Corners of the cold test will be far removed from the heater wells. The buried waste in these corners will not come up to temperature unless there is a combustion process. This will verify that no underground fires have occurred.

At $320^{\circ} \mathrm{C}$ the nitrate salts begin to melt and decompose at $380-400^{\circ} \mathrm{C}$ (potassium-sodium nitrate mixtures). All easily oxidizable substances are gone and the only remaining carbon are carbon residues from pyrolysis and carbon soot. As the nitrate salt decomposition begins, the carbon residues that remain may provide beneficial reduction in nitrous gases by reacting with them, reducing the gas to nitrogen. Thermal desorption proceeds until the entire waste seam is over $450{ }^{\circ} \mathrm{C}$. Generally $90 \%$ of the site will be at temperatures averaging $500^{\circ} \mathrm{C}$ or higher.

The off-gas concentrations of carbon dioxide and nitrous oxide will go to zero and indicate the remediation has been successful. At this point, the underground heaters can be turned off. The aboveground piping system heaters remain on to bake off any gases that have condensed on them. The off-gas system can then be turned off and the entire site allowed to cool. When the wells are near ambient temperature, they can be removed or capped.

\subsubsection{Process Monitoring}

The lance/drill insertion matrix for the pit will be designed to minimize the impact of heater and well insertion on all surveyed locations for all instrumentation connections in the test pit. Air samplers will be used to determine the simulated contamination released during the resistive heater placement. Both the particulate concentration and total particulate are measured from two samplers located as close as possible to the drilling operation. The contamination resulting from drilling through contaminated waste will be known and these sampling efforts can be used as guideline to air sampler setup.

The simulated field-scale test will be performed with a full ISTD off-gas treatment system consisting of a prefilter, a high-efficiency particulate air (HEPA) filter, thermal oxidizer, and charcoal filter. A standard thermocouple/transducer arrangement used in past ISTD operations will be used for monitoring the field test. These thermocouple/transducer units will be placed at all heater and vacuum wells and in between points at the locations suspected of having the slowest heat gain. Both the temperature and flow at these points gives the best indication of the status of the ISTD process subsurface.

The thermal oxidizer will oxidize any residual organic/acid gas contaminants while the granulated activated charcoal (GAC) is a final organic chloride emission insurance step. The GAC does not experience a heavy load due to the efficiency of the thermal oxidizer and should last the entire remediation. The sample point between the thermal oxidizer and the GAC will indicate whether this remains true when landfill type debris is being remediated. If the significant amounts of chlorinated hydrocarbons are entering the GAC a sample changeout may be necessary. 
During ISTD processing, the off-gas treatment system will be sampled periodically to determine off-gas releases from upstream of the off-gas treatment system and at the off-gas system stack discharge. The off-gas system will also be continuously monitored for discharge of any regulated emissions (such as oxides of nitrogen $\left[\mathrm{NO}_{\mathrm{x}}\right]$ ). Additional system information, such as heat rate vs. time, $\mathrm{kWh} / \mathrm{kg}$ soil, total heat time, preparation time, down times (w/ reasons), total $\mathrm{kWh}$, and off-gas flow rates, will be collected for use in the applications assessment portion of the final report. A mass balance of the water removed, organic mass destroyed based on water and carbon dioxide measurements will be performed. The thermal properties of this containerized landfill debris/soil/waste will be determined from the heat rate and time for scaleup and use in the SDA test.

The data acquisition system common to the other remediations performed by the vendor will be used throughout the simulated field-scale test to measure individual well parameters such as pressure, temperature and gas flow. A variety of gases are measured in the off-gas systems: total hydrocarbons $(\mathrm{TH})$, carbon monoxide $(\mathrm{CO})$, carbon dioxide $\left(\mathrm{CO}_{2}\right)$, nitrogen oxides $\left(\mathrm{NO}_{\mathrm{x}}\right)$, hydrogen chloride $(\mathrm{HCl})$, and water $\left(\mathrm{H}_{2} \mathrm{O}\right)$. These gases indicate the amount and type of waste that is being treated and provide extensive information for control when correlated with the temperature, pressure, and flow. Many of the monitors give continuous data with some requiring only hourly readout. All data collection systems will have electrical isolation protection. The total area treated will be based on the thermocouple measurements. The rate of ISTD processing will generally be consistent with previous full-scale conventional ISTD tests. However, the operational vendor may slow the rate of processing down, as necessary, to control off-gas and vacuum. The off-gas system will continue operations after the heat to the wells is shut off and until no gases except air from in the treatment zone are detected.

\subsubsection{Post-Test Sampling and Excavation}

Immediately after power is terminated, samples of all the off-gas system components (including off-gas and pipe smears, and filter samples) will be taken and analyzed for total organic carbon, $\mathrm{pH}$, and lanthanide composition. The filter will be analyzed for total particulate and rare earth oxide content to provide information on particulate release of TRU components in the radioactive field-scale test, and verify the completeness of nitrate organics destruction during ISTD processing. The thermocouple data as the soil/waste cools will be used to evaluate the change in thermal properties from the organic/nitrate destruction and the soil sintering.

Once post-test sampling of the ISTD system is completed and all secondary wastes are appropriately contained, disassembly of the system can progress. The site stability test will be performed before the headers are dismantled. All system components and process related items will be removed from the test site. The surface level will be monitored throughout the cooling phase which lasts longer than the warming phase. The amount of subsidence experienced during ISTD testing will also be measured and recorded. Clean fill dirt will then be placed in the subsided earth to bring the area back to grade. Tensiometers or some other moisture measurement may be placed to monitor water balance for a 2-year period following the remediation.

Because of the short time between the simulated field-scale test and the radioactive field-scale test and the long time required for the test pit to cool (6 months), sampling of the cooled heated waste may not be possible before the radioactive field-scale test. After the test pit cools, samples will be taken to verify lab surrogate leaching tests. However, samples are not required to verify organic destruction (this is done by temperature) or operational safety. The sampling will follow the vendor procedures for PCB sampling. This involves composite samples from the coldest areas in the treatment zone. Further detail is given in the Test plan. The extent of the ISTD treated area can be determined from thermocouple data and will be compared to projections from the case of a solid soil site. This treated area also is used to evaluate waste/soil thermal properties. 
To complete the evaluation of the degree of subsidence potential from the loss of water and organics, a partial excavation of a corner of the waste pit will be performed sometime after cooling during the 2-year monitoring period. Excavation of only a small portion of the pit will allow the remaining section to be studied for subsidence over a 2-year period. Excavation will have to be performed in somewhat of an archeological manner, to allow areas of bridging caused by the combustion of large boxes to be seen. A primary objective of the excavation is to evaluate the degree of void collapse caused by the resistive heater lancing placement (and subsequent void filling).

Other items of interest in the excavation include the extent of waste package lancing caused by resistive heater and well emplacement and ancillary compaction. During excavation, an extensive photographic record will be made to visually define the condition of the remaining waste packaging. The area around the excavation will be safely secured during the excavation process. Tensiometers or lysimeters will be emplaced following any destructive examination, to help in the analysis during the post test monitoring.

\subsection{SDA Field-Scale Testing}

After the field-scale ISTD test on simulated buried waste, a radiological test will be performed. A portion of Pit 4 will be remediated. The radioactive field-scale ISTD test will be used to verify much of the data generated by the laboratory and simulated waste field-scale tests. In addition, the radioactive field-scale test will serve as a demonstration of the technology's implementability under actual site conditions. The radioactive test is performed under the same set of regulations and approvals expected under actual remediation operations. Therefore, it is expected that the test will provide a substantial portion of the data on the cost of site preparation, equipment mobilization, processing, equipment demobilization, site restoration, and post-test evaluation and monitoring. In addition, the implementability aspect of obtaining regulatory approval to proceed will also be assessed.

The proposed location of the radioactive field-scale test is the east side of Pit 4 . This portion of the pit is expected to contain mainly organic sludges. The specific location will be finalized based on further analysis of waste shipping records and organic vapor samples. A diagram of the proposed ISTD test site within the SDA is show below in Figure 5. 


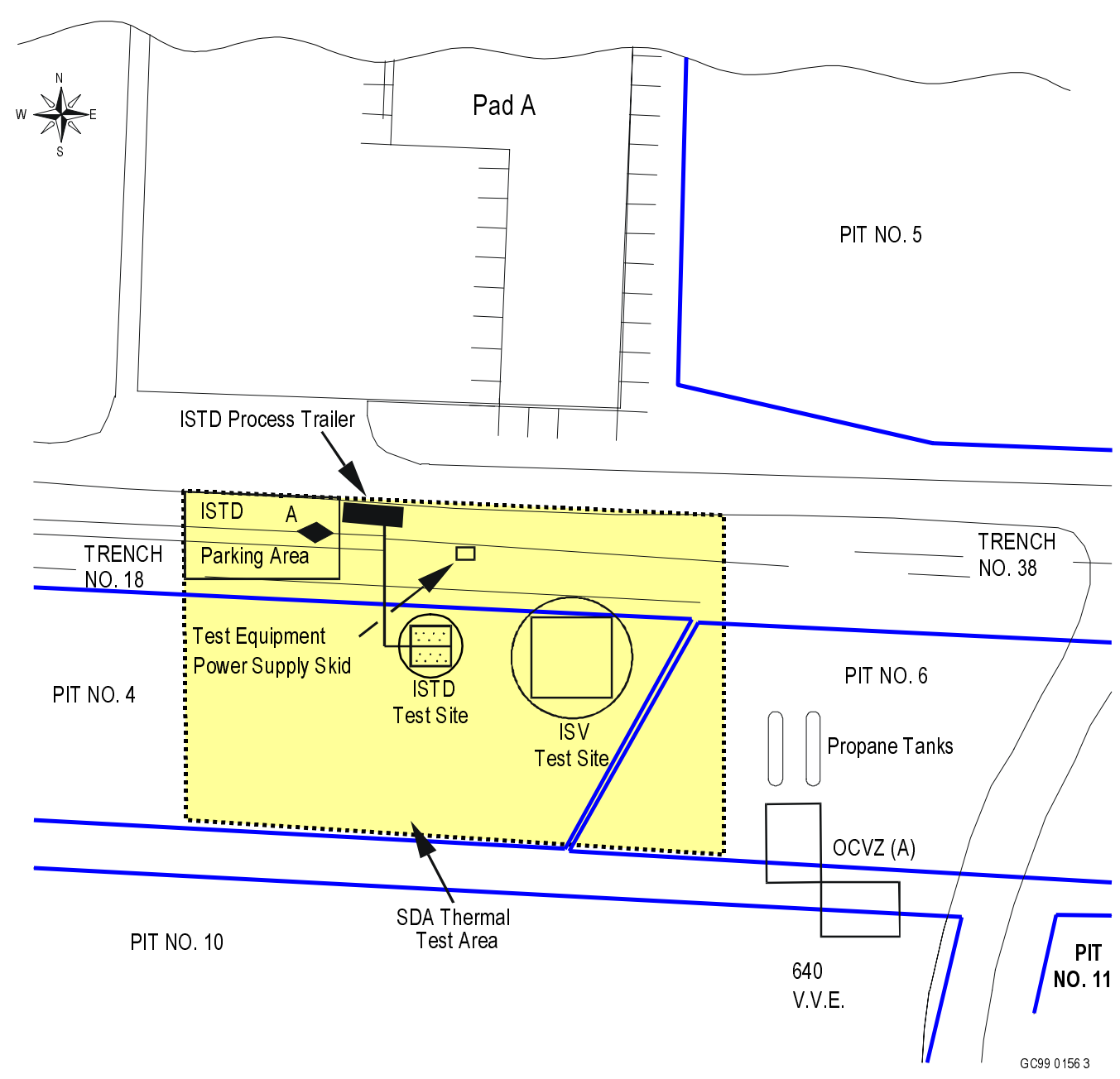

Figure 5. Location of the Pit 4 contents.

The halogenated hydrocarbon content on the east side of Pit 4 is four times as high as what would be expected under average conditions, which suggests that there was a higher presence of halogenated hydrocarbon material buried here than in other locations within the SDA. Since halogenated hydrocarbons are presently understood to be the primary risk drivers for the SDA, it follows that the selected site should contain a higher portion of hydrocarbons than would be commonly found. Disposal records also suggest that the entire waste contents in the east side of Pit 4 are 55-gal drums of Rocky Flats Series 74 sludge. There should be no large wooden boxes of debris, cardboard boxes of combustibles, 55-gal drums of debris waste, or any low-level waste containers in the location of the radioactive field-scale test. The drums in the east side of Pit 4 are buried in a random rather than a stacked orientation.

\subsubsection{Site Preparation}

The radioactive field-scale test for the ISTD TS will be conducted in the northeast corner of Pit 4 in the SDA. The pit is bordered on the east by the edge of Pit 6 , on the north by soil vaults, and on the south by Pit 10. Based on existing site data (Arrenholz and Knight 1991), the estimated depth of Pit 4 is $20.1 \mathrm{ft}$, with a soil underburden of $3.5 \mathrm{ft}$, a waste seam thickness of $9.1 \mathrm{ft}$, and a soil overburden of $7.5 \mathrm{ft}$. Geophysical surveys of the test pit and surrounding area will determine pit edge boundaries and specific location of adjacent pits and soil vault waste disposal areas. 
In situ thermal desorption of the radiological test will be performed on an area similar to the cold test (nominally $6 \times 6 \mathrm{~m}$ ). This size pit and $6 \mathrm{ft}$ spacing will require 13 wells, 6 of which are resistive heater only wells. This configuration might change based on the results obtained from the simulated waste test and the heat transfer in a buried waste environment. Resistive heater well placement at a spacing of 6 $\mathrm{ft}$ will require six heater-only wells and five vacuum/heater wells using the same well pattern planned for the simulated waste field test (vacuum wells are spaced at about $9 \mathrm{ft}$ and include heaters). The depth to basalt and as well as the depth of the waste seam will be determined when the heater and vacuum wells are installed.

Slotted pipes are used for vacuum wells and steel pipe for the heater wells. The geophysical survey data will be used to assist in placement of the slotted and steel pipes. Sufficient vacuum wells should be placed to intercept volatile contaminant migration throughout the anticipated soil temperature range of $10^{\circ} \mathrm{C}$ to $450^{\circ} \mathrm{C}$. The porosity provided by buried waste may make fewer wells necessary. The soil thermocouple data from the simulated waste field-scale test should define the extent vacuum wells must be placed for Pit 4 field-scale test.

Results from the simulated waste test will also define what monitoring equipment will be used in the Pit 4 field-scale test and the extent of grab sampling necessary. Generally the entire test will be set up as the simulated waste field-scale test and take place in the same manner. All thermocouples, heater wells, and pressure transducers will be placed by lancing into the waste seam. Vacuum wells may be drilled or lanced, approximately in the locations where pretest sampling was completed.

Power of sufficient quantity ( 0.5 megawatts) will be provided to the test site. A stable base for placement of the ISTD process equipment will be provided on the north side of Pit 4 . Gravel will be placed on top of the overburden soils associated with soil vaults located on the north side of Pit 4 . A lay down area for support equipment and process consumables will also be provided. Radiation levels in these areas are currently less than $1 \mathrm{mR} / \mathrm{hr}$, at contact, and are acceptable for test operations. The off-gas trailer will be placed as close as possible to the Pit 4 test area. Additional overburden may be placed over the treatment area to provide for subsidence, based on results from the simulated waste field test.

\subsubsection{Radiological Test}

The startup for the radiological test and the operational sequence will commence with heating and continue until the heat has penetrated outside the targeted treatment area. The rate of ISTD processing will be as close as possible to previous soil-based ISTD remediations. The uncontrolled atmospheric release of contamination is mainly controlled by the physics and chemistry of the process. The heaters and vacuum are adjusted to optimize the off-gas system capacity and to maintain sufficient vacuum to remove vapors without quenching the heating process. Further analysis of the underground fire potential will be addressed in that portion of the SAR. The rate of processing can also be controlled to keep the offgases being generated within the range for the off-gas system. The slow heating will prevent overloading the vacuum system or exceeding permitted amounts of gases $\left(\mathrm{NO}_{\mathrm{x}}\right.$ and $\left.\mathrm{HCl}\right)$.

The Pit 4 field-scale test will be performed with an off-gas treatment system consisting of prefilter, HEPA filter, thermal oxidizer, and activated charcoal absorbent. The thermal oxidizer will be installed on the off-gas system discharge to oxidize any residual organic/acid gas contaminants remaining in the offgas. During processing, the off-gas system will be sampled periodically to determine off-gas characteristics from the wells and at the off-gas system stack discharge. The off-gas system will also be monitored for discharge of radioactivity and other regulated emissions. Additional systems information such as heat rate vs. time, $\mathrm{kWh} / \mathrm{kg}$ soil, total heat time, preparation time, down times (with reasons), total $\mathrm{kWh}$, total heater well $\mathrm{kWh}$ and off-gas flow rates will be collected to provide data for the applications assessment portion of the final report. 
During ISTD operations, soil gas is monitored as part of the off-gas operation. Thermocouples placed in and between the boreholes will record soil temperature throughout the operation. Instrumentation proven to be effective in the simulated field-scale test will be used in the radioactive field-scale tests. During initial vacuum extraction, the pre off-gas line can sampled to determine concentration of the easily volatilized chlorinated organics (carbon tetrachloride, trichloroethylene, tetrachloroethylene, and 1,1,1-trichloroethane) coming to the off-gas system, without destruction.

The heat applied to the waste can be adjusted to keep off-gas emissions manageable while expediting desorption. The thermocouple data and off-gas composition indicate the stage of the process, for example steam distillation or oxidation is occurring. Heat will also be generated by organic combustion and contribute to the waste treatment.

\subsubsection{Demobilization}

The off-gas system will continue operations several days after ceasing heating until off-gases such as NOx and CO return to ambient air concentrations. Disassembly of the system can progress once posttest sampling of the equipment is completed and all secondary wastes are appropriately contained. Disassembly procedures will depend on effectiveness of the particulate filtration through the sand filters. The header system components will be smeared and handled based on contamination levels. Processrelated items downstream from the HEPA filter should not be contaminated. Smear samples will be taken to verify this, then they will be removed from the test site. The amount of subsidence experienced during the field test will also be measured and recorded. Clean fill dirt will be placed in any subsided area to match SDA surface grade.

\subsubsection{Post-Test Sampling}

Sampling of the off-gas system, filters, and system internal smear samples will be performed according to the test plan. Data will be used to determine appropriate methods for waste disposal and for verifying process contamination control.

After ISTD processing, the temperature loss in the soil and waste will be monitored. It is estimated that a site this size may take 6 months to return to ambient temperature. Samples or cores will be taken to verify complete decomposition of nitrate and organic material. Cores are taken minimally from the coolest spots in the treatment area. Each soil and metal sample is analyzed for total composition, as well as potential leachability. Information of the estimated amount of heat input, gases released, and heated waste dimensions are used to estimate energy balance. Chloride and NOx data give an estimate of COPCs chlorinated organics and nitrate salts processed. $\mathrm{CO}_{2}$ and $\mathrm{CO}$ content can be used for organic mass balances.

After sufficient time has been granted to allow the resultant heated waste to cool, samples of the heated waste will be collected and analyzed for total composition and contaminants of concern, chlorinated organics, nitrates and radionuclides. Samples containing toxic metals and or radionuclides can be leach tested with TCLP (EPA Method 8081) and/or ANS 16.1 to verify leach-resistance gained upon heating soil and waste.

The Lab scale leach test is primarily a comparative test to answer the question, does the heating of actinides change their leachability from soil and sludge matrices? Secondary uses of leach information are for risk assessment and transport modeling. The field-scale leach test on the SDA post-test samples are intended to verify the lab findings. This depends on a sufficient source term being present on a sludge and soil matrix in the samples recovered. Both TCLP and ANS 16.1 are contaminant leach protocols, the former is for regulatory determination of toxicity of certain metals in a landfill the latter the leach resistance of solidified low level waste. Either test can be used in a comparative manner though more 
fundamental diffusion information is obtained from the ANS 16.1. The TCLP is a more rapid test but does not provide diffusion data. An accelerated version of ANS 16.1 can also be used if diffusion type information is needed for the risk model input. Neither test is intended to be a simulation of leaching at the SDA.

In addition, scanning electron microscopy (SEM) of the heated soil or sludge waste will be used to define the degree of sintering of the clay from the heat, and the degree of COPC partitioning (if any) caused by sintering. The results of this SEM analysis, in combination with leach testing, can be used to better define the durability of various COPCs in the heated soil or sludge waste. The leach analysis results will be compared against the results of the lab-scale ISTD tests to correlate the field and lab results as to the degree of actinide leachability from the resultant treated waste. 


\section{EQUIPMENT AND MATERIALS}

\subsection{Required Equipment/Materials for the Lab-Scale Tests}

A lab-scale test of the leachability of actinides will be performed on spiked simulated matrices (simulated sludges, RWMC soil) and actual samples from SDA coring and characterization activities. The required equipment and materials for the lab-scale determination of reduction in leaching and nitrate decomposition upon heating of simulated and actual samples of wastes/soil include:

- $\quad$ SDA TRU contaminated, sludge, salt and soil samples

- $\quad$ RWMC lakebed soil

- $\quad$ Oil-Dri

- $\quad$ Rare earth (cerium, terbium, lanthanum) oxide tracer.

Detailed information on the equipment and materials to be used for the simulated lab-scale tests will be described in the ISTD test plan.

\subsection{Required Equipment/Materials for the Simulated Field-Scale Test}

The simulated field-scale test portion of the treatability study will be performed at the RWMC at a cold test pit located north of the SDA. The technology licensee will provide the ISTD off-gas equipment with associated system hardware and monitoring equipment. The INEEL Management and Operations $(\mathrm{M} \& \mathrm{O})$ contractor will provide power, construct the test pit and provide all test pit instrumentation and subsequent test sampling support. The $\mathrm{M} \& \mathrm{O}$ contractor will also provide all heavy equipment support required to complete ISTD installation and setup.

The required equipment and materials for the simulated field-scale test include approximately:

- $\quad 130$ Metal 55-gal drums (with lids)

- $\quad$ Fifty $1 \times 2 \times 2 \mathrm{ft}$ cardboard waste boxes

- $\quad$ Two $4 \times 4 \times 7 \mathrm{ft}$ wooden waste boxes

- $\quad$ Four $4 \times 4 \times 4 \mathrm{ft}$ wooden waste boxes

- $\quad 10,000 \mathrm{lb}$ of combustibles (wood, cloth, paper, plastics)

- $\quad 11,000 \mathrm{lb}$ scrap metal

- $\quad 4,000 \mathrm{lb}$ scrap wood

- $\quad 4,000 \mathrm{lb}$ scrap concrete

- $\quad 4,000 \mathrm{lb}$ scrap asphalt 
- $\quad 2,000 \mathrm{lb}$ filter (wood and paper) material

- $\quad 10 \mathrm{yd}^{3} \mathrm{RWMC}$ lakebed soil

- $\quad$ 2,000 lb Portland cement

- $\quad$ 7,500 lb Texaco Regal Oil, R\&O 68

- $\quad 5,000$ gal isopropanol

- $\quad 1,500 \mathrm{lb}$ calcium silicate

- $\quad$ 1,500 lb Oil-Dri absorbent

- $\quad 4,000 \mathrm{lb}$ sodium nitrate

- $\quad 2,000 \mathrm{lb}$ potassium nitrate

- $\quad 400 \mathrm{lb}$ lanthanum or other rare earth oxides

- $\quad$ One full-size compressed gas cylinder

- $\quad$ High-volume air samplers (filters, pumps, motors)

- $\quad$ Low-volume air samplers (filters, pumps, motors)

- $\quad$ Test pit instrumentation

- $\quad$ Type $\mathrm{K}$ thermocouples

- $\quad$ Pressure transducers

- Instrumentation

- $\quad$ Tensiometers (optional post TS monitoring)

- 24 resistive heating elements (about $300 \mathrm{w} / \mathrm{ft}$ ) in stainless steel pipe

- 12 slotted stainless steel vacuum well screens or prepack units

- Headers, well controllers, and associated collection piping

- $\quad$ ISTD off-gas system

- $\quad$ Cyclone separator

- $\quad$ High temperature HEPA filtration bank

- $\quad$ Thermal oxidizer

- $\quad$ Isokinetic stack sampler 
- $\quad$ Off-gas monitor system for $\mathrm{CO}_{2}, \mathrm{CO}, \mathrm{HCl}, \mathrm{NOx}, \mathrm{THC}, \mathrm{H}_{2} \mathrm{O}$, organics

- Data acquisition system

- $\quad$ Electrical power for ISTD system $(1 \mathrm{kV}, 1500 \mathrm{~kW})$

- Resistive heater lancing placement equipment

- $\quad$ Portable crane of sufficient capacity for heater and well placement

- Excavation equipment (post-test monitoring).

- Heavy equipment, forklifts, drilling rig, or lance to penetrate overburden and place heaters and well casings in the desired processing area.

Detailed information on the equipment and materials to be used for the simulated field-scale test will be described in the ISTD test plan.

\subsection{Required Equipment for the Radioactive Field-Scale Test}

TerraTherm Corporation or its licensee will perform the radioactive field-scale test portion of the treatability study at the RWMC on the east end of Pit 4, in the SDA. They will provide the large-scale ISTD equipment with associated system hardware and monitoring equipment. The INEEL M\&O contractor will provide power, along with all heavy equipment support required to complete ISTD process equipment installation and setup, pretest and post-test sampling, test instrumentation, and support activities for the test.

The required equipment and materials for the radioactive field-scale test will be the same as the cold test with these additional items:

- Radiological continuous air monitors (CAMs) before and after the HEPA filters and in the offgas system

- Bag-out equipment for heater assembly replacement if necessary.

Other radiological control items may be required. Detailed information on the equipment and materials to be used for the radioactive field-scale test will be described in the ISTD test plan. 


\section{SAMPLING AND ANALYSIS}

This section addresses the sampling and analyses that will be conducted to support the ISTD treatability study. A test plan will be prepared by TerraTherm or technology licensee and the INEEL $\mathrm{M} \& \mathrm{O}$ contractor that will describe in detail the testing protocols, sampling, and analytical methods. Specific data quality objectives will also be defined in the test plan based on the test objectives and experimental design described in this work plan.

Analytical laboratories approved by INEEL's Sample Management Office (SMO) will perform characterization-type analyses. INEEL's list of SMO-approved analytical laboratories will be supplied to the operational vendor as part of the Request for Proposal. Other analyses needed for meeting the needs of the treatability study may require other laboratories not on the SMO list but with comparable quality standards. An evaluation by SMO and a one-time variance or other provisional requirement will be sought if needed.

The applicable documents providing the requirements for sampling and analysis are as follows:

- Treatability Study Test Plan

- $\quad$ Work Plan for Operable Unit 7-13/14 Waste Area Group 7 Comprehensive Remedial Investigation/Feasibility Study (Becker et al 1996)

- $\quad$ Project Health and Safety Plan

- $\quad$ The current list of SMO-approved Analytical Laboratories

- $\quad$ SMO Service Request Form

- $\quad$ Applicable drawings associated with the Pit 4 of the SDA, and its surroundings at the RWMC

- $\quad$ Project Quality Assurance Project Plan (QAPjP)

- $\quad$ Historical and analytical data from past waste characterization activities on both Pit 4 , and the area surrounding Pit 4 of the SDA

- $\quad$ Addendum to the Work Plan for the Operable Unit 7-13/14 Waste Area Group 7 Comprehensive Remedial Investigation/Feasibility Study (DOE-ID 1998a).

Each phase of the ISTD treatability study will involve sampling and analysis. The following sections list the sampling and analysis requirements for lab-scale testing, nonradioactive field-scale testing, and radioactive field-scale testing. Details as to the minimum detection limits that will be set for each analysis are to be included in the treatability study test plan.

\subsection{Lab-Scale Test Sampling and Analysis}

Lab-scale tests will follow standard sampling and analysis protocols for each procedure used. Standard procedures will be used where feasible as well as good laboratory practices for custom procedures. Characteristics of RWMC lakebed soil for parameters that influence heating such as moisture, heat capacity, and bulk density will be obtained from the core analysis activities. 


\subsubsection{Actinide Leachability}

One of the parameters that will be determined in lab-scale testing is actinide leachability. Data will be collected during the test to determine the (1) composition of the water used for leaching, (2) composition of the solid phase containing the actinides, (3) solution to solid ratio, and (4) residence time of water in contact with the solid phase. All of these factors influence the leachability of actinides.

Chemical and physical changes that occur after soil and buried waste are heated will be measured by a series of leach tests such as TCLP, a modified ANS 16.1 (Low-Level Waste Leach) or ASTM 3486 (Accelerated Leach Test) commonly used to quantify contaminant mobility. These tests are primarily to provide a standard leach procedure to compare actinide leachability before and after heating. Secondary uses of the data for risk assessment and modeling are also being considered. Sampling and analysis of actual contaminated waste (soil, sludge) samples from the SDA will follow the sampling and analysis plan contained in the test plan. Specific segregation needed after characterization will depend on the type and amounts of samples obtained. Standard radionuclide analysis will be used for the leachates before and after leaching.

Each of the above sample types will be apportioned to provide sufficient sample for triplicate testing at 4 different temperatures representative of major ISTD processing phases:

- $\quad 15-25^{\circ} \mathrm{C},-$ ambient temperature -(control)

- $\quad 100-120^{\circ} \mathrm{C}$ - dewatering phase

- 200-300 $\mathrm{C}$ - organic decomposition phase

- $\quad 380-450^{\circ} \mathrm{C}$ - nitrate decomposition phase.

The composition of the water will be determined by starting with water of known and documented initial purity and adding reagent grade chemicals of known purity to produce an initial composition. Both the Eh and $\mathrm{pH}$ of the water will be determined using EPA standard methods.

The solid phase will be representative of actinide-contaminated waste and soil to be treated by ISTD. The solid phase will be analyzed for actinide concentrations $\left({ }^{234} \mathrm{U},{ }^{235} \mathrm{U},{ }^{238} \mathrm{U},{ }^{237} \mathrm{~Np},{ }^{238} \mathrm{Pu},{ }^{239 / 240} \mathrm{Pu}\right.$, and ${ }^{241} \mathrm{Am}$ ) using standard alpha and gamma spectroscopic techniques and subsequently heated in the laboratory to simulate ISTD treatment. Appropriate tracers will be added to determine the effects of sorption on reaction vessels and other surfaces.

Each spiked or contaminated dry solids (sludge, soil) will be weighed in appropriate containers. A measured portion of water or other leach solution will be added to the containers. Total weight will then be determined. Residence time will be measured to the nearest minute using a chronometer. The concentration of actinides in both solid and liquid phases will be measured following the extraction. The liquid might be analyzed for major cations if the a total change in solubility of primary soil species is also desired. Cations are measured using EPA techniques SW-846 methods 6010 and 7610 or equivalents (EPA, 1986), pH using EPA technique 150.1, Eh using APHA method 2580B, total hardness using EPA technique 310.2, and major anions $\left(\mathrm{F}^{-}, \mathrm{SO}_{4}{ }^{-2}, \mathrm{PO}_{4}{ }^{-3}, \mathrm{NO}_{3}{ }^{-}\right.$, and $\left.\mathrm{Cl}^{-}\right)$using EPA methods 300 and 340.2. 


\subsubsection{Nitrate decomposition upon heating}

Nitrate salts must be safely (worker protection) and completely (effectiveness) destroyed during ISTD processing. To validate nitrate destruction, lab-scale heating of nitrate salts above decomposition temperatures of $380-400^{\circ} \mathrm{C}$ will be tested. Heating the nitrates to these temperatures should result in the dissociation and breakdown of nitrate anions and off-gassing of nitrous oxides and nitrogen gas. The rate of decomposition will be tested lab-scale using the surrogate and actual salts with soil and inorganic sludge. The rate of heating will be faster than the actual field-scale test with the rate of heating correlated with the rate of gas generation.

Destruction of nitrate salts will be examined in the laboratory by slowly heating representative aliquots of high-nitrate contaminated waste. The sample will be subjected to the expected temperature regime and monitored for sudden exothermic reactions using thermocouples that are accurate to $\pm 5^{\circ} \mathrm{C}$. Off-gas samples will be taken periodically during heating after the $200^{\circ} \mathrm{C}$ isotherm is reached, and these samples will be analyzed for $\mathrm{NO}_{\mathrm{x}}$ with a $\mathrm{NO}_{\mathrm{x}}$ analyzer. Once the samples are allowed to cool, the treated waste will be analyzed for nitrates using EPA technique SW-846 9200.

The temperature data will be examined to determine if any rapid exothermic reactions occurred. The amount and timing of $\mathrm{NO}_{\mathrm{x}}$ evolution will be determined from the $\mathrm{NO}_{\mathrm{x}}$ data. The completeness of nitrate destruction will be demonstrated by analysis of nitrate levels in post-treatment waste.

\subsection{Simulated Waste Field-Scale Test Sampling and Analysis}

Most of the sampling during the simulated field-scale test will be for gases generated as a result of the ISTD process. Gas sampling will be performed in two phases: for particulate releases during mobilization and demobilization and real-time monitoring during operations. In addition, some post-test soil and waste samples will be taken. Operational measurements taken during the test include temperature and pressure to provide both implementability and effectiveness data. Temperature and pressure data are obtained at each vacuum well and heater well. Temperature data is also taken at the "cold spots" those farthest from any heaters.

\subsubsection{Contamination Spread}

Hi-Vol ambient air filter samples will be taken during the resistive heating well emplacement and demobilization. The air samplers will be placed in the immediate vicinity of each hole as each well is emplaced such that the sampler's air sweep entrance is as close as practical to the well emplacement drill or lance. Sampling will occur continuously during the entire well emplacement operation. At least $2 \mathrm{Hi}$ Vol air samplers will be used during each well emplacement.

Air sampling, filter change out, and filter handling will be in accordance with standard Total Suspended Particulate (TSP) procedures. It is assumed that little if any dust will be generated by the sonic drill. The air flow is monitored for any sign of blockage or filter overloading. If there is sufficient dust to overload filter the entire drilling operation will have to be reengineered. The filter is changed for each well emplacement, i.e., filters will be changed for both vacuum well drilling and resistive heater lancing. Each changed-out filter will be marked as to its exact time of service and then placed in a container that eliminates any potential for filter loss, in accordance with routine procedures for Hi Vol sampling. Following the resistive heater lancing placement activity, all collected air filters will be sent to an analytical laboratory and separately analyzed for both total particulate and total lanthanum oxide (per ICP or ICP-MS, EPA Method 6010 or 6020). 
Smear samples obtained during lancing will also be taken using standard techniques. Smear samples will be taken near the bottom of the resistive heater lance, the area of highest contamination potential. Smear samples will be taken from all items removed from the test area, especially if heaters and vacuum screens are removed. Smear samples will be taken after every lance insertion, for a total of at least 8 smear samples. There will be no attempt to remove the dust from the drill stem until a smear sample has been taken. Once a smear sample has been taken, the entire lance will be wiped down, to avoid cross-contamination between samples. Each smear sample will be submitted for both total particulate analysis and rare earth oxide analysis (via ICP or ICP-MS, EPA Method 6010 or 6020).

\subsubsection{Nitrate and Organic Destruction}

A primary goal of the ISTD simulated field-scale test is to remove nitrates and organics from the waste seam. The off-gas monitoring is performed in accordance with a standard procedure developed and approved by EPA for 7 prior ISTD tests. Off-gas characterization will be performed for $\mathrm{HCl}$ (hydrogen chloride), THC (total hydrocarbons), $\mathrm{CO}$ (carbon monoxide), $\mathrm{CO}_{2}$ (carbon dioxide), $\mathrm{NO}_{\mathrm{x}}$ (nitrous oxides$\mathrm{NO}, \mathrm{N}_{2} \mathrm{O}, \mathrm{NO}_{2}$ ), $\mathrm{O}_{2}$ (oxygen), $\mathrm{SO}_{2}$ (sulfur dioxide), and $\mathrm{H}_{2} \mathrm{O}$ (water). Sampling of the off gas is performed before heat is applied and continues until desired temperatures are achieved. The results of the organic vapor analysis will be routinely recorded to a data acquisition system. Results from the final offgas sampling effort will be compared to the initial effort to determine the extent of volatile organic contaminant transport during ISTD processing. Gases will also be sampled at a point prior to the off-gas treatment system to estimate the in situ destruction.

During previous applications of ISTD, there has been negligible particulate release to the ISTD offgas treatment system, however, the potential generation of particulates from pyrolyzed debris and especially the spread of actinide contamination during ISTD processing has not been quantified. Samples from the interior of the off-gas treatment system components such as collection headers, off-gas piping will be collected after the system has cooled via smears or pipe rinsates. The HEPA filter will also be sampled and analyzed for both total particulate and lanthanide concentration (per EPA Method 6010 or 6020). In addition, some of the off-gas component samples will be analyzed for nitrites (EPA Method 300). The total filter particulate and rare earth oxide released will be estimated. The results will provide information on the suspected entrainability of TRU components in the radioactive field-scale test, the degree of nitrate destruction underground prior to the off-gas treatment system, and the completeness of pyrolysis experienced by trash and Texaco Regal Oil during ISTD processing.

\subsubsection{Subsidence/Site Stability and Moisture Return}

The cold field-scale test site will be monitored for subsidence and water infiltration for 2 years following termination of power to the waste. Range-finder instrumentation will be used to measure void dimensions in the containers before and after ISTD treatment. Void dimensions will also be measured directly after the treated volume has cooled in the limited destruction excavation. The primary measurement will be ground level measurements made throughout the operation and for several years later. Moisture will be measured with tensiometers or by direct sampling. These measurements will be detailed in the test plan. Samples will be analyzed for lanthanide oxide composition, particle size, and attachment to soil.

\subsubsection{Administrative Feasibility}

Many activities supporting the readiness of field-scale testing will provide data to support assessment of the administrative feasibility of applying ISTD to the SDA. Relevant data includes the time and effort required to gain readiness review approval and operational data that support emission permitting, secondary waste disposal, and treated waste assessments. 


\subsubsection{Cost}

The field test cost will be determined from the actual costs incurred and those calculated from the test such as energy usage. All supplies (heaters, wells, offgas system) will be itemized and operational history logged. In the past, the primary costs have been the length of time for remediation as the system labor costs can be extensive. Any necessary methods for scaling-up the remedial cost of ISTD from the field scale to full scale will be provided in the final field-scale test report. Costs to be incurred in remediating the entire SDA will be inferred from the cold field test and compared to those of the radiological test in Pit 4.

\subsubsection{Secondary Waste}

The entire system design is set up to minimize secondary waste. The high-temperature prefilter and HEPA system capture all radioactive particles. The efficiency of the system for higher boiling point chlorinated organics is $99.9999 \%$, thus all hazardous organic contaminants concern such as TCE and $\mathrm{CCl}_{4}$ are destroyed in ground and by the Thermal oxidizer to detection levels. Secondary waste data will be obtained on the cold test by the particulate and rare earth oxide loading on the filtration system and the presence of any organics in the backup charcoal system. The header piping before the HEPA filter may be secondary waste in the radiological test and will be smeared for contaminated particulate content. Smearing for tracers in the simulated test will indicate the likelihood of particulate movement. The wells and heater elements will not be removed in the radiological test.

\subsubsection{Gas Cylinders}

A Type $\mathrm{K}$ thermocouple and a pressure transducer will be attached to the sealed gas cylinder to monitor the conditions of the gas cylinder throughout the heating process.

\subsection{SDA Field-Scale Test Sampling and Analysis}

The sampling and analysis activities for the radioactive field-scale test are expected to be similar to those used in the simulated field-scale test. Additional sampling for airborne radioactivity during mobilization and radionuclide monitoring in the off-gas system treatment train will be used. The method of sampling and analysis will be the same as the simulated field-scale test methods.

The primary difference associated with radioactive field-scale testing is that there will be fewer core samples of the treated waste and no destructive examination. Samples will be taken after sufficient time has elapsed to allow the soil and waste to cool (approximately one month). Up to 5 cores will be taken. The coreholes will be spaced a minimum of $4 \mathrm{ft}$ from each other, and will be at least $1 \mathrm{ft}$ away from the edge cold pit. From each core, soil samples will be taken near both the top and the bottom. Each soil/sludge/or metal sample will then be analyzed for total composition, via EPA Method 6010 or 6020 (with total sample dilution). In addition, ANS 16.1 (Jantzen and Bibler 1987) leach testing will verify the fixation of radionuclides studied in the lab test. The fixation data from the compositional analysis will serve to define the relative durability of treated wastes compared to untreated.

Other differences for sampling and analysis from the simulated waste field-scale test include (1) no post-test moisture monitoring of the treated zone and (2) no monitoring of sealed gas cylinders.

\subsubsection{Actinide Leachability}

As part of the radioactive field-scale test, the treated mass will be sampled after treatment and a sufficient cooling period. Four cores will be taken from the treated mass. These cores will be spaced at 
least $4 \mathrm{ft}$ apart and split for testing. One set of sample splits will be tested for actinide leachability. The analysis of actinide leachability will be follow the steps outlined above for determination of actinide leachability during lab-scale testing. The cores also will be analyzed for leachability using TCLP to help determine the regulatory status of the post-treatment waste using EPA Method SW-846 1311. 


\section{DATA MANAGEMENT}

Data generated during the testing will be managed in accordance with guidelines provided in the Data Management Plan for the Idaho National Engineering Laboratory Environmental Restoration Program (INEL 1995c). This plan provides or references procedures and requirements necessary to develop a database of relevant information, which can be readily accessible and accurately maintained. The plan describes the data flow process, data custodianship, and organizational and individual responsibilities associated with data management. The plan also provides the project file and reporting requirements, and identifies extensive database capability requirements to allow selective data sorting, analysis, formatting, and reporting.

The data management plan provides the requirements for managing the data generated from the ISTD treatability study. There will, however, be some deviations from the data management plan. Deviations are due to information that is not directly recorded in logbooks or from laboratory data that is not tracked by the Environmental Restoration Information System (ERIS). For the ISTD treatability study, a majority of the measurements and information will be recorded on data sheets that need to be included in the final data package that will be sent to INEEL at the conclusion of the project. Off-gas analyses-analytical data shall not be tracked in ERIS.

In each of the above-mentioned cases, the data and information will be placed in Administrative Record and Document Control. Additionally, hard copies of the raw data and test results will be summarized in the final treatability study report. Specific data quality objectives and data validation requirements (as necessary) are specified in the Test Plan. Program Requirements Document (PRD)-111 "Records and Forms Management," will assist in ensuring that information is available when needed. Management Control Procedures (MCPs) will be invoked for the ISTD treatability study. The primary MCPs that will be used are:

- MCP-204, "Administrative Record/Information Repository Procedure”

- MCP-205, "Records Management"

- MCP-230, "Environmental Restoration Document Control Center Interface"

- MCP-231, "Logbooks"

- MCP-240, "Internal/Independent Review of Documents"

- MCP-328, “Test Plans"

- MCP-452, "Treatability Studies”

- MCP-244, "Chain of Custody, Sampling, Handling, and Packaging"

- $\quad$ MCP-277, "Sampling and Analysis Process for Environmental Restoration (ER) Funded Activities"

- MCP-2825, "Laboratory Notebooks Maintenance."

Other MCPs may be invoked, depending on process specific data management needs. 


\section{DATA ANALYSIS AND INTERPRETATION}

Data will be summarized and evaluated to determine the validity and performance of the treatment process after the testing phases of ISTD are complete. One goal of this evaluation will be to determine the quality of the data collected. All quantitative data will be checked to assess precision (using relative percent difference for duplicate matrix spikes), accuracy (percent recovery of matrix spikes), and completeness (percentage of data that are valid). If the quality assurance objectives are not met, consensus on a path forward will be sought with the INEEL M\&O Contractor, DOE-ID; EPA Region 10; and the Idaho Department of Health and Welfare (IDHW).

Valid equations and procedures must be used to prepare data for it to be scientifically valid, legally defensible, and comparable. Sections 8.1 and 8.2 discuss data reduction and data validation, respectively, for all of the data that will be collected. Section 8.3 discusses the procedures for assessing the data. Section 8.4, 8.5, and 8.6 discuss the specific data to be collected during the lab-scale, nonradioactive field-scale, and radioactive field-scale test phases of the project and how that data will be analyzed and interpreted. Section 12 of this document discusses how this data will be reported.

\subsection{Data Reduction for All Tests}

All data reduction will be completed as specified in the analytical method or procedure. Where data reduction is not computerized, calculations will be performed in permanently bound notebooks or on preprinted data reduction pages. The data reduction for some analyses includes analyst interpretations of raw data and manual calculations. The analyst interpretations will be written in ink on the raw data when this is required. Corrections will be made as necessary and documented and dated in ink on the original sheets.

\subsection{Data Validation for All Tests}

Data validation begins with the sample collector, analyst, or data collector and continues until the data are reported. The individual analysts will verify and sign for the completion of the appropriate data forms to verify the completeness and correctness of data acquisition and reduction. The ISTD Principle Investigator will review the computer and manual data reduction results and inspect laboratory notebooks and data sheets. These actions will be taken to verify data reduction correctness and completeness and to ensure close adherence to the specified analytical method protocols. Calibrations and quality control (QC) data will be examined by the individual analysts to verify that all instrument systems are in control and that quality assurance objectives for precision, accuracy, completeness, and method detection limit are being met. Specific designation as to the INEEL M\&O Contractor validation level for each piece of data will be included in the treatability study test plan. follows:

The principal criteria that will validate the integrity of data during collection and reporting are as

- Verification that chain-of-custody procedures have been followed (where applicable)

- Verification by the project analyst that all raw data generated for the project have been stored on disk and/or hard copy and that storage locations have been documented

- Examination of the data by the ISTD Principal Investigator or data reduction personnel to verify adequacy of documentation. 
Outlier data are defined as QC data lying outside a specific QC objective window for precision or accuracy for a given method. Should QC data be outside control limits, the principal investigator will investigate the potential causes of the problem. The data will be flagged with a data qualifier.

\subsection{Procedures for Assessing Data}

\subsubsection{Notation}

Measurements collected during the treatability study are intended to determine properties of materials. More precisely, the variance and bias of the measurement process are to be estimated. The variance and bias correspond to the precision and the accuracy, respectively, of the measurement processes.

Let $M$ denote a measurement and let $\sigma_{\text {meas }}^{2}$ denote the variance of the measurement process. If $\mathrm{n}$ measurements are taken, denote them by $M_{i}$, and denote their average by $M_{\text {avg. }}$. The sample variance shall be defined as:

$s_{\text {meas }}^{2}=[1 /(n-1)] \sum\left(M_{i}-M_{a v g}\right)^{2}$.

The sample variance, $s_{\text {meas }}^{2}$, will be used to estimate the variance of the measurement process, $\sigma_{\text {meas. }}^{2}$

Each measurement is intended to measure some true value, $T$. The bias, $B$, is defined as the difference of the long-term average measurement and the true value. $M_{\text {avg }}$ approximates the long-term measurement, but is not exactly the same because $M_{\text {avg }}$ only involves $n$ measurements. The true value is known, approximately, in a test situation. Therefore, the bias $B$ can be estimated in a test situation by:

$B_{\wedge}=M_{\text {avg }}$ - (approximation of true value).

\subsubsection{Estimation of the variance of the measurement process $\left(\sigma^{2}\right.$ meas $)$}

The sample variance, $s_{\text {meas }}^{2}$ is an unbiased estimator of $\sigma_{\text {meas }}^{2}$, that is, $s^{2}$ estimates $\sigma^{2}$ with perfect accuracy. Consider now the precision of $s^{2}$. Assuming that the measurements are independent and normally distributed, a $95 \%$ confidence interval for $\sigma^{2}$ is:

$(n-1) s^{2} / \chi^{2} 0.975 \leq \sigma^{2} \leq(n-1) s^{2} / \chi^{2} 0.025$

where $\chi^{2}{ }_{0.975}$ is the $97.5^{\text {th }}$ percentile of a $\chi^{2}$ distribution with $n-1$ degrees of freedom, and $\chi^{2}{ }_{0.025}$ is the $2.5^{\text {th }}$ percentile. If $n=5$, this interval becomes

$4 s^{2} / 11.1 \leq \sigma^{2} \leq 4 s / 0.484$

$0.36 s^{2} \leq \sigma^{2} \leq 8.26 s^{2}$

so that $\sigma^{2}$ is within a factor of 10 of $s^{2}$, as required by the data quality objectives. Therefore, $\sigma$ is within a factor of 3 of $s$. 


\subsubsection{Estimation of Bias}

The tests will be set up so that the approximation of the true value of a measurement is an unbiased estimate of the true value. That is, any one approximation may be too high or too low, but the average over many possible setups is the true value. The variance of the approximation to the true value is denoted $\sigma^{2}$ true, and must be estimated by knowledge of the test setups. For example, if the true value is the location of the vitrified mass, a contributor to $\sigma^{2}$ true would include measurement error in recording the location (possibly negligible). The magnitude of the error must be estimated by considering the nature of all contributors.

The bias $B$ is estimated by using $B_{\wedge}$, as defined above. Because $M_{\text {avg }}$ is an unbiased estimator of the long-term average measurement, and the approximation of the true value is assumed to be an unbiased estimator of the true value, it follows that $B_{\wedge}$ is an unbiased estimator of $\mathrm{B}$, that is $B_{\wedge}$ has perfect accuracy. Regarding precision, the variance of $B_{\wedge}$ :

$\operatorname{var}\left(B_{\wedge}\right)=\operatorname{var}\left(M_{\text {avg }}\right)+\operatorname{var}($ approximation of the true value $)=\sigma_{\text {meas }}^{2} / n+\sigma_{\text {true }}^{2}$,

and the standard deviation is the square root of $\operatorname{var}\left(B_{\wedge}\right)$. An estimate of the standard deviation can be made before conducting any tests based on expert opinion of the two $\sigma$ 's. During data interpretation, the pre-test estimate will be used to say that with $95 \%$ probability the difference between $B \wedge-B$ will be in the range of $\pm 2 \mathrm{x}$ (the estimated standard deviation of $B_{\wedge}$ ).

\subsection{Lab-Scale Test Data Interpretation}

The lab-scale tests for ISTD will test for actinide leachability after treatment and nitrate decomposition. These experiments will be conducted with core samples of actual waste as well as surrogate waste as discussed in Section 4. Samples will be taken and analyzed as described in Section 6.

\subsubsection{Actinide Leachability}

All of the parameters measured (see Section 6) to determine the leaching mechanism and quantification of the leach index will be used to determine a $K_{d}$ value for actinides in SDA waste media. The $K_{d}$ value is a parameter that can be used in the existing WAG 7-13/14 risk model to understand residual risk.

The $K_{d}$ value for each actinide will be calculated by dividing the concentration of the actinide in the solid phase by the concentration in solution. This will not be a true $K_{d}$ value since equilibrium may not be established, and the $\mathrm{K}_{\mathrm{d}}$ value will be specific to the waste type, solution chemistry, and residence time used in the experiment. The test parameters will be as realistic as possible, and the value will be compared to published literature values to confirm reasonableness.

\subsubsection{Nitrate Decomposition}

The purposes of this lab-scale test are to demonstrate that waste containing nitrate salts can be safely treated with ISTD, to quantify the effectiveness of in situ destruction of nitrate salts, and to quantify the amounts of $\mathrm{NO}_{\mathrm{x}}$ produced during treatment. The test is required before going to the SDA test to ensure that there is no risk of explosion in the off-gas treatment system and that appropriate air permitting is obtained. In addition, the data will provide information for the feasibility study alternative evaluation on the effectiveness of ISTD on nitrates, a COPC at the SDA. 


\subsection{Simulated Waste Field-Scale Test Data Interpretation}

Operational data, including voltage and amperage on each heater (energy usage); heater depths (treatment area); off-gas pressures, temperatures, and composition (destruction, progression, and efficiency); thermal oxidizer temperatures (emission ARARs); off-gas flow rates and pressures; and total energy expended will be measured during the nonradioactive field-scale test. Off-gas samples will be collected periodically during processing to verify the nature of the released gases. In addition, samples of low-grade prefilter, HEPA filter, and other off-gas streams will be taken after processing. Smear samples of exterior surfaces of the off-gas treatment system will be collected to evaluate possible release of particulates from the system. The data collected from the field-scale simulated waste pit tests will be used to plan the SDA test and to obtain approval to move into the SDA.

\subsubsection{Contamination Spread During Vacuum and Heater Well Emplacement and Demobilization}

Ambient air filter samples will be used during well emplacement in the cold test. Both air filter and smear samples will be used during demobilization. Rare earth tracer concentrations above background in these samples should define the likelihood of contamination spread (if any) expected from these activities in the SDA and the degree of confinement (if any) required. During demobilization in the cold test smear samples of the headers are collected. Tracer concentrations above background on these samples will give an indication of whether equipment can be decontaminated or must be discarded as secondary waste. Ambient air filters collected will be used to evaluate total potential contamination spread during the entire demobilization operation. Tracer source term and these results will then be used in conjunction with the expected concentrations of TRU isotopes in Pit 4 to verify no unacceptable actinide contamination spread during well emplacement at the SDA. This information should help define the best technique for header removal and whether wells and heaters should be removed from the SDA following treatment.

\subsubsection{Nitrate and Organic Destruction}

Off-gas sampling during the radioactive field-scale test will consist of both gas stack sampling during ISTD processing and particulate sampling of the filters both up and downstream of the HEPA system. The off-gas components or materials (i.e., equipment smears, off-gas pipe smears, filter material, etc.) will be sampled after the off-gas system is turned off. The real-time stack sampling will be used to confirm that the off-gas system effectively contains all radioactive and hazardous materials that are volatilized or entrained into the off-gas during processing and that the off-gas released from the stack meets air quality ARARs. Stack sampling equipment will include both a volatile organic sampling system and an isokinetic stack sampling system. These instruments give data in terms of total amount of a constituent over a certain volume of off-gas collected. The information can then be used to estimate the concentration of particular contaminants in the off-gas and the total amount of a particular contaminant released to the air during ISTD treatment.

\subsubsection{Subsidence/Site Stability and Moisture Return}

Results from site stability and moisture return data (see Section 6.2.3) will be used to estimate the movement of radionuclides in the treated waste and potential fixation to the soil. This data will be used in the feasibility study alternative evaluation.

\subsubsection{Administrative Feasibility}

The experience gained through completing the DOE Safety Analysis and Readiness Review process will be used to assess the administrative feasibility of ISTD application at the SDA. Off-gas 
emission data as well as the characterization of the treated waste and secondary waste will also assist in determining regulatory requirements.

\subsubsection{Cost}

Other operational data to be recorded during the radioactive field-scale test includes voltage and amperage supplied to heaters, pressures at vapor extraction wells, soil temperatures, off-gas chemical composition temperatures, flow volumes, HEPA filter pressure differentials, thermal oxidizer temperatures, and electrical energy expenditures. The operational data will help estimate power requirements and other costs resulting from ISTD processing of a dense buried waste seam such as exist in the SDA. Though the estimate of process economics can rely on processing experience from other sites treated with ISTD, it also will include the results from this test. Specific operational calculations that need to be determined from this test include man-hour requirements for operation of the system, operational man-hour requirements for mobilization and demobilization, power requirements for each volume, and $\mathrm{kW} \mathrm{hr} / \mathrm{kg}$ of processed waste.

Off normal occurrences during operations will be recorded by operations personnel in the project logbook as they occur. These may need to be reported to RWMC SS to make sure they are not reportable under MCP 190. The record will include a description of the event, an estimate of elapsed time of the event, an estimate or measurement of the impact of the event. Follow the radioactive field-scale test, all transient observations will be compared to the recorded database (if any) to better quantify the conditions at the time of the off normal occurrence. This information will be included in the final evaluation of ISTD processability of SDA waste from both a technical and economic standpoint.

\subsubsection{Secondary Waste}

The post-test off-gas component sampling will be used to define the degree of equipment decontamination needed and the types and amounts of secondary waste generated by ISTD processing. The off-gas pipe smears will beare analyzed for radioactive constituents, and this information will be used to define the amount of decontamination required to release the equipment and the amount of secondary waste expected from equipment decontamination. This is used to define whether to decontaminate the off-gas system following ISTD processing, or to purchase and dedicate the system for possible use on future remediations within the SDA.

Analysis of off-gas waste streams will target radioactive, hazardous organic, and hazardous inorganic constituents. This evaluation will determine whether the secondary waste should be classified as RCRA hazardous, TSCA-regulated, radioactive, or mixed waste in accordance with IDAPA 16.01.05.006 (40 CFR §262.11). Details of the sampling and analysis specifying number of samples, analytical methods, etc. for evaluation of secondary wastes will be given in the test plan. Knowledge of the types and volumes of secondary wastes generated by ISTD will allow determination of the amount of secondary wastes which can be recycled and the amounts of waste which will require active management. This will permit evaluation of the economics of ISTD of SDA buried waste within the requirements of CERCLA.

\subsubsection{Sealed Gas Cylinder}

Temperature and pressure data from the gas cylinder test will be used to determine the mechanism, rate, and temperature when the cylinder fails. The primary purpose of determining those factors is to verify safe operations before performing the SDA test. 


\subsection{SDA Field-Scale Test Data Analysis and Interpretation}

The data from the SDA test will be interpreted in the same manner as the simulated waste fieldscale test, with the following exceptions:

- There will be no data for moisture return to the treated zone

- There will be no gas cylinder processing data

- There will be actinide leachability data.

\subsubsection{Actinide Leachability}

The leachability data from the SDA field-scale test will be used to calculate a Kd value for actinides. The Kd value will be calculated in the same manner as discussed in Section 8.4.1. The Kd value from the SDA test will be compared to the Kd value from the lab-scale test. The $\mathrm{Kd}$ value is a parameter that will be put into the WAG 7-13/14 risk model to determine residual risk. 


\section{QUALITY ASSURANCE}

The ISTD treatability study and its associated activities shall be conducted according to a Quality Assurance Program (QAP) that meets the requirements of DOE Order 5700.6C, "Quality Assurance," or a national consensus standard such as American Society of Mechanical Engineers procedure NQA-1, "Quality Assurance Requirements for Nuclear Facility Applications." DOE 5700.6C is applicable to nonnuclear facilities and activities. Nuclear facilities and activities are governed by 10 CFR 830.120 using ASME NQA-1 as the quality assurance standard.

The latest revision of the Implementing Project Management Plan for the Idaho National Engineering and Environmental Laboratory Remediation (LMITCO June 1998) may be used if the safety analysis shows ISTD to be hazard category 3, or low hazard. If the safety analysis shows ISTD is hazard category 2 , or moderate hazard, a separate quality program plan will be developed to address the nuclear quality assurance requirements and compliance to 10 CFR 830.120, since both of these documents meet the requirements of DOE Order 5700.6c. The latest revision of the Quality Assurance Project Plan for Waste Area Groups 1, 2, 3, 4, 5, 6, 7, and 10 (DOE-ID December 1997) will be used to address data quality. If the operational vendor for ISTD desires to use their own Quality Program Plans and Quality Assurance Project Plans, copies of these plans will be sent to the INEEL M\&O contractor for internal review and approval before start of work or placement of the subcontract. 


\section{HEALTH AND SAFETY}

All lab- and field-scale tests will be performed at the INEEL. The lab-scale tests will likely be performed at TRA, while the simulated and radioactive field-scale tests will be performed at the RWMC. Testing performed at TRA will be performed in accordance with the established health and safety program.

A task-specific Health and Safety Plan (HSP) will be prepared to cover testing activities planned for the INEEL. The HSP will establish the procedures and requirements that will be used to minimize health and safety risks to persons working on the project. It will contain information about the hazards involved with performing the work and the specific actions and equipment to be used to protect persons working at the site. The HSP will ensure that the authorized safety basis as detailed in the safety analysis report (under development) is adequately implemented during testing operations. All personnel, including DOE, M\&O contractor, and subcontractor staff, working within the work control zones for the treatability study will be required to comply with HSP procedures and requirements. Activity outside the work control zones must comply with applicable health and safety procedures as defined in the applicable facility interface agreement. 


\section{RESIDUALS MANAGEMENT}

Residuals management refers to the management of any secondary wastes generated by the treatability study. Because the waste in the ISTD treatability study is regulated under CERCLA, all of the nonprocessed materials remaining after the nonradioactive field-scale tests will be managed as investigation-derived waste (IDW). Any secondary waste generated by the radioactive field-scale test will also be managed as IDW. As IDW, the residual waste materials will not have to be remediated until after the OU 7-13/14 record of decision has been signed. The designated IDW will be either left in place, or stored on the remediation site, in accordance with appropriate CERCLA regulations and requirements (42 USC § 9601 et seq.). A mixed waste TSD is also an option for disposal.

Waste management for the ISTD treatability study will be in accordance with the Waste Minimization/ Management Plan and Generator Treatment Plan for the ISTD treatability study, which will be written before testing begins. The Waste Minimization/Management Plan will address all CERCLA and non-CERCLA waste streams generated during the treatability study. This includes waste streams from the lab- and field-scale tests, sampling and analysis process wastes, maintenance and occupational waste from equipment operations, and equipment and maintenance supply disposition at the end of the treatability study. Estimates will also be made of the volumes and types of CERCLA and nonCERCLA waste streams expected to be generated during the ISTD treatability study.

Every waste stream will be evaluated to determine whether the waste is:

- $\quad$ Solid waste under RCRA

- $\quad$ RCRA Characterization Hazardous Waste (for RCRA solid wastes)

- $\quad$ RCRA-listed hazardous waste (for RCRA solid wastes)

- $\quad$ Subject to RCRA Land Disposal Restrictions (LDRs) for RCRA Characteristic or Listed Hazardous Waste

- $\quad$ To be treated to meet RCRA LDRs

- $\quad$ Subject to TSCA regulation for PCBs

- $\quad$ Radioactive.

These determinations will meet requirements of the Waste Certification Plan for the Environmental Restoration Program (INEL 1996), CERCLA, RCRA, TSCA, and applicable DOE orders. The determination will be subject to review by the INEEL M\&O contractor's ES\&H Manager, Environmental Affairs, and the Project Manager. The general strategy for waste management will be:

- $\quad$ Recycle or reuse materials and equipment wherever possible to decrease waste generation

- $\quad$ Return materials to the area of contamination where this can be accomplished successfully

- $\quad$ Manage the stream as nonhazardous, nonradioactive, non-TSCA regulated solid waste where possible

- $\quad$ Manage all other waste streams in cooperation with Environmental Affairs and WROC. 
The Waste Certification Plan for the Environmental Restoration Program (LMITCO 1996 INEL96/0043, Rev 1, October 1997) provides guidance on waste management for Environmental Restoration programs at the INEEL. The Waste Certification Plan provides the methodology and organization systems used by the ER Program to ensure that its wastes submitted to WROC, WERF, or RWMC for storage, treatment, and/or disposal meet the requirements of the DOE-ID criteria for radioactive waste defined in the INEEL RRWAC (DOE-ID 1998). The plan also defines program policies and applications for Environmental Restoration projects at the INEEL. This includes policies associated with CERCLA area of contamination compliance issues, IDW, land disposal restrictions, and CERCLA treatability studies.

Specific details associated with residual management of the three phases of the ISTD treatability study are detailed below. A Transportation Plan and the treatability study test plan, in conjunction with the waste minimization plan and Generator Treatment Plan will discuss the packaging and shipping of samples.

\subsection{Lab-Scale Testing}

The lab-scale testing will follow the waste minimization plan for laboratory operations. All radiological samples handled will adhere to requirements in the Test Plan that will contain a sampling and analysis plan. Spiked samples will be disposed in accordance with the specific lab waste minimization plan likely as low-level waste. Rare earth oxides to be used as radionuclide surrogates should have no hazardous characteristics and will be disposed of as routine lab wastes.

\subsection{Simulated Waste Field-Scale Testing}

The simulated field-scale test will use waste surrogates typical of waste found in actual radioactive buried waste at the INEEL SDA. However, to minimize cleanup costs, no RCRA toxic or radioactive materials will be included in the test. Various rare earth oxides are candidates to simulate the actinide oxides in the waste. None of these compounds are subject to regulation under RCRA, TSCA, or DOE Orders. The simulated test also will include sodium nitrate and potassium nitrate, to simulate nitrate salt waste streams buried at the SDA. The regulatory status of these nitrate salts is discussed in more detail below. Nonhazardous Texaco Regal Oil (R\&O 68), or canola oil in "kitty litter", or commercial calcium silicate absorbents will be added to simulate the oil-base of the organic sludges. These materials are not regulated as RCRA Hazardous Waste. All other materials added for the simulated field-scale testing will be nonhazardous components/materials added to simulated waste typically found in actual buried waste at the SDA.

Nitrate salts are oxidizers under 49 CFR 173.151, and waste nitrate salts may be regulated as D001 RCRA Characteristic Hazardous Waste. Treatment with ISTD, however, will dissociate, oxidize, and volatilize the nitrate component of the salt, leaving sodium and potassium oxide in soil because nitrate salts dissociate at temperatures of $380-400^{\circ} \mathrm{C}$. Since the materials used in simulated field-scale testing will not be waste until the treatability study is over, the nitrate salts will not be subject to RCRA regulation. Potential transport of nitrates into surrounding soils during ISTD processing is highly unlikely. Therefore, there should be no leftover nitrate oxidizers in the surrounding soil, following simulated fieldscale ISTD testing.

All water and organic residual materials will be removed from the simulated field-scale test site by ISTD processing. The resultant dry inorganic residue remaining in the pit will be monitored for subsidence for 2 years and may be sampled to verify absence of organics, and nitrate salts in any of the waste packages. 
There is little potential that any waste materials generated by this test will be RCRA Hazardous Waste as both the in situ and the thermal oxidizer destruction of even recalcitrant PCBs to $99.9999 \%$. The prefilter and the GAC will also be sampled to verify that no organic particulates or vapors remain. Final determination to verify materials are nonhazardous solid waste (and can be disposed as such) will be made based on the process knowledge and the operational measurements. The nonhazardous nature of the field-scale test pit contents also eliminates any hazardous secondary waste concerns.

If the off-gas secondary waste materials are found to be hazardous they will be packaged and stored onsite as IDW, pending completion of the WAG 7 ROD, or managed as RCRA Hazardous Waste with appropriate waste codes.

\subsection{SDA Field-Scale Testing}

The radioactive field-scale test will be conducted on the northeast corner of Pit 4 , within the INEEL SDA. Mixed RCRA hazardous and radioactive waste was disposed in Pit 4, and the waste includes a wide variety of RCRA listed waste codes. All secondary waste generated before, during, and after this test will be managed as Mixed Radioactive and RCRA Hazardous CERCLA IDW unless it can be demonstrated that the waste does not contain any of the original waste. Samples taken from the area of concern (ISTD treated waste, surrounding soil, metal waste) which contain any of the original waste also are likely to be subject to regulation as Mixed RCRA Hazardous and radioactive waste. These wastes will be managed as CERCLA IDW. The wastes may be returned to the area of contamination, stored as CERCLA IDW pending a ROD specifying a disposal route, or disposed at a RCRA Subtitle C facility (if the radionuclide levels are sufficiently low and applicable LDRs can be met).

The ISTD treated waste and metal waste created from the radioactive field-scale test need to be considered as radioactive (and RCRA Listed Hazardous) CERCLA IDW, following completion of the test. The resultant post-treatment treated waste will not be excavated following the test, but will stay in the pit and be allowed to cool. Following sufficient cooling, core samples of the solidified treated waste will be used to define whether or not the resultant treated wastes are RCRA Characteristic Hazardous IDW, as well as radioactive IDW and whether the waste meets LDR treatment standards for applicable Listed Hazardous Waste Codes.

Coring material from the drilling of vacuum wells will be stored as archived samples. These sample an be used to help determine the changes the ISTD process has on SDA material. This material may be replaced into the core holes when it is no longer needed or stored in a mixed waste storage facility with other radioactive residues that are also hazardous. The Advanced Mixed Facility may be used to treat these residues.

The off-gas wastes generated by the radioactive field-scale test will also be handled as RCRA Listed Hazardous Waste unless they can be demonstrated to not contain RCRA Listed Hazardous Waste. Samples will be analyzed to determine whether or not the waste streams are RCRA Characteristic Hazardous Waste and whether or not the waste is radioactive. The total volume of secondary wastes (including off-gas wastes) generated needs to be accurately estimated to define the total volume of waste expected from full-scale remediation of the SDA. As much of the equipment as possible will be decontaminated following the radioactive field-scale testing, so it can be released from the SDA. Any equipment that cannot be effectively decontaminated will be included in secondary waste volume estimates. The contaminated equipment, however, may still be useful for future ISTD remediation efforts within the SDA. Determining radioactivity and addressing NESHAP reporting requirements will be done under the appropriate RWMC and ER criteria. The Health and Safety Plan and the Waste Minimization Plan also address handling residuals. 


\section{COMMUNITY RELATIONS}

Community relations performed for the ISTD treatability study are designed to ensure community understanding of actions taken during the treatability study and to obtain community input on the treatability study program. Community relations are an integral part of CERCLA. The INEEL public affairs group of the INEEL M\&O Contractor has prepared a programmatic INEEL Community Relations Plan (INEL 1995b). This Community Relations Plan was issued as a DOE document representing the process established by mutual agreement between DOE-ID, EPA Region 10, and IDHW Division of Environmental Quality to address Environmental Restoration (ER) concerns at the INEEL. In addition, community relations for WAG 7-13/14 are discussed in both the WAG 7-13/14 Work Plan (Becker et al. 1996, Section 5.2) and the Addendum to the Work Plan (DOE 1998, Section 6.2). The INEEL Community Relations Plan and details for WAG 7-13/14 will guide the actions taken to ensure appropriate public involvement. Specifically, for the ISTD treatability study, two public fact sheets will be prepared and made available to the public, through the Administrative Record for OU 7-13/14; one before and one after testing is complete. The results from the ISTD treatability study will also be reported on and made

available to the public through the Administrative Record for OU 7-13/14. In addition, WAG 7-13/14 will support news/press releases and will actively relay test plans and treatability study results at public meetings. 


\section{REPORTS}

During the course of the treatability study, open lines of communication are essential to ensure smooth, accurate flow of information to all parties, directly or indirectly involved with the project. To ensure timely flow of current and projected progress, weekly reporting will be performed. A number of documents will be prepared that will support performing the tests. A final report will document the results of the entire treatability study, including documenting any changes from the Work Plan or Test Plan.

\subsection{Weekly Reports}

The technical lead or principal investigator (see Section 15) is responsible for submitting weekly reports updating the progress of the ISTD treatability study. As a minimum, the weekly reports will be distributed to the project manager (PM). The PM, as appropriate, will then forward the weekly reports or relevant information to the program manager, the DOE-Idaho Operation Office (DOE-ID) PM, and the control account managers. The weekly reports should include, but not be limited to, the following (for each week of the ISTD project):

1. Accomplishments of work performed for the week

2. Anticipated work to be performed for the following week

3. Any problems or issues encountered and the actions taken.

\subsection{Interim Support Documents}

A number of anticipated reports will support the tests. These include

- $\quad$ Test Plan that contains a Sampling and Analysis Plan

- Health and Safety Plan

- Quality Assurance Project Plan (QAPjP)

- Waste Management/Minimization Plan which shall include a Generator Treatment Plan.

The documents provide direction for activities that, when completed, provide data for the final treatability study report.

In addition, interim letter reports will be provided after the lab-scale testing and simulated fieldscale testing phases of the ISTD treatability study. The interim letter reports will summarize the results of each phase of testing or analysis and provide the necessary information to implement the next phase of the ISTD treatability study. The letter report on the:

- Lab-scale testing will include information on the leachability of radionuclides to ensure that before proceeding to the hot field-scale test, the ISTD processing will not increase the mobility of COPCs in the treatment zone.

- Simulated field-scale test will inform of the current effectiveness of ISTD for the remediation for organic and nitrate salts, well emplacement and operations while avoiding contamination 
spread, sampling and monitoring activities performed, and verification of safety upon heating a sealed gas cylinder..

- Radiological field-scale testing includes information on any detectable radionuclide levels above background from well emplacement and operations similarities of current organic and nitrate salts monitoring data to that of simulated test, and the overall success of avoiding above ground contamination.

\subsection{Final Treatability Study Report}

At the completion of the ISTD treatability study activities, a final report will be prepared documenting project activities, results, conclusions, and recommendations. Complete and accurate reporting is essential because decisions about the ISTD technology as a remedial alternative for waste areas in the SDA will be based in part on the outcome of this treatability study. The final report will be prepared in accordance with the EPA's Guide for Conducting Treatability Studies under the Comprehensive Environmental Response, Compensation, and Liability Act (EPA 1988). The purpose of the final report is to provide information for alternative evaluation for the RI/FS.

The final report will include an applicability analysis section that will describe how to conduct a full-scale ISTD remediation of buried waste at the SDA. The applicability analysis shall include time and cost estimates. The applicability analysis shall contain information on an estimate of the amount and type of secondary waste that would be generated from such a process (including recycling estimates and information on disposal), time estimates for ISTD processing, the full-operational cost of treating such a site, the cost of mobilization and demobilization, data on estimated downtimes between heating campaigns, and frequency estimates and anticipated duration of routine operational breakdowns. In addition, the applicability analysis needs to provide information on major equipment purchases that would have to be dedicated to the ISTD remediation at the SDA. The estimates will be based on a combination of data from the ISTD treatability study, and applicable vendor data from other ISTD operations.

Upon submittal of the final report, the subcontractor shall submit a complete data package from the ISTD treatability study to the INEEL M\&O Contractor, for record storage. This shall include a copy of all logbook entries during the test, instrumentation monitoring records, files, operational data files, and sampling and analysis files. The subcontractor will retain the originals of this data. The complete data package will include only those aspects of the test that have been funded by DOE and the INEEL M\&O Contractor. This data may be provided to INEEL M\&O Contractor and/or DOE at the subcontractor's discretion. The sampling and analysis data shall be submitted as an Excel computer file, for eventual incorporation into INEEL's Sample Management Office database. 


\section{SCHEDULE}

The schedule (Figure 6) was developed using INEEL's Integrated Safety Management philosophy. This philosophy implements a 5-step approach to systematically integrate safety considerations into management and work practices at all levels to accomplish the project mission while protecting the public, the worker, and the environment. The 5 steps include

1. Define the scope of work

2. Identify the hazards

3. Mitigate the hazards

4. Perform work within their controls, and

5. Provide lessons learned, feedback, and continuous improvement.

The Treatability Study Work Plan and Test Plan defines the work scope and obtains consensus among DOE, EPA Region 10, and IDHW. Safety assessments are being conducted concurrently with test planning to identify the potential hazards and to develop controls to mitigate these hazards (completion of draft April 1999). Once safety assessments are approved using INEEL review protocols (August 1999), the Test Plan will be reviewed to ensure that the prescribed safety controls are being implemented. The laboratory-scale and simulated waste field-scale test provide opportunity to ensure lessons learned are incorporated into the planning prior to startup of the field-scale test in Pit 4.

\begin{tabular}{|c|c|c|c|c|c|c|c|c|c|}
\hline Operable Unit 7 - 13/14 In Situ Thermal & & & & & 1st 2 & $\begin{aligned} 2000 \\
\text { Quarte } \\
\text { 2nd } 3 r\end{aligned}$ & $\begin{array}{l}0 \\
\text { eer } \\
\text { rd } 4 \text { th }\end{array}$ & 1 st & $\begin{array}{l}2001 \\
\text { Quarter } \\
\text { 2nd 3rd } 4 \text { th }\end{array}$ \\
\hline $\begin{array}{l}\text { Draft Work Plan Submitted to EPA/IDHW for } \\
\text { Review and Comment }\end{array}$ & 31-Mar-99 & & & & & & & & \\
\hline Draft Field-Scale Test Plan Sent to DOE-ID & 24-Jun-99 & & 1 & & & & & & \\
\hline ISTD Work Plan Finalized and Approved & 30-Jun-99 & & 1 & & & & & & \\
\hline Final ISTD Field-Scale Test Plan Sent to DOE-ID & 17-Aug-99 & & & & & & & & \\
\hline $\begin{array}{l}\text { Field-Scale Nonradioactive Test Pits Ready for } \\
\text { ISTD Testing }\end{array}$ & 29-Sep-99 & & & & & & & & \\
\hline $\begin{array}{l}\text { Complete Field-Scale Nonradioactive ISTD } \\
\text { Testing }\end{array}$ & 29-Feb-00 & & & & $\Delta$ & & & & \\
\hline Complete ISTD Radioactive Field-Scale Test & 27-Jul-00 & & & & & 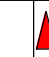 & & & \\
\hline $\begin{array}{l}\text { Complete Coring and Analysis of ISTD } \\
\text { Radioactive Field-Scale Test }\end{array}$ & 24-Jan-01 & & & & & & & $\Delta$ & \\
\hline $\begin{array}{l}\text { Draft Treatability Study Report Sent to EPA/IDHW } \\
\text { for Review and Comment }\end{array}$ & 30-May-01 & & & & & & & & $\Delta$ \\
\hline Final Treatability Study Report & 20-Jul-01 & & & & & & & & $\Delta$ \\
\hline
\end{tabular}

Figure 6. Working schedule for the ISTD treatability study. 


\section{MANAGEMENT AND STAFFING}

The ISTD treatability study organization structure reflects the resources and expertise required to perform the work and produce a technically superior product, while minimizing the risks to worker health and safety. A subcontractor will be directly responsible for performing all treatability testing and reporting the results to INEEL M\&O Contractor. However, the INEEL M\&O Contractor has ultimate responsibility for the technical quality of the work performed. Conduction of the ISTD treatability study will be a cooperative effort between the subcontractor and several INEEL M\&O Contractor organizations including Environmental Restoration, Applied Engineering Developmental Laboratory Department, and RWMC Operations. In light of the cooperative effort, the team has been assembled to include persons that have experience with similar treatability study activities and have interfaced with, or directly supported the RWMC. Key project personnel and their specific responsibilities are listed as follows:

Agency Team Members

DOE WAG 7 Manager

DOE WAG 7 Project Scientist

EPA Region 10

IDHW Project Manager

INEEL M\&O Contractor Team Members

ER Buried Waste Department Manager

D. K. Jorgensen

WAG 7 Treatability Study Project Manager

WAG 7 Treatability Study Technical Lead

WAG 7 Remedial Investigation Technical Lead

WAG 7 Health and Safety Officer

WAG 7 Feasibility Study Project Manager

ISV Principal Investigator

ISV Field Team Lead

ISV Quality Engineer

RWMC Operations Supervisor

RWMC Work Control Supervisor
A. T. Jines

A. T. Armstrong

R. W. Poeton

Gerry Winter
D. F. Nickelson

B. H. Becker

R. W. Roblee

R. A. Hyde

P. G. Shaw

P. A. Sloan, Jr.

R. G. Thompson

J. R. Bishoff

J. M. Wasylow
B. Bonnema

\section{Subcontractor Team Members}

Chief ISTD Team Leader

V. Frederick

Contracting Support Interface

C. Cassner

Chief Contracting Officer

C. A. Whitaker

The specific responsibilities associated with each of these team members will be defined in both the Health and Safety Plan and the treatability study test plan. The organizational relationship between these key personnel is as detailed in the Interface Agreement between ER and the RWMC (IAG-15). 


\section{BUDGET}

Table 13 shows the proposed budget for the ISTD Treatability Study.

Table 13. Proposed budget for the ISTD treatability study.

\begin{tabular}{lc} 
Fiscal Year & $\begin{array}{c}\text { Proposed Budget } \\
(\$ \mathrm{M})\end{array}$ \\
\hline FY-99 & 1.33 \\
FY-00 & 2.13 \\
FY-01 & 0.18 \\
\hline Total & 3.64
\end{tabular}




\section{REFERENCES}

AEC, 1970, Policy Statement Regarding Solid Waste Burial, Immediate Action Directive No. 0511-21, U.S. Atomic Energy Commission.

Anderson, S. R., and B. D. Lewis, May 1989, Stratigraphy of the Unsaturated Zone at the Radioactive Waste Management Complex, Idaho National Engineering Laboratory, Idaho, U. S. Geological Survey Water Resources Investigations Report 89-4065.

Anderson, S. R., M. J. Liszewski, and D. J. Ackerman, June 1996, Thickness of Surficial Sediments at and near the Idaho National Engineering Laboratory, Idaho, U.S. Geological Survey Open-File Report 96-330.

Arranholz, D. A., and J. L. Knight, 1991, A Brief Analysis and Description of Transuranic Wastes in the Subsurface Disposal Area of the Radioactive Waste Management Complex, EGG-WTD-9438, EG\&G Idaho, Inc., Idaho National Engineering Laboratory, Idaho Falls, Idaho.

Becker, B. H., T. A. Bensen, C. S. Blackmore, D. E. Burns, B. N. Burton, N. L. Hampton, R. M. Huntley, R. W. Jones, D. K. Jorgensen, S. O. Magnuson, C. Shapiro, and R. L. VanHorn, May 1996, Work Plan for Operable Unit 7-13/14 Waste Area Group 7 Comprehensive Remedial Investigation/ Feasibility Study, INEL-95/0343, Lockheed Martin Idaho Technologies Company, Rev. 0.

Bowman, A. L., W. F. Downs, K. S. Moor, and B. F. Russell, September 1984, INEL Environmental Characterization Report, Vol. 2, EGG-NPR-6688, EG\&G Idaho, Inc.

Cleveland, J. M., The Chemistry of Plutonium, American Nuclear Society, LaGrange, Illinois, 1979, pp. 48, 291, 464, 570, 574.

Chatwin T. D. et al., June 1992, Final Work Plan for the Organic Contamination in the Vadose Zone Operable Unit 7-08 Focused RI/FS, EGG-WM-10049, EG\&G Idaho, Inc.

DOE-ID, July 1993, INEL Transuranic Waste Acceptance Criteria, DOE/ID-10074, U. S. Department of Energy, Idaho Operations Office, Rev. 5.

DOE-ID, March 1996, Idaho National Engineering Laboratory Comprehensive Facility Land Use Plan, DOE/ID-10514, U. S. Department of Energy, Idaho Operations Office.

DOE-ID, February 1997, Idaho National Engineering and Environmental Laboratory Reusable Property, Recyclable Materials, and Waste Acceptance Criteria, DOE/ID-10381, U. S. Department of Energy, Idaho Operations Office.

DOE-ID, December 1997, Quality Assurance Project Plan for Waste Area Groups 1,2,3,4,5,6,7,20 and Inactive Sites, DOE/ID-10587, (formerly INEL-95/0086) Rev.5, U. S. Department of Energy, Idaho Operations Office.

DOE-ID, March 1998a, Addendum to the Work Plan for the Operable Unit 7-13/14 Waste Area Group 7 Comprehensive Remedial Investigation/Feasibility Study, DOE/ID-10622, Draft Revision 2, Idaho National Engineering Laboratory, U. S. Department of Energy, Idaho Operations Office. 
DOE-ID, March 1998b, Interim Risk Assessment and Contaminant Screening for the Waste Area Group 7 Remedial Investigation, DOE/ID-10659, Draft Revision 2, Idaho National Engineering Laboratory, U. S. Department of Energy, Idaho Operations Office.

EG\&G, July 1985, A History of the Radioactive Waste Management Complex at the Idaho National Engineering Laboratory, WM-F1-81-003, EG\&G Idaho, Inc., Rev. 3.

EG\&G, December 1988, RCRA Facility Investigation Work Plan, Volume 1, EGG-WM-8219, EG\&G Idaho, Inc.

EPA, October 1988, Guidance for Conducting Remedial Investigations and Feasibility Studies Under CERCLA, Interim Final, EPA/540/G-89/004, U.S. Environmental Protection Agency.

EPA, January 1995, Guidance for Conducting Remedial Investigations and Feasibility Studies Under CERCLA, Interim Final, EPA/540/G-89/004, U.S. Environmental Protection Agency.

Farnsworth, 1999, ISV Treatability Study Work Plan.

Gale L. and D. Stermer, March 1989, PREPP Partitioning Studies, EGG-MS-88456, EG\&G Idaho, Inc., Idaho Falls, Idaho.

Grandy, J. D., T. L. Eddy, and G. L. Anderson, January 1993, TSA Waste Stream and Final Vitrified Waste Composition, EGG-MS-10617, EG\&G Idaho, Inc., Idaho Falls, Idaho.

Hansen K, Conley D., Vinegar H. J. et al., December 1998, "In Situ Thermal Desorption of Coal Tars," International Symposium on Environmental Biotechnologies and Site Remediation Technologies Orlando Florida, pp. 1-22.

INEL, March 1995a, Quality Assurance Project Plan for Waste Area Groups 1, 2, 3, 4, 5, 6, 7, and 10, INEL-95/0086, Idaho National Engineering Laboratory, Idaho Falls, Idaho.

INEL, May 1995b, Community Relations Plan, Lockheed Martin Idaho Technologies Company, Idaho National Engineering Laboratory.

INEL, June 1995c, Data Management Plan for the INEL Environmental Restoration Program, INEL95/0257, Idaho National Engineering Laboratory, Idaho Falls, Idaho.

INEL, 1996, Waste Certification Plan for the Environmental Restoration Program, INEL-96/ 0043, Idaho National Engineering Laboratory, Idaho Falls, Idaho.

INEL, June 1997, Quality Program Plan for Environmental Restoration Program, PLN-125, Idaho National Engineering Laboratory, Idaho Falls, Idaho.

Langer, 1980, Respirable Particulate Releases.

LMITCO, 1999, Interface Agreement Between RWMC and the WAG-7 OU-13/14 Treatability Studies Project, IAG-15, Lockheed Martin Idaho Technologies Company, Idaho Falls, Idaho, draft.

LMITCO, 1998, Implementing Project Management Plan for the Idaho National Engineering and Environmental Laboratory Remediation Program, INEEL/EXT-97-00032, (formerly EGG-WM8676) Rev.5, Lockheed Martin Idaho Technologies Company. 
LMITCO, February 1995, Safety Analysis Report for the Radioactive Waste Management Complex, INEL-94/0226 (formerly EGG-WM-10881), Lockheed Martin Idaho Technologies Company, Rev. 0.

Low, J., December 1985, Annual Technology Assessment and Progress Report for the Buried TRU Waste Program at the INEL, EGG-2429, EG\&G Idaho, Inc., Idaho Falls, Idaho.

Low, J. et al., January 1987, Annual Technology Assessment and Progress Report for the Buried TRU Waste Program at the INEL (1986), EGG-2483, EG\&G Idaho, Inc., Idaho Falls, Idaho.

Low, J. and G. Loomis, January 1988, Annual Technology Assessment and Progress Report for the Buried TRU Waste Program at the INEL (1987), EGG-2525, EG\&G Idaho, Inc., Idaho Falls, Idaho.

Loomis, G., March 1989, Design and Construction Details Cold Test Pit of the INEL Simulated TRU Test Pit, EDF BWP-ISV-009, EG\&G Idaho, Inc., Idaho Falls, Idaho.

Loomis G. and D. N. Thompson, January 1995, Innovative Grout/Retrieval Demonstration Final Report, INEL-94/0001, LMITCO., Idaho Falls, Idaho.

Loomis G., D. Thompson, and J. Heiser, December 1995, Innovative Subsurface Stabilization of Transuranic Pits and Trenches Report, INEL-94/0632, LMITCO., Idaho Falls, Idaho

Navatril, J. D. and A. W. Schulz, “Actinide Separations," ACS Symposium Series 117, Washington, DC, 1980, pp. 71-88, 101-130.

Schuman R. and R. Tallman, November 1981, Properties and Simulation of Rocky Flats Waste Sludges, RE-N-81-011 Internal Technical Report, EG\&G Idaho, Inc., Idaho Falls, Idaho

Shaw P, July 1993, Laboratory-Scale Vitrification of Low Level Radioactive Nitrate Salts and Soils from the INEL, EGG-WRTD-10640, EG\&G Idaho, Inc., Idaho Falls, Idaho

Sheldon R. B, H. J. Vinegar, et al., October 1996, "Field Demonstration of a Full-Scale In Situ Thermal desorption System for the Remediation of PCB and Other Hydrocarbons," Hazardous Waste World Superfund XVII, Washington DC.

Stegemeier G. L. and H. J. Vinegar, March 1995, "Soil Remediation by Surface Heating and Vacuum Extraction," Society of Petroleum Engineers Inc., SPE 29771, SPE/EPA Exploration and Production Environmental Conference Houston Texas, pp. 1-20.

Tucker, R. F., R. A. Nelson, and C. C. Miller, March 1983, Low Level Radwaste Solidification, EPRI-NP2900.

Turk, E. H. and C. L. Roswell, March 1978, Analysis of United States Geological Survey: Soil and Soil Leachings by Neutron Activation Analysis, RE-P-78-029, EG\&G Idaho, Inc., Idaho National Engineering Laboratory, Idaho Falls, Idaho.

Vinegar H. J., G. L. Stegemeier, R. B. Sheldon, October 1997, "Remediation of Deep Soil Contamination Using Thermal Vacuum Wells," Annual Technical Conference and Exhibition, San Antonio ,Texas, Society of Petroleum Engineers Inc., SPE 39291, pp. 905-918. 
Vinegar H. J., G. L. Stegemeier et al., December 1998, In Situ Thermal Desorption System- TerraTherm Environmental Services Inc, Company and Process overview, Houston Texas, pp. 100.

Wick, O. J., 1980, Plutonium Handbook, American Nuclear Society, Volume 1, Chapter 6, "Corrosion and Oxidation," pp. 145-190 and Chapter 8, "Plutonium Refractory Compounds," pp. 240-298. 


\section{Appendix A \\ Emplacement Information For In Situ Thermal Desorption Wells}




\section{Appendix A \\ Emplacement Information For In Situ Thermal Desorption Wells}

\section{INTRODUCTION}

In Situ Thermal Desorption (ISTD) requires heater and vacuum wells be placed in the ground at the SDA. The heat mobilizes and destroys the organic chemicals, and the vacuum removes vapors to the offgas system. The ISTD process has been successfully performed in non-radiological settings outside the INEEL, but ISTD vacuum wells have never been placed in radioactive buried waste.

ISTD vacuum wells require a slotted or wire-wrapped well screen casing. The openings allow the heated organic vapors and inorganic gases from nitrate salt and organic destruction to be drawn through the soil into the thermal/vacuum well and out to the offgas treatment system. The openings also give a pathway for radioactively contaminated particles to exit the waste even before heat is applied to the system as the wells are being installed.

The purpose of this appendix is to outline the emplacement techniques to control radiological particulate contamination that might be spread when the wells are placed underground in buried waste debris at the SDA. Soil and waste debris can give off TRU containing fine particulates when it is disturbed in a subsurface drilling operation that can contaminate equipment and personnel. This appendix summarizes hardware options available to emplace the vacuum/heater wells and references standard procedures proposed to control contamination as they are emplaced in the SDA. Information was gathered about options for emplacing Vacuum Wells from developed procedures for the Pit 9 Probehole and Coring, contamination control requirements (Radiological Control Manual), engineering judgement, and the ISTD vendor TerraTherm (TerraTherm 1998).

\section{SDA WASTE DEBRIS PENETRATION OPTIONS}

Two general options have been investigated for vacuum screen well emplacement lancing and drilling. Procedures for both of these types of underground penetration have been written as part of the Pit 9 phase 1 sampling and extensively reviewed (TPR 155)

Lancing as a penetration method can:

- $\quad$ Be performed without removal of any waste material

- $\quad$ Emit little dust and thus little contamination

- $\quad$ Be performed without removing anything from the ground

- $\quad$ Go through most types of landfill type debris and soil

- $\quad$ Emplace all heater-only wells and thermocouples

- $\quad$ Emplace specially designed vacuum/heater “prepack wells 
- $\quad$ Be performed by "sonic" methods.

However, lancing usually:

- $\quad$ Requires special high-strength pipe

- Involves removal of casing,

- $\quad$ Cannot penetrate basalt, boulders or large steel objects

The lancing of probeholes has been studied for OU 7-10 (Pit 9) phase one sampling. A remotely operated Sonic Drill has been designed for this process (Horn 1999). An extensive procedure has been written and is in its $5^{\text {th }}$ revision (TPR 155a). A picture of the Sonic Drill is shown in the figure below. Solid steel pipe up to 5.5-in. OD with a steel point that is capped at the top is sonically driven through the waste to basalt. The possibility of contamination release during lancing is very low since the system is sealed.

Drilling as a penetration method can:

- $\quad$ Be performed through basalt, landfill type debris, soil

- $\quad$ Be performed with special newly designed contamination control devices

- $\quad$ Go through most types of

- $\quad$ Emplace conventional vacuum/heater wells

- $\quad$ Be performed by "sonic" methods

However drilling usually:

- $\quad$ Requires special contamination control devices

- Involves removal of material

- Cannot penetrate large steel objects

The drilling of coreholes has been studied for OU 7-10 (Pit 9) phase one sampling. The same remotely operated Sonic Drill platform than can lance probeholes can drill and remove cores (Horn 1999). An extensive procedure has been written to do this and is in its first revision (TPR 155b). Drilling to penetrate the buried waste and place vacuum wells is closer to the traditional method the vendor (TerraTherm 1998) has used for previous vacuum well emplacements 


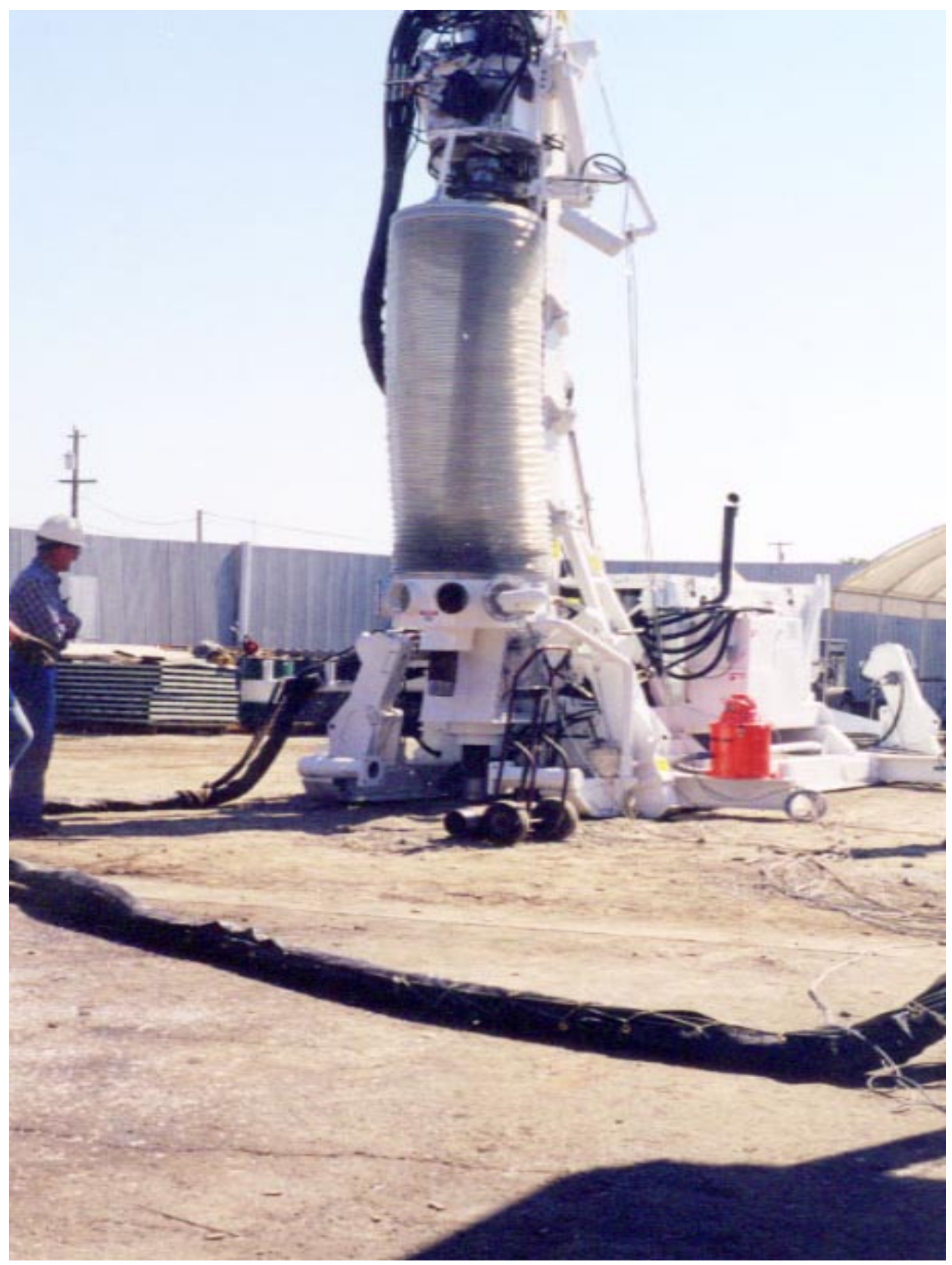

The Sonic Drill Platform with the Drill String Enclosure 


\section{LANCING PREPACK ISTD VACUUM/HEATER WELLS}

The material for the vacuum well screen that has been used in the past is stainless wire wrapped around supports and welded to the supports. The well screen does not have sufficient strength for lancing into the ground. To lance the vacuum well, a supporting pipe is needed. This pipe could be removed to reveal the holes, be perforated to allow vapors through or made of a destructive material such as plastic that an be burned away by the heater assembly. The latter two share the advantage that nothing is removed from the hole thus enhancing containment of radioactivity during the entire well emplacement process.

A prepack system has been developed to minimize over-the-well operations and take advantage of the benefits of not removing material from the hole. The prepack incorporates the sand annulus in the screen vacuum well and the central heater can with dual heater elements. This entire unit is placed in a perforated steel pipe similar to the probe hole pipe that will be used in Pit 9. The unit is sonically lanced into the waste. A screw cap can then be removed under proper radiological control to attach the power to the heaters and the vacuum pipes to the well. The prepack design needs to be finalized to fit within the sonic platform device and under probe hole procedures. The prepack method of emplacement is the best way to minimize contamination during ISTD well emplacement.

\section{DRILLING HOLES FOR VACUUM WELL EMPLACEMENT}

The conventional vacuum well emplacement process requires that a hole be drilled for well screen emplacement. The vacuum wells are then placed in the drilled hole, which is usually of greater diameter by at least $0.5 \mathrm{inch}$. Sand is placed between the hole and the well screen to act as a pre-filter for near-the-well soot generation (most particulates are filtered as they pass through the surrounding soil. A $0.5-1$ in. sand layer has been effective during past remediations. The heater assemblies are smaller in diameter than the vacuum wells so they can be placed inside the vacuum well screen.

The newly designed Sonic drilling for probehole installation can also be used for coring the SDA. It has been fitted with secondary containment for this activity called the Drill String Enclosure (DSE). The DSE provides containment during drilling, sample, and casing removal to prevent the spread or release of contamination to the environment. Procedures have been written for performing core sampling in SDA pits (TPR 155b). The Sonic DSE has being developed for use with OU 7-10 (Pit 9, Pit 4, and Pit 10). The ISTD emplacement of wells will use the experience and technology gained by the OU 7-10 drilling. Some modifications in the process following core removal would have to be made for vacuum well emplacement.

As the hole is sonically drilled, a casing is pressed down in the hole to prevent the sides from falling in and allow the core to be removed. The drilling would be essentially the same as the OU 7-10; when the core is completely removed, the well screen can be emplaced. The well screen would be loaded into the DSE and the lengths connected. When the sections of well screen extend above the buried waste, the screen can be changed to solid piping up to the top and above overburden. The top of the vacuum well would be sealed with containment sleeving. The well casing must now be removed to allow vapors to move to the offgas system. The casing is withdrawn in sections within the enclosure and bagged out. As the casing is removed, sand will be added to fill the void left from the casing. The tent 
containment or a glovebox can then be installed over the vacuum well. With the tent or glovebox installed, the top half of the vacuum well connections can be completed.

The rest of the ISTD installation will be the same as any other remediation site, within the constraints of radiological control including installation of prefilters and HEPA filters to the outlet vapor extraction lines. The vacuum well can be designed for emplacement, utilizing the DSE and the experience gained from OU 7-10 drilling with the DSE.

\section{CONCLUSION}

The sonic drill and the DSE allows traditional vacuum well emplacement. The use of an advanced prepack also uses the sonic drill platform and appears to be the more preferable in terms of simplicity and contamination control. The experience of probe hole and core hole installation during use of both the sonic drill platform and the DSE at other WAG 7 sites (Pit 9) should help finalize the placement method. The use of the sonic platform on actual SDA waste is essential for the success of ISTD well placement worked out. Successful use of the DSE will be required if the traditional ISTD well emplacement is to be considered. The design of an advanced prepack placed with the sonic drill platform is the most feasible of the two options for placing the vacuum well.

\section{REFERENCES}

TerraTherm Environmental Services Inc. A Handbook for In-Situ Thermal Desorption, December 1998

Guy Loomis, Alternative Emplacement Technique for Subsurface Stabilization of Buried Waste Sites, Session 18 Environmental Restoration, Waste Management Conference 98, Tucson Arizona, March 1998

Rick Horn, Resonant Sonic Drilling, Sonic Drilling System, Drill String Enclosure, Personnel Communication, 1999

Technical Procedures, Environmental Restoration, LMITCO, 1999

Probe-hole Installation,

Core-hole Drilling and Sampling at Pit 9,

Probehole and Corehole Abandonment, Handling Storage and Shipping OU-7-10

Contingency Project Core Samples, TPR-158

Nonstandard Drilling Events,
TPR-155a Rev 5

TPR-155b Rev 0

TPR-157

TPR-161 Rev 0

Work Plan for Stage 1 of the Operable Unit 7-10 Contingency Project, DOE/ID-10623 June 1998 Rev.0 252.01 